upf. $\begin{array}{ll}\text { Universitat } \\ \text { Pompeu Fabra } \\ \text { Barcelona }\end{array} \quad \begin{aligned} & \text { Department } \\ & \text { of Economics and Business }\end{aligned}$

Economics Working Paper Series

Working Paper No. 1596

\title{
International commodity prices and civil war outbreak: new evidence for sub- Saharan Africa and beyond
}

Antonio Ciccone

January 2018 


\title{
International Commodity Prices and Civil War Outbreak: New Evidence for Sub-Saharan Africa and Beyond
}

\author{
Antonio Ciccone*
}

January 2018

\begin{abstract}
A new dataset by Bazzi and Blattman (2014) allows examining the effects of international commodity prices on the risk of civil war outbreak with more comprehensive data. I find that international commodity price downturns sparked civil wars in Sub-Saharan Africa. Another finding with the new dataset is that commodity price downturns also sparked civil wars beyond Sub-Saharan Africa since 1980. Effects are sizable relative to the baseline risk of civil war outbreak. My conclusions contrast with those of Bazzi and Blattman, who argue that the new dataset rejects that commodity price downturns cause civil wars. The reason is that I calculate commodity price shocks using time-invariant (fixed) export shares as commodity weights. Bazzi and Blattman also calculate commodity price shocks using export shares as commodity weights but the exports shares they use are time-varying. Using time-invariant export shares as commodity weights ensures that time variation in price shocks solely reflects changes in international commodity prices. Price shocks based on time-varying export shares partly reflect (possibly endogenous) changes in the quantity and variety of countries' exports, which jeopardizes causal estimation. I also show that setting timeinvariant export shares equal to average export shares over the sample period, can be a way of dealing with attenuation bias due to mismeasured export shares. When I differentiate between agricultural commodities on the one hand and minerals, oil, and gas on the other, I find stronger increases in the risk of civil war outbreak following downturns in agricultural commodity prices.
\end{abstract}

*Mannheim University, UPF, Barcelona GSE, and CEPR; antonio.ciccone@uni-mannheim.de. I thank Hassieb Pakzad for excellent research assistance. I also thank Francesco Caselli, Mathieu Couttenier, Ruben Durante, Libertad Gonzalez, Hannes Müller, Marta Reynal-Querol, and Dominic Rohner for very useful comments. 


\section{Introduction}

Civil wars are intrastate conflicts involving large-scale armed combat. Their total death toll in the last 60 years is estimated in the tens of millions (e.g. Fearon and Laitin, 2003; Ghobhara, Huth, and Russett, 2003; Eck and Hultman, 2007). It is striking how many deaths would have been avoided if the risk of civil war outbreak had been fractions of a percentage point lower. The economic or social policies to reduce civil war risk are unclear however (e.g. Fearon, Humphreys, and Weinstein, 2009; Nunn and Qian, 2014). Developing such policies is likely to require a better understanding of the causes of civil wars.

A central question in the debate on the causes of civil wars is the role played by economic conditions (e.g. Collier and Hoeffler, 2004; Djankov and Reynal-Querol, 2010). An early literature examined whether civil wars are more likely in countries where incomes are low or falling. Recently, attention has shifted to whether civil wars are sparked by droughts, falling international commodity prices, or other exogenous causes of negative income shocks (e.g. Miguel, Satyanath, and Sergenti, 2004; Sandholt Jensen and Skrede Gleditsch, 2009; Bruckner and Ciccone, 2010; Bazzi and Blattman, 2014; Maertens, 2016).

I study the effects of international commodity price fluctuations on civil war outbreak. Such effects have been examined in several previous studies, reviewed by Blattman and Miguel (2010). A natural starting point for any new study is Bazzi and Blattman's (2014) recent reexamination of the effects of commodity prices on civil war outbreak, also reviewed by Blattman and Miguel. Bazzi and Blattman conclude that civil wars are unrelated to commodity price fluctuations, even when they follow previous studies and focus on Sub-Saharan African civil wars as recorded by the UCDP/PRIO Armed Conflict Dataset (e.g. Miguel, Satyanath, and Sergenti, 2004; Sandholt Jensen and Skrede Gleditsch, 2009; Bruckner and Ciccone, 2010). ${ }^{1}$ While this conclusion contrasts with previous findings, it is based on a new dataset with more comprehensive coverage of commodity prices and exports.

The more comprehensive coverage of commodity prices and exports in Bazzi and Blattman's new dataset is valuable for research, as it allows including more commodity data and countries

\footnotetext{
${ }^{1}$ UCDP stands for Uppsala Conflict Data Program and PRIO for Peace Research Institute of Oslo.
} 
in the empirical analysis. I use the new dataset to argue that international commodity price downturns sparked civil wars in Sub-Saharan Africa as recorded by UCDP/PRIO. This is true since 1980 - the period Miguel, Satyanath, and Sergenti (2004), Sandholt Jensen and Skrede Gleditsch (2009), and Bruckner and Ciccone (2010) focus on - and over a longer period. Another finding with the new dataset is that since 1980, commodity price downturns also sparked civil wars in a wide sample of countries in Africa, the Middle East, Latin America, and Asia.

My conclusions using Bazzi and Blattman's new dataset contrast with those of Bazzi and Blattman. The reason is that I calculate commodity price shocks using time-invariant (fixed) export shares as commodity weights. Bazzi and Blattman also calculate commodity price shocks using export shares as commodity weights but the export shares they use are time-varying. To show that time-invariant export shares are key for my findings that international commodity price downturns sparked civil wars, I start with the data and the regression specification of Bazzi and Blattman. I then confirm my results with up-to-date UCDP/PRIO data.

If the goal of the empirical analysis is to uncover whether civil wars are sparked by downturns in international commodity prices, it is better to calculate country-specific commodity price shocks using time-invariant (fixed) export shares than using time-varying export shares. Using time-varying export shares implies that the time variation in price shocks reflects changes in international commodity prices as well as changes in the quantity and type of commodities exported by a country. By contrast, time-invariant export shares as commodity weights ensure that the time variation in price shocks solely reflects changes in international commodity prices. This is useful because changes in the quantity and type of commodities exported by a country could reflect social, political, or economic changes that affect the risk of civil war in the country. $^{2}$ Moreover, the quantity and type of commodities exported by a country may change as a consequence of unobservable changes in the likelihood of civil war in the country. Obtaining country-specific commodity price shocks using time-varying export shares may therefore compromise the goal of estimating causal effects of international commodity price shocks. This is why I avoid time-varying export shares and calculate country-specific commodity price shocks using time-invariant export shares as commodity weights. ${ }^{3}$

\footnotetext{
${ }^{2}$ They could also reflect natural resource discoveries, which may have a different effect on civil war risk than international commodity price changes (e.g. Cotet and Tsui, 2013).

${ }^{3}$ Other papers estimating causal effects of commodity price shocks using time-invariant export weights are Miller and Deaton (1995), Deaton (1999), Bruckner and Ciccone (2010), and Caselli and Tesei (2016) for
} 
Bazzi and Blattman also calculate country-specific commodity price shocks using export shares as commodity weights but do not keep export shares fixed over time. Specifically, their export-share-weighted commodity price shocks can be derived in two steps. First, calculate a $\log$ commodity price index for country $c$ and year $t$ as $\log P_{c, t}=\sum_{i} \omega_{i, c, t}^{B B} \log p_{i, t}$ where $p_{i, t}$ is the international price of commodity $i$ in year $t$ and $\omega_{i, c, t}^{B B}$ is the time-varying weight of commodity $i$ for country $c$ (the sum is across commodities). The weight $\omega_{i, c, t}^{B B}$ is set equal to average exports of the commodity between years $t-2$ and $t-4$ relative to total commodity exports. ${ }^{4}$ Second, obtain country-specific commodity price shocks as the change over time in the log commodity price index, $B$ Bshock $k_{c, t}=\sum_{i}\left(\omega_{i, c, t}^{B B} \log p_{i, t}-\omega_{i, c, t-1}^{B B} \log p_{i, t-1}\right) .{ }^{5}$ Bazzi and Blattman show that this commodity price shock measure leads to the conclusion that negative commodity price shocks do not spark civil wars in Sub-Saharan Africa as recorded by the UCDP/PRIO Armed Conflict Dataset. ${ }^{6}$

As Bazzi and Blattman use time-varying commodity export shares as commodity weights, their measure of price shocks partly reflects changes over time in the variety and quantity of a country's exports. These changes could be correlated with the underlying likelihood of civil war in the country, which jeopardizes causal estimation. Another issue with Bazzi and Blattman's commodity price shocks is that they may produce price shocks in years where there are no price shocks. The reason is that the export weights Bazzi and Blattman use to obtain commodity price shocks in year $t$ reflect lagged export shares between years $t-2$ and $t-4$. As export shares are based on the value of exports, changes in lagged export shares partly reflect past example.

${ }^{4}$ The time-varying weights used by Bazzi and Blattman are slightly more involved (in a way that does not matter here) and explained in Section 3.1.2. Bazzi and Blattman also present results with time-invariant weights (fixed at commodity export shares around 1980, as this is close to the midpoint of their longest samples), but these are based on a different commodity price shock measure that incorporates countries' aggregate commodity exports relative to GDP. For more on the cross-country association between aggregate commodity exports relative to GDP and the effect of commodity price shocks on civil war risk, see Section 4.2.3.

${ }^{5}$ Bazzi and Blattman actually subtract US CPI inflation from the change in the log price index. Suppressing the US CPI term does not affect the empirical analysis however, as the term is common across countries and is therefore absorbed by the year fixed effects always included in the empirical analysis.

${ }^{6}$ Bazzi and Blattman discuss in some detail why their results contrast with the previous literature (page 16). They discard explicitly as inconsequential any issues related to the coding of the commodity price shock measure. The main reasons Bazzi and Blattman list are the coding of the UCDP/PRIO civil war measure, the version of the UCDP/PRIO data used, and the time period covered. I use the exact coding of the UCDP/PRIO war measure and data of Bazzi and Blattman as a starting point in my empirical analysis to highlight the role of time-invariant versus time-varying export shares as commodity weights. (Bazzi and Blattman also mention a minor issue regarding the use of a small-sample adjustment of the standard errors). 
commodity price shocks. Hence, Bazzi and Blattman's measure of commodity price shocks may generate spurious price shocks in year $t$ because of price shocks two to four years earlier. ${ }^{7}$ These spurious price shocks may lead to unwarranted conclusions regarding the effect of commodity price shocks on civil wars.

In contrast to Bazzi and Blattman, I obtain country-specific commodity price shocks using time-invariant (fixed) export shares as commodity weights. Specifically, I calculate commodity price shocks in country $c$ in year $t$ as $\sum_{i} \omega_{i, c}^{F W}\left(\log p_{i, t}-\log p_{i, t-1}\right)$ where $F W$ stands for fixed weight. This is a special case of Bazzi and Blattman's shock, BBshock $c_{c, t}^{B B}$ as detailed above, with $\omega_{i, c, t}^{B B}=\omega_{i, c}^{F W}$. I also consider a version of these price shocks that captures commodity price changes over 3 -year periods, obtained as $\sum_{i} \omega_{i, c}^{F W}\left(\log p_{i, t}-\log p_{i, t-3}\right)$, following Miller and Deaton (1995), Deaton (1999), and Bruckner and Ciccone (2010).

The time-invariant export shares I use to obtain fixed-weight commodity price shocks are either export shares in a specific year or average export shares over the sample period. Using average export shares over the sample period is attractive as export shares in any single year may be unrepresentative for the entire sample period. There is an additional advantage of using average export shares over the sample period as time-invariant commodity weights. I show that this can be a way of dealing with attenuation bias due to mismeasured export shares as long as, loosely speaking, the serial correlation in the measurement error is limited. This is a useful result as export shares in the Bazzi and Blattman dataset (and elsewhere) are certainly measured with some error. Hence, commodity price shocks using export shares as commodity weights are measured with some error too, and not taking this into account would result in biased estimates of the effect of price shocks on civil war risk.

My empirical analysis starts with the time period since 1980, following Miguel, Satyanath, and Sergenti (2004), Sandholt Jensen and Skrede Gleditsch (2009), and Bruckner and Ciccone. I find that negative commodity price shocks - contemporaneous as well as lagged - lead to statistically significant increases in the risk of civil war outbreak. This is the case whether the

\footnotetext{
${ }^{7}$ Formally, rearranging yields $B B s h o c k_{c, t}=\sum_{i}\left(\omega_{i, c, t}^{B B}-\omega_{i, c, t-1}^{B B}\right) \log p_{i, t}+\sum_{i} \omega_{i, c, t-1}^{B B}\left(\log p_{i, t}-\log p_{i, t-1}\right)$ where $B B s h o c k_{c, t}$ is the Bazzi and Blattman commodity price shock measure I have detailed in the main text. As the Bazzi and Blattman time-varying commodity weights $\omega_{i, c, t}^{B B}$ reflect lagged export shares between years $t-2$ and $t-4$, the time change in the weights $\omega_{i, c, t}^{B B}-\omega_{i, c, t-1}^{B B}$ in the first term on the right-hand side of the equation reflects the change in lagged export shares, which in turn partly reflects lagged commodity price shocks. As a result, the Bazzi and Blattman measure of commodity price shocks BBshock $k_{c, t}$ may indicate a price shock in year $t$ although there is no price shock as $\log p_{i, t}-\log p_{i, t-1}=0$ for all commodities.
} 
time-invariant export shares used as commodity weights are set equal to average export shares over the sample period, or set equal to export shares in 1990 as in Deaton (1999) and Bruckner and Ciccone (2010). The contemporaneous effect implies that a negative commodity price shock of one standard deviation raises the risk of civil war outbreak by around 1.7 percentage points. This effect is large when compared to the $2.6 \%$ baseline risk of civil war outbreak in Sub-Saharan Africa since 1980. That commodity price downturns increase civil war risk since 1980 becomes particularly clear when I measure price downturns over 3-year periods. Such commodity price downturns also result in statistically significant increases in the risk of civil war outbreak in Sub-Saharan Africa since 1957, the first year of the new dataset.

Another finding with Bazzi and Blattman's new dataset is that since 1980, international commodity price downturns also sparked civil wars in a wide sample of countries including all larger countries in Africa, the Middle East, Latin America, and Asia. The pattern of effects for the wider sample is somewhat different than for Sub-Saharan Africa. The effect of contemporaneous commodity price shocks on the risk of civil war outbreak is statistically stronger in the wider sample. On the other hand, there is no evidence of statistically significant effects of lagged commodity price shocks. A negative commodity price shock of one standard deviation raises the risk of civil war outbreak in the wider sample by around one percentage point, about half of the baseline risk of civil war outbreak of $2 \%^{8}$

I also estimate the effects of international commodity price downturns on the risk of civil war when the commodity price shock is split into two parts: (i) a commodity price shock that collects agricultural commodities, and (ii) a commodity price shock that collects minerals, gas, and oil. This generally yields stronger increases in the risk of civil war outbreak following downturns in agricultural commodity prices (see Bruckner and Ciccone, 2010, and Bazzi and

\footnotetext{
${ }^{8}$ In unreported results, I confirm the consensus in the literature that country-specific international commodity price shocks do not trigger UCDP/PRIO civil conflicts, which include smaller conflicts as well as civil wars (e.g. Bruckner and Ciccone, 2010; Bazzi and Blattman, 2014; McGuirk and Burke, 2017). As pointed out by McGuirk and Burke (2017), a possible reason is that many civil conflicts may be too local to be sparked by country-level commodity price shocks. McGuirk and Burke's analysis at the local level within Sub-Saharan African countries indicates that negative international shocks in the price of food crops raise the risk of civil conflict in localities where the crop is produced. These findings are in line with Berman and Couttenier's (2015) earlier results on the impact of global agricultural demand shocks on local civil conflicts within Sub-Saharan African countries. Berman, Couttenier, Rohner, and Thoenig (2017) examine the effects of international shocks in the price of minerals on the risk of civil conflict within Sub-Saharan African countries and find that negative price shocks lower civil conflict risk in localities where the minerals are mined. For an analysis of the effects of civil conflict on African economic growth see Müller (2016).
} 
Blattman, 2014, for previous results by commodity type). In particular, I find that 3-year downturns in agricultural commodity prices raised the risk of civil war outbreak since 1980 and also since 1957 whether I focus on countries in Sub-Saharan Africa or consider all larger countries in Africa, the Middle East, Latin America, and Asia.

The country-specific commodity price shocks I use always weigh commodities by their shares in exports, as in Deaton and Miller (1995), Deaton (1999), and Bruckner and Ciccone (2010) for example. Bazzi and Blattman present results where commodity prices are weighted by export shares, and results where commodity weights are commodity export shares multiplied by aggregate exports relative to GDP. To understand the rationale for commodity weights that also reflect aggregate exports relative to GDP, it is useful to consider the following baseline scenario. Suppose that countries' aggregate commodity exports relative to GDP are unrelated to characteristics of countries that play a role (i) for the effect of international commodity price shocks on income and (ii) for the effect of income shocks on the risk of civil war outbreak. Suppose also that income is the only channel through which international commodity price shocks affect civil war risk. In this baseline scenario, commodity price shocks should translate into a stronger effect on income and on civil war risk in countries with larger commodity exports relative to GDP. This is because larger commodity exports relative to GDP magnify the effect of commodity price shocks on income but are assumed to not affect the causal chain from commodity price shocks to civil war risk in any other way. The assumptions behind the baseline scenario might not be satisfied however. For example, Caselli and Tesei (2016) argue that abundant natural resources - a main determinant of large aggregate commodity exports relative to GDP - shape a country's political institutions. These institutions may matter for the effect of commodity price shocks on income as well as the effect of income shocks on the risk of civil war outbreak.

To examine the empirical association between countries' aggregate commodity exports relative to GDP and the effect of commodity price shocks on civil war risk, I proceed in the following way. I first group countries by whether their aggregate commodity exports relative to GDP are above or below the cross-country median. Then I estimate the effect of my fixed-weight commodity price shocks on civil war risk separately in the two subsamples. For Sub-Saharan Africa, I find a statistically significant effect of international commodity price shocks on civil 
war risk in countries with commodity exports relative to GDP below the median but not in countries above the median. This result does not conform with the prediction of the baseline scenario above, where aggregate commodity exports affect the causal chain from commodity price shocks to civil war risk only in that they magnify the effect of commodity price shocks on income. For the wider sample of countries, there is some weak evidence for the prediction of the baseline scenario. Support for the baseline scenario is therefore inexistent or weak, depending on whether one considers Sub-Saharan Africa or a wider sample of countries. This could indicate that income is not the only channel through which commodity price shocks affect civil war risk. Alternatively, the prediction of the baseline scenario could be invalidated by heterogeneity in the effect of commodity price shocks on income or by heterogeneity in the effect of income shocks on the risk of civil war outbreak.

I also use a median-sample-split approach to explore the empirical association between the effect of commodity price shocks on civil war risk and countries' income per capita, income inequality, and ethnic fragmentation. I find that downturns in international commodity prices spark civil wars in poor countries but not in rich countries; in countries with low inequality but not in countries with high inequality; and in countries with low ethnic fragmentation but not in countries with high ethnic fragmentation. More research would be needed to see whether these results can be rationalized theoretically or whether they are driven by omitted country characteristics (Fearon, 2005; Fearon, Kasara, and Laitin, 2007; Caselli and Tesei, 2016).

The remainder of the paper is structured as follows. Section 2 discusses the data. Section 3 discusses the construction of the country-specific commodity price shocks; the main estimating equations; and how mismeasured commodity export shares can be dealt with. Section 4 presents the empirical results using the Bazzi and Blattman data only, reexamines these results using up-to-date UCDP/PRIO civil war data, and explores cross-country heterogeneity in the effect of commodity price shocks on civil war risk. Section 5 concludes.

\section{Data}

I discuss the civil war data first, the commodity data second, and all other data last. 


\subsection{Civil war data}

My empirical work is based on the UCDP/PRIO Armed Conflict Dataset also used in the previous studies of civil war by Miguel, Satyanath, and Sergenti (2004), Sandholt Jensen and Skrede Gleditsch (2009), and Bruckner and Ciccone (2010) for example. I first present this dataset and then compare it with the COW (Correlates of War) civil war dataset.

\subsubsection{Civil war data from UCDP/PRIO}

The civil war measures I use are based on the UCDP/PRIO civil war dataset. I start using the exact coding of Bazzi and Blattman (2014). I also use the latest version of the UCDP/PRIO dataset (UCDP/PRIO Armed Conflict Dataset version 4-2016).

UCDP/PRIO defines a civil war as a contested incompatibility that concerns government and/or territory where the use of armed force between two parties, of which at least one is the government of a state, results in at least 1,000 battle-related deaths during the calendar year. Hence, UCDP/PRIO civil wars always entail large-scale fighting in the coded calendar year. When I use the latest version of the UCDP/PRIO dataset, I follow Sandholt Jensen and Skrede Gleditsch (2009), Bruckner and Ciccone, and Bazzi and Blattman in coding a civil war in a country only if the civil war takes place in the country's territory.

The left-hand-side variable in my empirical analysis is an indicator variable for civil war outbreak (onset). This indicator can be thought of as capturing the flare-ups in large-scale fighting. The indicator for civil war outbreak is one for country $c$ in year $t$ if there is a civil war in the country in year $t$ and there was no civil war in the country in the previous year. The indicator is zero for country $c$ in year $t$ if there is no civil war in the country in year $t$ and there was no civil war in the country in the previous year. The indicator for civil war outbreak is not defined for country $c$ in year $t$ if there was a civil war in the country in the previous year.

\subsubsection{Comparing the UCDP/PRIO and COW measures of civil war}

Bazzi and Blattman use different measures of civil war but argue that the most relevant ones are the UCDP/PRIO and COW (Correlates of War) measures as they capture the ebb and flow of the incentives for war. The same two datasets were considered in Miguel, Satyanath, and Sergenti's (2004) seminal study of civil conflict, but they discarded the COW dataset because 
of inconsistencies and lack of transparency.

Leaving aside issues of consistency and transparency, the COW measure of civil war used by Bazzi and Blattman differs conceptually from their UCDP/PRIO measure in two main ways. Bazzi and Blattman's UCDP/PRIO measure of civil war only codes a civil war for a country if the civil war takes place in the territory of the country. On the other hand, their COW measure of civil war does not adopt this territorial criterion. It is useful to illustrate the implications of this conceptual difference with the example of Nigeria. There is no civil war in Nigeria between 1990 and 1998 according to Bazzi and Blattman's UCDP/PRIO measure. However, according to their COW measure of civil war, Nigeria was involved in one civil war in 1990, two civil wars in 1992, and another civil war in 1998. None of these COW civil wars were fought in Nigeria. The 1990 COW civil war corresponds to the Nigerian military's involvement in a Liberian civil war that started in 1989. In 1990, a group of West African states including Nigeria, sent mainly Nigerian troops to support the Liberian government. One of the two 1992 COW civil wars involving Nigeria corresponds to another engagement of the Nigerian military in this Liberian civil war, again as part of a group of West African states. The second of the two 1992 COW civil wars involving Nigeria corresponds to an engagement of the Nigerian military in a civil war in Somalia, as part of a large group of states including Australia, Canada, Germany, and the United States. The 1998 COW civil war involving Nigeria corresponds to the Nigerian military's engagement in a civil war in Sierra Leone.

Economic conditions in a country may play more of a role for civil wars in the country than for military engagements of the country's government in civil wars elsewhere (Sandholt Jensen and Skrede Gleditsch, 2009). As a result, one may find a weaker effect of downturns in the international prices of a country's export commodities on Bazzi and Blattman's COW measure of civil war than their UCDP/PRIO measure of civil war.

There is a second conceptual difference between the COW measure of civil war used by Bazzi and Blattman and their UCDP/PRIO measure. When UCDP/PRIO codes a civil war in calendar year $t$, it is because estimates indicate more than 1,000 battle deaths in year $t$. That is, the 1,000 battle-deaths threshold is applied to calendar years. This matches the calendar-year coding of the economic shocks potentially sparking civil wars in existing studies (e.g. Miguel, Satyanath, and Sergenti, 2004; Bruckner and Ciccone, 2010; Bazzi and Blattman, 2014). 
The COW definition of civil wars also involves a 1,000 battle-deaths threshold ("battlerelated deaths" is the exact language used) but not for calendar years. COW's "current requirement for all categories of wars is for 1,000 battle-related deaths per year (twelve-month period beginning with the start date of the war) among all the qualified war participants" (Sarkees, 2010, page 15). That is, COW applies the 1,000 battle-deaths threshold to the twelve-month period following the start of a civil war. The start of a civil war is dated by the formal declaration if followed by immediate combat or by the first day of combat. As civil wars may not start with large-scale combat, COW may date civil wars to have started in calendar year $t$ although there was no large-scale fighting in that year. This can make it difficult to uncover a causal effect of calendar-year economic shocks on flare-ups in large-scale fighting using the COW measure of civil war. ${ }^{9}$

\subsection{Commodity price and export data}

All commodity price and export data comes from Bazzi and Blattman (2014). They collect price data for 65 commodities from the IMF International Financial Statistics, the US Bureau of Labor Statistics, and several other sources. Bazzi and Blattman's primary source of commodity export data is the United Nations Commodity Trade Statistics Database. They combine this dataset with other export data and use interpolation to fill gaps. The result is a large database with shares of 65 different commodities in total exports by country and year. This data is available for Sub-Saharan Africa, and for countries with populations over one million in Africa, the Middle East, Latin America, and Asia.

\footnotetext{
${ }^{9}$ To see this in an example, consider a scenario where a negative commodity price shock in calendar year $t$ does in fact increase the probability of flare-ups in fighting with more than 1,000 deaths in year $t$. Suppose that half the civil wars start with a minor battle in the second half of a calendar year, followed by a major battle with more than 1,000 deaths in the first half of next calendar year. The other half of civil wars start with a major battle with more than 1,000 deaths. The COW coding rule would then code half of the calendar years $t$ with more than 1,000 battle deaths as civil wars that started in calendar year $t$ and the other half as civil wars that started in calendar year $t-1$. The fact that in this example, the COW coding rule would distribute the flare-ups in large-scale fighting in calendar year $t$ across two different calendar years, can make it difficult to find an effect of calendar-year economic shocks in any year on COW civil wars in finite samples.
} 


\section{$2.3 \quad$ Other data}

Following Miguel, Satyanath, and Sergenti (2004) and Bruckner and Ciccone (2010), my empirical analysis also accounts for rainfall shocks and export demand shocks from OECD countries. My measure of rainfall shocks follows Maertens (2016) and is obtained using two different rainfall datasets from the US National Oceanic and Atmospheric Administration. The first dataset is the GPCP rainfall data, which has the advantage of combining gauge and satellite measurements but is only available since 1979. The second dataset is the GPCC rainfall data, which is available for the longest period considered here. My measure of export demand shocks from OECD countries follows Acemoglu, Johnson, Robinson, and Yared (2008) and is calculated combining GDP data from the Penn World Tables with export data from the OECD Statistics.

\section{Empirical Framework}

I first discuss how the country-specific commodity price shocks used are constructed. Then I present the main estimating equations and explain how mismeasured commodity export shares can be dealt with.

\subsection{Country-specific commodity price shocks}

I start by presenting Bazzi and Blattman's (2014) export-share-weighted commodity price shocks. Then I describe how I modify Bazzi and Blattman's formulas to obtain commodity price shocks based on time-invariant (fixed) export shares. Finally, I discuss why it may make sense to obtain a trimmed version of commodity price shocks that ignores exports of countries if these exports constitute a significant share of world supply.

\subsubsection{Commodity price shocks using time-varying export weights}

To relate Bazzi and Blattman's export-share-weighted commodity price shocks to other measures of price shocks it is useful to start with the following definition of the commodity price 
shock in country $c$ between years $T$ and $t>T$

$$
\operatorname{shock}_{c, t}^{T}=\sum_{i=1}^{65}\left(\omega_{i, c, t}^{t} \log p_{i, t}-\omega_{i, c, t}^{T} \log p_{i, T}\right)
$$

with $\omega_{i, c, t}^{\tau}$ the (export-share-based) weight assigned to the (log) year- $\tau$ price of commodity $i$ entering the year- $t$ shock. The sum is over the 65 commodities for which there is data. I consider year-to-year shocks $(T=t-1)$ as well as shocks over 3 -year periods $(T=t-3)$ in my empirical work.

To better understand the commodity price shocks in (1), it is useful to start with the case where shocks are measured year-to-year and simplify to a Laspeyres, Paasche, or Fisher price-index growth formula. Setting the commodity weight $\omega_{i, c, t}^{\tau}$ equal to the export share of commodity $i$ in the total commodity exports of country $c$ in year $t-1, s_{i, c, t-1}$, the shock in (1) becomes the growth rate (in log points) of a Laspeyres price index (PI) between $t-1$ and $t$

$$
P I \operatorname{shock} k_{c, t}=\sum_{i=1}^{65} s_{i, c, t-1}\left(\log p_{i, t}-\log p_{i, t-1}\right)
$$

Using the commodity export share in year $t$ or the average commodity export share in years $t$ and $t-1$ instead of the commodity export share in year $t-1$, yields the growth rate of a Paasche or Fisher price index respectively.

Bazzi and Blattman use the following year-to-year version of the shock in (1)

$$
B \text { Bshock } k_{c, t}=\sum_{i=1}^{65}\left(\omega_{i, c, t}^{B B} \log p_{i, t}-\omega_{i, c, t-1}^{B B} \log p_{i, t-1}\right)
$$

with weights $\omega_{i, c, t}^{B B}$ reflecting lagged averages of commodity export shares. Specifically

$$
\omega_{i, c, t}^{B B}=\frac{\left(e_{i, c, t-2}+e_{i, c, t-3}+e_{i, c, t-4}\right) / 3}{\sum_{i=1}^{65}\left(e_{i, c, t-2}+e_{i, c, t-3}+e_{i, c, t-4}\right) / 3}
$$

with $e_{i, c, t}$ defined as exports of commodity $i$ by country $c$ in year $t$ over the country's total exports during the year

$$
e_{i, c, t}=\frac{\text { exports of commodity } i \text { by country } c \text { in year } t}{\text { total exports by country } c \text { in year } t}
$$


The sum across commodities in the denominator of (4) is a normalization ensuring that the weights sum to one across commodities for a given country-year (the export shares $e_{i, c, t}$ do not necessarily sum to one across commodities for a given country-year, as total exports in the denominator of (5) may contain non-commodity exports).

The formula in (3) differs from the formula described in Bazzi and Blattman in two respects (which are both inconsequential empirically). First, Bazzi and Blattman subtract a term capturing US consumer price inflation from (3). However, as this term is the same for all countries $c$, it ends up being absorbed by the year fixed effects that Bazzi and Blattman include in their estimating equation. Hence, subtracting US consumer price inflation from (3) is unnecessary given the estimating equation. Second, Bazzi and Blattman write that the weights used in (3) are $\omega_{i, c, t}^{B B}=\left(e_{i, c, t-2}+e_{i, c, t-3}+e_{i, c, t-4}\right) / 3$ instead of (4) (in their Online Appendix, page 4). As the commodity export shares $e_{i, c, t}$ are shares in total exports, these weights would - in contrast to the weights in (4) - not necessarily sum to one for a given country-year. However, the export-share-weighted commodity price shocks Bazzi and Blattman use in their empirical work do incorporate a normalization of the weights as in (4). ${ }^{10}$

\subsubsection{Commodity price shocks using time-invariant (fixed) export weights}

My empirical analysis using time-invariant export weights follows the formulas used by Bazzi and Blattman except that the commodity weights in (3) are taken to be time-invariant. I set the time-invariant (fixed) commodity weights $\omega_{i, c}^{F W}$, where $F W$ stands for fixed weight, equal to export shares in total commodity exports $s_{i, c}$. These are calculated using time-invariant commodity export shares in total exports $e_{i, c}$ obtained from the Bazzi and Blattman dataset.

\footnotetext{
${ }^{10}$ Appendix Figure 2 illustrates this graphically (all appendices are available online at www.antoniociccone.eu). The figure is based on the shocks in Bazzi and Blattman's Online Appendix Table 11, second column, which covers their full sample with 4781 observations (later columns use the same shock for subsamples). Bazzi and Blattman actually use standardized shocks (shocks standardized by the standard deviation in the sample) but their dataset also contains the non-standardized version of these shocks. I already mentioned that the Bazzi and Blattman shocks are obtained as (3) minus the US CPI inflation. I therefore add US CPI inflation, also taken from the Bazzi and Blattman data, to the Bazzi and Blattman non-standardized shocks to get the shocks as defined in (3). Let me refer to these shocks as the simplified original Bazzi and Blattman shocks. I then plot these simplified original Bazzi and Blattman shocks against reconstructed shocks that do and do not use the normalization to one in (4). The reconstructed shocks are obtained using Bazzi and Blattman's raw commodity price and export data in (3) and (4). Appendix Figure 2 shows that the shocks used by Bazzi and Blattman line up perfectly with the reconstructed shocks with the normalization in (4) but not the reconstructed shocks without the normalization.
} 
Formally,

$$
\omega_{i, c}^{F W}=s_{i, c}=\frac{e_{i, c}}{\sum_{i=1}^{65} e_{i, c}} .
$$

Hence, my year-to-year fixed-weight commodity price shocks for country $c$ in year $t$ are

$$
F W \text { shock }_{c, t}=\sum_{i=1}^{65} s_{i, c}\left(\log p_{i, t}-\log p_{i, t-1}\right) .
$$

For the time-invariant commodity export shares $s_{i, c}$, I consider three alternatives constructed with Bazzi and Blattman's data for total export shares $e_{i, c, t}$ in (5)

$$
s_{i, c}= \begin{cases}s_{i, c}^{1980}=\frac{e_{i, c, 1980}}{\sum_{i} e_{i, c, 1980}} & {[\mathrm{~A}]} \\ s_{i, c}^{1990}=\frac{e_{i, c, 1990}}{\sum_{i} e_{i, c, 1990}} & {[\mathrm{~B}]} \\ \bar{s}_{i, c}=\frac{1}{T-\tau+1} \sum_{t=\tau}^{T}\left(\frac{e_{i, c, t}}{\sum_{i} e_{i, c, t}}\right) & {[\mathrm{C}]}\end{cases}
$$

The average export shares over the sample period in $[\mathrm{C}]$ are the most attractive timeinvariant commodity weights for two reasons. First, they ensure that time-invariant commodity weights reflect exports over the entire time period. Second, as I show below, using average export shares over the sample period can be a way of dealing with attenuation bias due to mismeasured export shares. The time-invariant commodity weights in $[\mathrm{B}]$ and $[\mathrm{C}]$ are less attractive choices as they pick export shares in specific years, which makes them less representative for the whole time period than average export shares over the sample period and also more prone to measurement error. Still, they are useful for comparison with results in the literature.

\subsubsection{Commodity price shocks incorporating price maker cutoffs}

To detect a causal effect of international commodity price shocks on civil war risk, it may sometimes be useful to consider a trimmed version of country-specific commodity price shocks. Trimmed price shocks drop commodities from a country's price index in years where exports constitute a significant share of world supply. The utility of trimmed price shocks might seem doubtful, as dropping commodities would seem to lead to worse measures of the commodity 
price shocks countries are subject to. This in turn would seem to only make it harder to detect an effect of commodity price shocks on civil war risk.

However, there may also be advantages of using trimmed country-specific commodity price shocks. To see this, suppose that a country exports so much of a certain commodity that supply shocks in the country end up affecting the international price of the commodity. In this case, an empirical researcher might end up concluding that negative commodity price shocks do not cause an increase in the risk of civil war although they actually do. This is because an increase in the underlying likelihood of civil war in a country exporting a significant share of the world supply of a commodity may result in higher international prices of the commodity. If the higher underlying likelihood of civil war turns into an actual civil war, the researcher would observe a civil war outbreak following higher (not lower) international prices for the country's exports. Hence, the response of international commodity prices to unobservable changes in the underlying country-level likelihood of civil war outbreak could mask that lower international commodity prices cause an increase in the risk of civil war outbreak.

If the commodity exports of some countries affect international commodity prices, one may therefore find that negative commodity price shocks do not increase civil war risk using the price shocks in the previous subsections, even though negative commodity price shocks do actually cause civil wars. Because of this issue, Bruckner and Ciccone (2010) propose the following. First obtain country-specific commodity price shocks using data on all exports as in the previous subsections. If these shocks do not yield an effect of commodity price shocks on civil war risk, then check the robustness of this (non)finding. Robustness is checked by recalculating commodity price shocks ignoring commodity exports of a country if these exports exceed a threshold of $3 \%$ of world supply. If such trimming results in a statistically significant, negative effect of country-specific commodity price shocks on civil war risk, the (non)finding using nontrimmed commodity price shocks may be due to confounding effects of unobservable changes in the underlying likelihood of civil war.

Bazzi and Blattman adapt Bruckner and Ciccone's approach to their time-varying commodity price shock measure and focus on a $10 \%$ threshold for the share of world supply (they refer to such thresholds as price maker cutoffs). Their procedure can be thought of in two steps. First, set the weight applied to commodity $i$ in year $t$ and country $c$ in (3) equal to zero if exports of 
commodity $i$ by country $c$ are above the price maker cutoff in year $t-1$. Second, obtain the remaining weights in (3) using (4) but excluding all commodities whose exports exceeded the price maker cutoff in the first step.

I adapt Bazzi and Blattman's approach to the case with time-invariant (fixed) commodity weights in the following way. When I obtain the time-invariant weights in (8)[A] using 1980 total export shares, I set $e_{i, c, 1980}$ equal to zero if exports of commodity $i$ by country $c$ exceeded the price maker cutoff in 1979. ${ }^{11}$ The approach for the case of time-invariant weights fixed at 1990 export shares in (8)[B] is analogous. When time-invariant weights are set equal to export shares averaged over the sample period, in (8)[C], I proceed in two steps. First, apply the price maker cutoff to all export shares $e_{i, c, t}$ to obtain new export shares $e_{i, c, t}^{P M C}$ as $e_{i, c, t}^{P M C}=e_{i, c, t}$ if exports of the commodity as a share of world supply were below the price maker cutoff in year $t-1$ and $e_{i, c, t}^{P M C}=0$ otherwise. Second, use these new export shares in $(8)[\mathrm{C}]$.

\subsection{Main estimating equations}

The estimating equation for year-on-year (annual) commodity price shocks is

$$
C \text { WarIndicator }_{c, t}=\text { controls }_{c, t}+b_{0} \text { shock }_{c, t}^{t-1}+b_{1} \text { shock }_{c, t-1}^{t-2}+b_{2} \text { shock }_{c, t-2}^{t-3}
$$

where $\operatorname{shock}_{c, t}^{t-1}$ is the annual commodity price shock between years $t-1$ and $t$ obtained either using time-varying commodity weights or time-invariant (fixed) commodity weights. $C$ WarIndicator $_{c, t}$ is an indicator variable for civil war outbreak (onset) that takes a value of one if there is a civil war in year $t$ but not $t-1$ and a value of zero if there is no civil war in years $t$ and $t-1$, see Section 2.1.1 for details. The controls always include (i) country fixed effects; (ii) year fixed effects; and (iii) country-specific linear time trends.

The cumulative effect of annual commodity price shocks on the risk of civil war outbreak over 3 -year periods in (9) is $b_{0}+b_{1}+b_{2}$. I check for the statistical significance of the cumulative effect by testing the hypothesis that $b_{0}+b_{1}+b_{2}$ is equal to zero.

I also estimate the effect of commodity price shocks over the 3-year period between years

\footnotetext{
${ }^{11}$ I use 1979 to mimic the timing of Bazzi and Blattman's price maker cutoffs. Results do not change if I apply price maker cutoffs to the year when the export share is measured, as suggested by Bruckner and Ciccone.
} 
$t-3$ and $t$, shock $_{c, t}^{t-3}$, on the risk of civil war outbreak using

$$
\text { CWarIndicator }_{c, t}=\text { controls }_{c, t}+\text { b shock }_{c, t}^{t-3} \text {. }
$$

\subsection{Dealing with mismeasured export shares}

Export shares in the Bazzi and Blattman dataset are certainly measured with some error. Hence, price shocks using export shares as commodity weights are measured with some error also, and not taking this into account would result in biased estimates of the effect of price shocks on civil war risk.

It turns out that there are ways of dealing with mismeasured export shares if, loosely formulated, there is limited serial correlation in the measurement error $\varepsilon_{i, c, t}=s_{i, c, t}^{m}-s_{i, c, t}^{*}$, where $s_{i, c, t}^{m}$ is the mismeasured export share and $s_{i, c, t}^{*}$ the true export share of commodity $i$ in the total commodity exports of country $c$ in year $t$. A condition regarding the serial correlation in the measurement error that turns out to be useful is K-dependence (Amemiya, 1985). ${ }^{12}$

Definition The stochastic processes for the measurement error $\varepsilon_{i, c, t}$ of commodities $i=$ $1, \ldots, D$ of country $c$ are $K$-dependent if $\left(\varepsilon_{i, c, t_{1}}, \ldots, \varepsilon_{i, c, t_{n}}\right)$ is independent of $\left(\varepsilon_{j, c, \tau_{1}}, \ldots, \varepsilon_{j, c, \tau_{m}}\right)$ for any $i, j$ and set of integers satisfying $t_{1}<\ldots<t_{n}<\tau_{1}<\ldots<\tau_{m}$ and $t_{n}+K<\tau_{1}$.

Intuitively, this allows that for each country $c$, the measurement errors in the export shares of commodities are correlated within time windows of width $K$ but not outside such time windows. A very simple example where the condition is satisfied is when measurement errors follow moving-average processes of order smaller $K$ based on i.i.d. shocks.

When the measurement error satisfies K-dependence for a given country and is independent across countries, it is possible to obtain consistent estimates of the true effect of commodity price shocks on civil war risk as the sample period goes to infinity. Specifically, suppose that the true risk of civil war is determined by

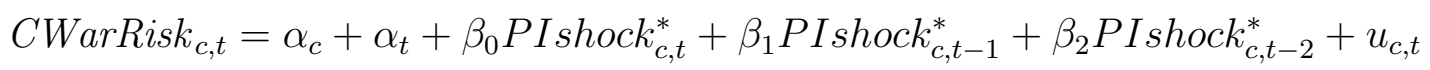

\footnotetext{
${ }^{12}$ An advantage of this condition is that it does not impose restrictions on the functional form of serial correlation. Such conditions would be unlikely to capture the measurement error in the Bazzi and Blattman dataset as missing data is interpolated.
} 
where the commodity price shock $P I s h o c k_{c, t}^{*}$ is the price-index growth in (2) obtained using the true $\left(^{*}\right)$ export shares $s_{i, c, t-1}^{*}$ of commodity $i$ in total commodity exports of country $c$ in year $t-1 ; \alpha_{c}, \alpha_{t}$ are country and year fixed effects; and $u_{c, t}$ captures exogenous shocks to the risk of civil war. Consistent estimates of $\beta_{0}, \beta_{1}$, and $\beta_{2}$ in (11) can be obtained by applying an instrumental-variables approach to the estimating equation

$$
\text { CWarIndicator }_{c, t}=a_{c}+a_{t}+b_{0} \text { PIshock } \text { W }_{c, t}^{m}+b_{1} \text { PIshock }_{c, t-1}^{m}+b_{2} \text { PIshock } \text { s,t-2 }^{m}
$$

where the commodity price shock $P I$ shock $_{c, t}^{m}$ is the price-index growth rate in (2) obtained using the mismeasured $(m)$ shares $s_{i, c, t-1}^{m}$ of commodity $i$ in total commodity exports of country $c$ in year $t-1$. The instrument for PIshock $k_{c, t}^{m}$ in (12) is the fixed-weight commodity price shock

$$
\overline{F W} \operatorname{shock}_{c, t}^{m}=\sum_{i=1}^{65} \bar{s}_{i, c}^{m}\left(\log p_{i, t}-\log p_{i, t-1}\right)
$$

where $\bar{s}_{i, c}^{m}$ is the average mismeasured export share of commodity $i$ in total commodity exports of country $c$ over the sample period. This result is proven in Appendix A. ${ }^{13}$ Intuitively, the idea behind the approach is that the measurement error in the average mismeasured export shares $\bar{s}_{i, c}^{m}$ used as commodity weights in the fixed-weight price-shock instrument in (13) averages out as the sample period goes to infinity. As a result, the correlation between the measurement error in the instrument and the measurement error in the price shocks on the right-hand side of (12) ends up going to zero as the sample period goes to infinity.

It is also interesting to consider the reduced-form $(r)$ regression model obtained by using the fixed-weight shocks in (13) as the right-hand-side variables in (12)

$$
C \text { WarIndicator }_{c, t}=a_{c}+a_{t}+b_{0}^{r} \overline{F W} \text { shock }_{c, t}^{m}+b_{1}^{r} \overline{F W} \text { shock }_{c, t-1}^{m}+b_{2}^{r} \overline{F W} \text { shock }_{c, t-2}^{m} \text {. }
$$

A key question is what the least-squares slope estimates $\widehat{\mathbf{b}^{\mathbf{r}}}=\left[\widehat{b_{0}^{r}}, \widehat{b_{1}^{r}}, \widehat{b_{2}^{r}}\right]^{\prime}$ of (14) converge to as the sample period goes to infinity. To answer this question it is useful to denote the vector of true slopes in $(11)$ by $\beta=\left[\beta_{0}, \beta_{1}, \beta_{2}\right]^{\prime}$. It can be shown that when the measurement error satisfies K-dependence for a given country and is independent across countries

\footnotetext{
${ }^{13}$ All appendices are available online at www.antoniociccone.eu.
} 


$$
\operatorname{plim}_{T \rightarrow \infty} \widehat{\mathbf{b}^{\mathbf{r}}}=(\mathbf{I}+\boldsymbol{\Gamma}) \beta .
$$

I is the identity matrix and $\boldsymbol{\Gamma}$ is the probability limit of the matrix $\widehat{\Gamma}=\left[\widehat{\gamma}_{\mathbf{0}}, \widehat{\gamma}_{\mathbf{1}}, \widehat{\gamma}_{\mathbf{2}}\right]$ where the column vectors $\widehat{\gamma}_{\mathbf{k}}$ collect the least-squares slopes $\widehat{\gamma}_{\mathbf{k}}=\left[\widehat{\gamma}_{k 0}, \widehat{\gamma}_{k 1}, \widehat{\gamma}_{k 2}\right]^{\prime}$ when regressing $z_{c, t}^{k}=\sum_{i}\left(s_{i, c, t-1-k}^{m}-\bar{s}_{i, c}^{m}\right)\left(\log p_{i, t-k}-\log p_{i, t-1-k}\right)$ on the right-hand-side variables in (14). ${ }^{14}$

The result in (15) is also proven in Appendix A. Intuitively, the idea is that there are two issues with the reduced-form regression in (14) when compared to the true model in (11). First, there is measurement error in the right-hand-side variables of the reduced-form regression (due to the mismeasured commodity export shares). Second, there is an omitted-variable issue as the reduced-form regression in (14) solely takes into account the average commodity export shares over the sample period, while the true model in (11) implies that the true risk of civil war also reflects the time variation in commodity export shares. When the measurement error satisfies K-dependence, the measurement error issue is resolved as the sample period goes to infinity, but the omitted-variable issue isn't.

However, K-dependence implies that the omitted-variable bias can be estimated consistently using mismeasured versions of the omitted variables. This is why $\boldsymbol{\Gamma}$ in (15) can be estimated consistently by regressing $z_{c, t}^{k}$ on the right-hand-side variables in (14). Intuitively, the variables $z_{c, t}^{k}=\sum_{i}\left(s_{i, c, t-1-k}^{m}-\bar{s}_{i, c}^{m}\right)\left(\log p_{i, t-k}-\log p_{i, t-1-k}\right)$ are the mismeasured versions of the omitted variables, that is, the mismeasured difference between (i) the commodity price shock in $t-k$ using time-varying export shares as commodity weights and (ii) the commodity price shock in $t-k$ using average export shares over the sample period as commodity weights. ${ }^{15}$

\section{Commodity price shocks and civil war risk}

I first present results for the effect of international commodity price shocks on the risk of civil war outbreak using Bazzi and Blattman's (2014) new dataset only. I start with Sub-Saharan Africa and then turn to a wider sample with all larger countries in Africa, the Middle East, Latin America, and Asia. I also check these results with up-to-date UCDP/PRIO data and

\footnotetext{
${ }^{14}$ Hence, the estimating equations are $z_{c, t}^{k}=\gamma_{c}+\gamma_{t}+\gamma_{k 0} \overline{F W}$ shock $k_{c, t}^{m}+\gamma_{k 1} \overline{F W} \operatorname{shock} k_{c, t-1}^{m}+\gamma_{k 2} \overline{F W} s h o c k_{c, t-2}^{m}$.

${ }^{15}$ In practice, I always estimate the elements of $\boldsymbol{\Gamma}$ in (15) to be very small, and find that the reduced-form least-squares regression in (14) and the instrumental-variables regression in (12)-(13) yield very similar results.
} 
explore cross-country heterogeneity in the effect of international commodity price shocks on civil war risk.

\subsection{Results using the Bazzi and Blattman data only}

All the commodity price and export data in this section comes from Bazzi and Blattman's (2014) new dataset. The civil war outbreak indicator is also taken from Bazzi and Blattman's dataset. I start with the effect of commodity price shocks on the risk of civil war outbreak in Sub-Saharan Africa since 1980. Then I turn to Sub-Saharan Africa since 1957, the first year in Bazzi and Blattman's dataset. I also examine the effect of commodity price shocks on civil war risk since 1980 and since 1957 in Africa, the Middle East, Latin America, and Asia. The end year of my analysis is always 2007, the last year with all the necessary data in Bazzi and Blattman's dataset.

\subsubsection{Results for Sub-Saharan Africa since 1980}

Following Miguel, Satyanath, and Sergenti's (2004) seminal study of the effect of rainfall shocks on civil conflict and civil war in Sub-Saharan Africa, several studies of civil war in Sub-Saharan Africa focus on the period since 1980 (e.g. Sandholt Jensen and Skrede Gleditsch, 2009; Bruckner and Ciccone, 2010; Maertens, 2016). The reason is that Miguel, Satyanath, and Sergenti use a measure of rainfall that has the advantage of incorporating satellite data but is only available since 1979. Focusing on the period since 1980 allows researchers to use the same rainfall data as Miguel, Satyanath, and Sergenti rather than rainfall data they argue is less reliable. In addition to results for the period since 1980, I also present results for the period since 1982 considered by Bazzi and Blattman.

Annual commodity price shocks Table 1, Panel A summarizes the least-squares point estimates (in percent) when estimating the effect of annual fixed-weight commodity price shocks on the risk of civil war outbreak using equation (9). Panel B summarizes the p-values of these point estimates (also in percent) based on robust standard errors clustered at the country level. The table presents results using three different choices for time-invariant commodity weights. Export shares in 1990, export shares in 1980, and the average export shares over the 1980-2007 
period, see Section 3.1.2 for details. The results cover three different choices for price maker cutoffs. A $10 \%$ price maker cutoff, a $3 \%$ price maker cutoff, and no price maker cutoff, see Section 3.1.3 for details. The table presents results for the 1980-2007 period and for the shorter 1982-2007 period. ${ }^{16}$ This yields a total of 18 sets of results.

The point estimates in shaded cells are statistically significant at the $10 \%$ level. A first conclusion from the table is that the effect of contemporaneous commodity price shocks (shocks in year $t$ ) on the risk of civil war outbreak is generally statistically significant at the $10 \%$ level. The exception is with 1980 export weights and a 3\% price maker cutoff. However, fixing timeinvariant commodity export weights at 1980 export shares doesn't seem the best choice. If one had to pick export shares in a single year as the time-invariant commodity export weights, 1980 would be dominated by 1990 as it is closer to the midpoint of the sample period. An additional advantage of using export shares in 1990 as time-invariant commodity export weights is that the results become more directly comparable with Bruckner and Ciccone (2010), who mostly use 1990 export shares from Deaton (1999) as time-invariant commodity export weights.

The results in Table 1 with 1990 export shares as the time-invariant commodity weights point clearly to significant effects of commodity price shocks on the risk of civil war outbreak. This is the case for different price maker cutoffs and time periods. The effect of commodity price shocks in year $t$ is negative and statistically significant at the $5 \%$ level, and the effect of commodity price shocks in year $t-2$ is negative and statistically significant at the $10 \%$ level. The effect is somewhat stronger overall than in Bruckner and Ciccone (2010)(in their Table 2, first column, without price maker cutoffs). Bruckner and Ciccone find an effect of $-6 \%$ for commodity price shocks in year $t$ and $-9 \%$ for shocks in year $t-2$. The point estimates in Table 1 are around $-10 \%$ for commodity price shocks in year $t$ and around $-8 \%$ for shocks in year $t-2$. The levels of statistical significance are similar.

Instead of setting time-invariant export weights equal to export shares in a single year, one may set them equal to average export shares over the sample period. This is attractive as it ensures that time-invariant commodity weights reflect exports over the time period. Moreover, it is a way of dealing with mismeasured export shares, see Section 3.3. As can be seen in Table 1, setting time-invariant export weights equal to average export shares over the sample period

\footnotetext{
${ }^{16}$ My 1980-2007 sample has 1007 observations. The shorter Bazzi and Blattman 1982-2007 sample has 932 observations (see their Online Appendix Table 11, fourth column).
} 
yields very similar point estimates to the case where time-invariant export weights are set equal to 1990 export shares. Moreover, commodity price shocks in year $t$ and in year $t-2$ generally remain statistically significant at the $10 \%$ level. The exception is the effect of shocks in year $t-2$ when the $3 \%$ price maker cutoff is combined with the shorter 1982-2007 period.

The estimates in Table 1 imply sizable effects of commodity price shocks on the risk of civil war outbreak relative to baseline risk. The baseline risk of civil war outbreak in Sub-Saharan Africa 1980-2007 is $2.6 \%$. The point estimates on contemporaneous commodity price shocks using average 1980-2007 export shares as commodity weights, imply that a negative commodity price shock of one standard deviation raises the risk of civil war by 1.7 percentage points.

Cumulative effect of annual commodity price shocks Table 1, Panel C summarizes the 3-year cumulative effect of commodity price shocks on the risk of civil war outbreak for the 18 specifications in Table 1. This effect is obtained as the sum of the three annual effects. It can be seen that 3 -year cumulative effects range from $-16 \%$ to $-22 \%$. For example, this implies that after a sequence of three negative commodity price shocks of one standard deviation each, the risk of civil war outbreak is between 3 and 4 percentage points higher than before. The hypothesis of no cumulative effect is generally rejected at the $5 \%$ significance level. The exceptions are two specifications combining the $3 \%$ price maker cutoff with the shorter 19822007 period, where the hypothesis of no cumulative effect is rejected at the $6 \%$ significance level. Appendix Figure 1 illustrates the cumulative effects in Table 1 graphically.

Instrumental-variables estimation The export shares in the Bazzi and Blattman dataset are certainly measured with some error. A way of dealing with mismeasured export shares is to use the instrumental-variables approach presented in (12)-(13) in Section 3.3. The estimating equation is (12), where the commodity price shocks on the right-hand side are obtained using mismeasured time-varying export shares $s_{i, c, t}^{m}$. The instruments for the mismeasured price shocks in (12) are the fixed-weight commodity price shocks in (13). A key feature of these fixed-weight shocks is that the time-invariant weights $\bar{s}_{i, c}^{m}$ used are the average mismeasured commodity export shares over the sample period. As explained in Section 3.3, this instrumentalvariables approach yields consistent estimates of the true marginal effects of commodity price shocks on civil war risk, $\beta$ in (11), if the serial correlation in the measurement error is limited. 
When I implement the instrumental-variables approach in (12)-(13), I obtain estimates that are very similar to the least-squares estimates in Table 1 where the time-invariant commodity weights are set equal to the average commodity export shares over the sample period (19802007). ${ }^{17}$ These results in Table 1 correspond to the least-squares estimates of the reduced-form regression in (14). Hence, the instrumental-variables approach in (12)-(13) and the reducedform least-squares approach in (14) yield very similar results for Sub-Saharan Africa since 1980. For example, consider the results for the 1980-2007 period and a 3\% price maker cutoff in Table 1. The point estimates are $-10 \%$ for shocks in year $t,-3 \%$ for shocks in year $t-1$, and $-9 \%$ for the shocks in year $t-2$. The commodity price shocks in years $t$ and $t-2$ are statistically significant at the $10 \%$ level. The corresponding instrumental-variables estimates I obtain are $-10 \%$ for shocks in year $t,-2 \%$ for shocks in year $t-1,-9 \%$ for the shocks in year $t-2$, and the commodity price shocks in years $t$ and $t-2$ are statistically significant at the $10 \%$ level.

The reason why the instrumental-variables approach in (12)-(13) and the reduced-form least-squares approach in (14) yield very similar effects of price shocks on civil war risk in SubSaharan Africa since 1980 can be understood using the result in equation (15). This result was shown to hold as long as the serial correlation in the measurement error is limited as specified in Section 3.3. The result states that the reduced-form least-squares estimates converge to the true marginal effects of commodity price shocks on civil war risk, $\beta$ in (11), plus a term $\Gamma \beta$ that captures an omitted-variable bias. Moreover, $\boldsymbol{\Gamma}$ can be estimated consistently with the least-squares regressions presented after (15). When I do this for Sub-Saharan Africa since 1980, I find that the omitted-variable bias is estimated to be very small. This would explain why the reduced-form least-squares approach in (14) and the instrumental-variables approach in (12)-(13) yield very similar results.

\section{Annual commodity price shocks with controls Detailed results for the effect of} annual commodity price shocks on the risk of civil war outbreak over the 1980-2007 period are presented in Appendix Table 1. ${ }^{18}$ The table presents results for a price maker cutoff of $10 \%$, which is the cutoff Bazzi and Blattman focus on. I start with time-varying commodity weights following Bazzi and Blattman's approach. Then I turn to the three different time-invariant

\footnotetext{
${ }^{17}$ The first-stage regressions of the price shocks on the right-hand side of (12) on the fixed-weight price shocks in (13) used as instruments yield strong effects of the instruments.

${ }^{18}$ All appendices are available online at www.antoniociccone.eu.
} 
commodity weights already used in Table $1 .{ }^{19}$ The controls used are variables capturing OECD demand for Sub-Saharan countries' exports and rainfall shocks. I report point estimates, standard errors (in parentheses), and p-values of the hypothesis that the effect is zero (in square brackets).

Column (1) uses commodity price shocks obtained with time-varying commodity weights following Bazzi and Blattman's approach, see Section 3.1.1 for details. The results indicate that no single commodity price shock is statistically significant at the $10 \%$ level. However, results could still indicate a statistically significant cumulative effect of commodity price shocks on the risk of civil war outbreak over 3-year periods. The table therefore reports the p-value of the hypothesis test that the sum of the coefficients on the three commodity price shocks is equal to zero. The p-value of 0.11 indicates that the hypothesis of no cumulative effect cannot be rejected at the $10 \%$ significance level. Hence, commodity price shocks with time-varying commodity weights yield statistically insignificant effects on the risk of civil war outbreak.

Columns (2)-(10), examine the response of civil war risk to annual commodity price shocks obtained with three different time-invariant commodity weights: average 1980-2007 export shares; 1990 export shares; and 1980 export shares. The baseline results without additional controls in columns (2), (5), and (8) indicate that commodity price shocks in years $t$ and $t-2$ have a statistically significant, negative effect on the risk of civil war outbreak no matter which set of time-invariant export shares is used as commodity weights. The p-values of the statistically significant price shocks vary between $4 \%$ and $8 \%$. The hypothesis that the sum of the coefficients on the three commodity price shocks is equal to zero (no cumulative effect) can be rejected at the $5 \%$ level in all cases.

Columns (3), (6), and (9) extend the baseline specifications by controlling for the OECD export demand variable that Bruckner and Ciccone (2010) construct following Acemoglu, Johnson, Robinson, and Yared (2008). This variable is meant to capture variation over time in the OECD demand for Sub-Saharan countries' exports. For country $c$ in year $t$, the variable is the weighted sum of real GDP growth of OECD countries between $t-1$ and $t$. The weights are equal to the 1990 exports of country $c$ to each OECD destination relative to country c's GDP. Hence, the variable captures changes in the demand for Sub-Saharan African exports due to

\footnotetext{
${ }^{19}$ Detailed results for the price maker cutoff of $3 \%$ and the 1982-2007 period are in Appendix Tables 11-13.
} 
faster or slower growth in OECD countries. The negative, statistically significant coefficient on the OECD export demand variable indicates that civil wars become more likely following downturns in OECD export demand. Overall, the negative effect of annual commodity price shocks in years $t$ and $t-2$ on the risk of civil war outbreak becomes somewhat stronger with the OECD export demand variable as a control.

Columns (4), (7), and (10) extend the specifications with OECD export demand by controlling for rainfall shocks using the GPCP rainfall data incorporating satellite measurements. The specification follows Maertens (2016). He points out that the effect of rainfall on agricultural output is found to be quadratic and hump-shaped in the agricultural economics literature. That is, more rainfall increases agricultural output only up to a point. Maertens then observes that if negative shocks to agricultural output raise the risk of civil war, the effect of rainfall on the risk of civil war outbreak should be quadratic and U-shaped. He finds this to be the case. ${ }^{20}$ My results confirm Maertens' findings and show that the negative effect of commodity price shocks and OECD export demand on civil war risk is robust to controlling for rainfall shocks.

A detour with the Bazzi and Blattman shocks Table 2, Panel A summarizes the point estimates (in percent) when estimating the effect of the annual Bazzi and Blattman commodity price shocks on the risk of civil war outbreak using equation (9). The Bazzi and Blattman commodity price shocks are obtained using time-varying export weights, as explained in (3)-(5). Table 2 contains both least-squares results (LS BB) and instrumental-variable results (IV). The instrumental-variables results use the same estimating equation as the least-squares results, but the Bazzi and Blattman commodity price shocks are instrumented with the commodity price shocks using time-invariant (fixed) export weights. The point estimates in shaded cells are statistically significant at the $10 \%$ level. Panel B summarizes the p-values of these point estimates (also in percent) based on robust standard errors clustered at the country level.

There are three different instrumental-variables specifications in Table 1, depending on whether the fixed-weight commodity price shocks used as instruments are obtained at fixed 1980 export shares, at fixed 1990 export shares, or at average export shares over the 1980-2007

\footnotetext{
${ }^{20}$ Maertens thereby resolves the debate around the effect of rainfall shocks on civil war outbreak in SubSaharan Africa, see Miguel, Satyanath, and Sergenti (2004) for one side of the debate and Sandholt Jensen and Skrede Gleditsch (2009) and Ciccone (2011) for the other. This literature had assumed linear or logarithmic effects of rainfall on civil war risk.
} 
period. The first-stage regressions yield strong effects of the instruments on the Bazzi and Blattman commodity price shocks in all three cases.

The least-squares results in Table 2 (LS BB) show clearly that the Bazzi and Blattman commodity price shocks generally have a statistically insignificant effect on the risk of civil war outbreak. This is true for the 1980-2007 period and the shorter 1982-2007 period.

One the other hand, the instrumental-variables results in Table 2 (IV) generally indicate a negative and statistically significant effect of the Bazzi and Blattman commodity price shocks on the risk of civil war outbreak. This is true for the 1980-2007 and the 1982-2007 period.

Table 2, Panel C summarizes the 3-year cumulative effect of commodity price shocks on the risk of civil war outbreak for all specifications. This effect is obtained as the sum of the three annual effects. It can be seen that the cumulative effects implied by the least-squares estimates with the Bazzi and Blattman commodity price shocks are between $-12 \%$ and $-16 \%$ and never statistically significant at the $10 \%$ level.

On the other hand, it can also be seen from Table 2, Panel $\mathrm{C}$ that the cumulative effects implied by the instrumental-variables estimates are between $-20 \%$ and $-26 \%$ and always statistically significant at the $5 \%$ level.

There could be different reasons why the least-squares estimates with the Bazzi and Blattman commodity price shocks in Table 2 indicate statistically insignificant effects on civil war risk, while the instrumental-variables estimates generally indicate statistically significant effects on civil war risk. It could be that the least-squares estimates are biased (towards zero) due to export shares, and hence Bazzi and Blattman commodity price shocks, being measured with error. Alternatively, the least-squares estimates with the Bazzi and Blattman commodity price shocks could be biased because the time-varying export shares reflect unobservable time variation in the underlying likelihood of civil war.

Commodity price shocks over 3-year periods Table 3 summarizes the effect of 3-year fixed-weight commodity price shocks for different time-invariant commodity weights, different price maker cutoffs, and for the 1980-2007 as well as the shorter 1982-2007 period (a total of 18 specifications). The estimating equation is (10). ${ }^{21}$ It can be seen that the effect of 3 -year

\footnotetext{
${ }^{21}$ The 3-year commodity price shock specification in equation (10) can be seen as the annual specification in equation (9) under the restriction that the coefficients of the three annual commodity price shocks are equal.
} 
commodity price shocks on the risk of civil war outbreak is generally statistically significant at the $5 \%$ level. The exceptions are two specifications combining the $3 \%$ price maker cutoff and the shorter 1982-2007 period, where the p-values are $6 \%$ and $7 \%$.

The effect of 3-year commodity price shocks on the risk of civil war outbreak is around $-6 \%$. This is similar to the result of Bruckner and Ciccone $(-6 \%$, in their Table 2 , fifth column). The estimates imply that a negative 3-year commodity price shock of one standard deviation raises the risk of civil war outbreak by around 1.8 percentage points. This is sizable compared to the $2.6 \%$ baseline risk of civil war outbreak.

Detailed results for the effect of 3-year commodity price shocks on the risk of civil war outbreak are presented in Appendix Table 2. The price maker cutoff is the $10 \%$ value that Bazzi and Blattman focus on. ${ }^{22}$ 3-year commodity price shocks are always statistically significant at the $5 \%$ level, no matter which time-invariant commodity weights are chosen. Point estimates are $-6 \%$ to $-7 \%$.

\subsubsection{Results for Sub-Saharan Africa 1957-2007}

The longest period with data for Sub-Saharan Africa in Bazzi and Blattman's new dataset is 1957-2007. Bruckner and Ciccone's (2010) analysis for Sub-Saharan Africa since 1960 indicates that negative commodity price shocks sparked civil wars over this period when price shocks are measured over 3-year periods. I now examine whether this is also true using Bazzi and Blattman's data since 1957.

Commodity price shocks over 3-year periods Table 4 summarizes the effect of 3-year fixed-weight commodity price shocks over the 1957-2007 period. The table presents results for different time-invariant commodity weights and price maker cutoffs (a total of 9 specifications). The effect of 3-year commodity price shocks on the risk of civil war outbreak is between $-2 \%$ and $-4 \%$. This effect is statistically significant at the $10 \%$ level, except when time-invariant commodity export weights for the 50-year period are fixed at values in a specific year and a $3 \%$ price maker cutoff is applied. But fixing time-invariant commodity export weights at their values in a single year doesn't seem the best choice for the 50-year period considered.

The hypothesis that the coefficients on three annual commodity price shocks are equal is tested in the detailed appendix tables and never rejected at standard significance levels.

${ }^{22}$ Detailed results for the price maker cutoff of 3\% and the 1982-2007 period are in Appendix Tables 14-16. 
The point estimates in Table 4 imply that over the 1957-2007 period, a negative 3-year commodity price shock of one standard deviation raised the risk of civil war in Sub-Saharan Africa by around one percentage point. This is about half of the baseline risk of civil war outbreak in Sub-Saharan Africa over this period.

Detailed results using different choices for time-invariant commodity export weights and the $10 \%$ price maker cutoff Bazzi and Blattman focus on are in Appendix Table 3. ${ }^{23}$ I report point estimates, standard errors (in parentheses), and p-values of the hypothesis that the effect is zero (in square brackets). The effect of 3-year commodity price shocks on the risk of civil war outbreak is around $-3.7 \%$ and statistically significant at the $6 \%$ level when time-invariant commodity weights are set equal to average export shares over the sample period. Effects are somewhat weaker when time-invariant commodity weights are set equal to export shares in a single year. But again, fixing time-invariant commodity export weights at their values in a single year doesn't seem the best choice for the 50-year period considered. The effects are stronger than comparable estimates in Bruckner and Ciccone (2010)(for the period since 1960, they estimate an effect of $-1.7 \%$, see their Table 7 , second column). Overall, results become somewhat stronger when I control for OECD export growth following Bruckner and Ciccone (2010) and for rainfall shocks following Maertens (2016). ${ }^{24}$

\subsubsection{Results for Africa, the Middle East, Latin America, and Asia}

Bazzi and Blattman's (2014) dataset also contains commodity export and civil war data for countries in Africa, the Middle East, Latin America, and Asia with populations over one million (118 countries). I start by examining the effect of commodity price shocks on the risk of civil war outbreak in this wider sample since 1980 and then turn to the period since 1957.

Annual commodity price shocks since 1980 Table 5 summarizes the results for annual fixed-weight commodity price shocks over the 1980-2007 period using different timeinvariant export weights and price maker cutoffs (a total of 9 specifications). The effect of commodity price shocks in year $t$ on the risk of civil war outbreak is negative and statistically

\footnotetext{
${ }^{23}$ Detailed results for the price maker cutoff of $3 \%$ are in Appendix Table 17.

${ }^{24}$ I use the GPCC rainfall data based on gauge measurements only, as the GPCP rainfall data incorporating satellite measurements only starts in 1979.
} 
significant at the $5 \%$ level in all specifications. The strength of the effect is between $-4 \%$ and $-7 \%$. The pattern of results for the wider sample is somewhat different than for Sub-Saharan Africa. The effect of commodity price shocks in year $t$ on the risk of civil war outbreak is stronger statistically in the wider sample. On the other hand, there is no evidence of statistically significant effects of lagged commodity price shocks.

Detailed results for the effect of annual commodity price shocks on the risk of civil war outbreak over the 1980-2007 period are reported in Appendix Table 4. The results use the $10 \%$ price maker cutoff that Bazzi and Blattman focus on and cover the three different choices for time-invariant commodity weights, 1980 export shares, 1990 export shares, and the average export shares over the sample period. I report point estimates, standard errors (in parentheses), and p-values of the hypothesis that the effect is zero (in square brackets). The set of control variables includes the OECD export growth variable of Bruckner and Ciccone (2010). I do not present results with controls for rainfall shocks as these were never statistically significant, which may reflect that rainfall does not affect agricultural output in the wider sample. The results indicate that the effect of commodity price shocks in year $t$ on the risk of civil war outbreak is negative and statistically significant at the $5 \%$ level in all specifications. The strength of the effect is between $-4 \%$ and $-6 \%$. This implies that a negative commodity price shock of one standard deviation raises the risk of civil war outbreak by around one percentage point. This is about half the baseline risk of civil war outbreak in the sample.

Commodity price shocks over 3-year periods since 1980 Table 6 summarizes the results for 3-year fixed-weight commodity price shocks over the 1980-2007 period using different time-invariant export weights and price maker cutoffs (a total of 9 specifications). 3-year commodity price shocks have a negative effect that is statistically significant at the $10 \%$ level in all specifications. The strength of the effect is between $-3 \%$ and $-4 \%$. The implied increase in the risk of civil war outbreak of a negative 3-year commodity price shock of one standard deviation is around 0.8 percentage points. This is about $40 \%$ of the $1.9 \%$ baseline risk of civil war outbreak in the sample.

Detailed results for the effect of 3-year commodity price shocks on the risk of civil war outbreak over the 1980-2007 period are reported in Appendix Table 5. The results again use the $10 \%$ price maker cutoff that Bazzi and Blattman focus on and cover the three different 
choices for time-invariant commodity weights, 1980 export shares, 1990 export shares, and the average export shares over the sample period. The effect of 3-year commodity price shocks on the risk of civil war outbreak is negative and statistically significant at the $10 \%$ level in all specifications. The strength of the effect is around $-3 \%$.

Commodity price shocks over 3-year periods since 1957 Results for the effect of 3-year fixed-weight commodity price shocks on the risk of civil war outbreak for all larger countries in Africa, the Middle East, Latin America, and Asia over the 1957-2007 period are summarized in Appendix Tables 6 and 7. Appendix Table 6 contains detailed results using a 10\% price maker cutoff. Time-invariant weights are fixed at three different values, 1980 export shares, 1990 export shares, and the average export shares over the sample period. 3-year commodity price shocks are not a statistically significant determinant of civil war risk over this long period in the wider sample. This conclusion is generally confirmed by Appendix Table 7, which summarizes the results for different time-invariant export weights and price maker cutoffs (a total of 9 specifications). An interesting exception is the case where time-invariant export weights are set equal to the sample average and a $3 \%$ price maker cutoff is used. In this case, the effect of 3-year commodity price shocks on the risk of civil war outbreak is negative and statistically significant at the $10 \%$ level. As explained in Section 3.1.3, this could indicate that the (non)findings using no price maker cutoff or a $10 \%$ price maker cutoff may be due to confounding effects of (unobserved) changes in the underlying likelihood of civil war. This is because application of the $3 \%$ price maker cutoff is the most stringent way of suppressing such confounding effects. ${ }^{25}$

I also estimate the effects of 3-year commodity price shocks on civil war risk when the commodity price shock is split into two parts: (i) a commodity price shock that collects minerals, gas, and oil, and (ii) a commodity price shock that collects agricultural commodities (see Section 4.2.2 for more details on this split). This yields that agricultural commodity price shocks have

\footnotetext{
${ }^{25} \mathrm{An}$ interesting issue is why (unobservable) changes in the underlying likelihood of civil war would mask a negative causal effect of commodity price shocks on the risk of civil war outbreak in the wider sample over the 1957-2007 period but not in Sub-Saharan Africa, see the results for Sub-Saharan Africa in Table 6 with time-invariant export weights set equal to average export shares over the sample period. A possibility would be that confounding effects are stronger in the wider sample. For example, for the case of crude oil, around $90 \%$ of country-years with exports between $3 \%$ and $10 \%$ of world supply correspond to countries outside of Sub-Saharan Africa.
} 
a negative and statistically significant effect on the risk of civil war outbreak whether I use the $10 \%$ or the $3 \%$ price maker cutoff.

\subsection{Results with updated and extended civil war data}

The UCDP/PRIO civil war database used by Bazzi and Blattman (2014) to obtain the civil war outbreak indicator in the previous section has been updated and extended in time (UCDP/PRIO Armed Conflict Dataset version 4-2016). I now incorporate this database to make sure results are up-to-date. The data for commodity exports and prices continues to come from Bazzi and Blattman's dataset, which contains commodity prices up to 2009 (the UCDP/PRIO civil war outbreak indicator in the Bazzi and Blattman dataset only goes to 2007, which is why the end year in previous sections was 2007). This allows me to extend the period of analysis to 2009. I will focus on specifications with time-invariant commodity export weights set equal to average export shares over the sample period.

\subsubsection{Results for Sub-Saharan Africa}

Annual commodity price shocks since 1980 Table 7 presents results for the effect of annual fixed-weight commodity price shocks on the risk of civil war outbreak. The time period is 1980-2009. Time-invariant commodity export weights are set equal to the average commodity export share over the sample period. The table contains results both for the $10 \%$ price maker cutoff and the $3 \%$ price maker cutoff. I report point estimates, standard errors (in parentheses), and p-values of the hypothesis that the effect is zero (in square brackets). The effect of commodity price shocks in year $t$ on the risk of civil war outbreak is negative and statistically significant. The strength of the effect is around $-7 \%$. Results become somewhat stronger when I control for the OECD export growth variable of Bruckner and Ciccone (2010) as well as rainfall shocks following Maertens (2016). Compared to the results with the older and shorter UCDP/PRIO dataset used by Bazzi and Blattman, the effect is somewhat weaker quantitatively but somewhat stronger statistically. Commodity price shocks in year $t-1$ have a negative and statistically significant effect on the risk of civil war outbreak with the $10 \%$ price maker cutoff only. The hypothesis that the sum of the coefficients on the three annual commodity price shocks is equal to zero can be rejected at the $5 \%$ significance level in all 
specifications. This indicates a statistically significant cumulative effect of commodity price shocks on the risk of civil war outbreak.

Commodity price shocks over 3-year periods since 1980 Table 8 shows my results for the effect of 3-year fixed-weight commodity price shocks on the risk of civil war outbreak. The effect is negative and statistically significant at the $5 \%$ level in all specifications. The strength of the effect is around $-6 \%$. Compared to the results with the older and shorter UCDP/PRIO dataset used by Bazzi and Blattman, the effect is somewhat weaker quantitatively but somewhat stronger statistically. Results become somewhat stronger when I control for OECD export growth as well as rainfall shocks.

Commodity price shocks over 3-year periods since 1957 Table 9 presents results for the effect of 3-year fixed-weight commodity price shocks on the risk of civil war outbreak in Sub-Saharan Africa over the 1957-2009 period. The effect is between $-3 \%$ and $-4 \%$, and statistically significant at the $5 \%$ level in all specifications. Compared to the results with the older and shorter UCDP/PRIO dataset used by Bazzi and Blattman, the effect is similar quantitatively but stronger statistically. Results become somewhat stronger when I control for OECD export growth as well as rainfall shocks (using GPCC rainfall as GPCP satellite rainfall data is only available since 1979). ${ }^{26}$

\subsubsection{Results for Africa, the Middle East, Latin America, and Asia}

Annual commodity price shocks since 1980 Table 10 shows my results for the effect of annual fixed-weight commodity price shocks on the risk of civil war outbreak for the wider sample including all larger countries in Africa, the Middle East, Latin America, and Asia. The time period is 1980-2009. Time-invariant commodity export weights are set equal to the average commodity export share over the sample period. The table contains results both for the $10 \%$

\footnotetext{
${ }^{26}$ Appendix Tables 18-20 reestimate the baseline specifications in Tables 7-9 after splitting the commodity price shock into (i) a commodity price shock that collects minerals, gas, and oil, and (ii) a commodity price shock that collects agricultural commodities. Specifically, the minerals, gas, and oil commodity price shock is obtained using (7) but summing only over minerals, gas, and oil; the agricultural commodity price shock is obtained using (7) but summing only over agricultural commodities. The specifications with 3 -year commodity price shocks indicate that lower international prices raise the risk of civil war outbreak for both types of commodities, with somewhat stronger effects for agricultural commodities. The results with annual commodity price shocks are noisier but go in the same direction qualitatively.
} 
price maker cutoff and the $3 \%$ price maker cutoff. I report point estimates, standard errors (in parentheses), and p-values of the hypothesis that the effect is zero (in square brackets). The effect of commodity price shocks in year $t$ on the risk of civil war outbreak is $-3 \%$ to $-4 \%$ and statistically significant at the $6 \%$ level in all specifications. Compared to the results with the older and shorter UCDP/PRIO dataset used by Bazzi and Blattman (2014), the effect is somewhat weaker quantitatively and statistically. ${ }^{27}$ The hypothesis that the sum of the coefficients on the three annual commodity price shocks is equal to zero can be rejected at the $6 \%$ significance level in all specifications. This indicates a statistically significant cumulative effect of commodity price shocks on the risk of civil war outbreak.

Commodity price shocks over 3-year periods since 1980 Table 11 presents results for the effect of 3-year fixed-weight commodity price shocks on the risk of civil war outbreak for the wider sample and the 1980-2009 period. 3-year commodity price shocks have a negative and statistically significant effect on the risk of civil war outbreak. The strength of the effect is around $-3 \%$ and statistically significant at the $6 \%$ level in all specifications. Compared to the results with the older and shorter UCDP/PRIO dataset used by Bazzi and Blattman, the effect is similar quantitatively but stronger statistically.

Commodity price shocks over 3-year periods since 1957 Appendix Table 8 shows that there is no statistically significant effect of 3-year fixed-weight commodity price shocks on civil war risk in the wider sample of countries over the 1957-2009 period when the $10 \%$ price maker cutoff is applied. However, the effect of 3-year commodity price shocks on civil war risk becomes negative and statistically significant at the $2 \%$ level when the more stringent $3 \%$ price maker cutoff is used. This could indicate that the (non)finding with the $10 \%$ price maker cutoff may be due to confounding effects of (unobserved) changes in the underlying likelihood of civil war, as explained in Section 3.2.4 and the end of Section 4.2.3.

I also estimate the effects of 3-year commodity price shocks on civil war risk when the

\footnotetext{
${ }^{27}$ Appendix Tables 21-22 reestimate the baseline specifications in Tables 10 and 11 after splitting the commodity price shock into (i) a commodity price shock that collects minerals, gas, and oil, and (ii) a commodity price shock that collects agricultural commodities, see footnote 26 for details. The point estimates using 3 -year commodity price shocks indicate that lower international prices raise the risk of civil war outbreak for both types of commodities, but estimates are only statistically significant for agricultural commodities. The results with annual commodity price shocks yield statistically significant increases in civil war risk following lower international prices for both types of commodities, but the timing is different for the two types of commodities.
} 
commodity price shock is split into two parts: (i) a commodity price shock that collects minerals, gas, and oil, and (ii) a commodity price shock that collects agricultural commodities. This yields that agricultural commodity price shocks have a negative and statistically significant effect on the risk of civil war outbreak whether I use the $10 \%$ or the $3 \%$ price maker cutoff. The strength of the effect is around $2.5 \% .^{28}$

\subsubsection{Exploring cross-country heterogeneity}

Bazzi and Blattman (2014) consider a measure of country-specific commodity price shocks that incorporates countries' aggregate commodity exports relative to GDP. To see the rationale it is useful to consider the following baseline scenario. Suppose that countries' aggregate commodity exports relative to GDP are unrelated to characteristics of countries that play a role (i) for the effect of international commodity price shocks on income and (ii) for the effect of income shocks on the risk of civil war outbreak. Suppose also that income is the only channel through which international commodity price shocks affect civil war risk. In this baseline scenario, commodity price shocks should translate into a stronger effect on income and on civil war risk in countries with larger commodity exports relative to GDP. This is because larger commodity exports relative to GDP magnify the effect of commodity price shocks on income but are assumed to not affect the causal chain from commodity price shocks to civil war risk in any other way.

I examine the evidence for heterogeneity in the effect of commodity price shocks on civil war risk depending on countries' aggregate commodity exports relative to GDP in two steps. I first group countries by whether their aggregate commodity exports relative to GDP are above or below the cross-country median. Then I estimate the effect of 3-year fixed-weight commodity price shocks separately in the two subsamples. Countries' aggregate commodity exports relative to GDP are calculated using the data of Bazzi and Blattman. Specifically, for each country, I multiply the average of aggregate commodity exports relative to total exports over the relevant time period with the average of total exports relative to GDP over the time period. ${ }^{29}$

\footnotetext{
${ }^{28}$ The results are in Appendix Table 23. The split of the commodity price shock into two parts is explained in more detail in footnote 26 . With the $3 \%$ price maker cutoff, minerals, oil, and gas price shocks also have a negative and statistically significant effect on the risk of civil war outbreak.

${ }^{29}$ Using the notation in equation (3), a country's aggregate commodity exports relative to total exports is obtained as $\sum_{t} \sum_{i} e_{i, c, t} / \tau$ where $\tau$ is the length of the time period, $t$ the years included in the time period, and $i$ the index for the 65 commodities considered. The data for $e_{i, c, t}$ comes from Bazzi and Blattman. The average of a country's total exports relative to GDP is obtained as the average over the time period of the $(X / G D P)_{c, t}$
} 
Appendix Table 9 summarizes my results. For Sub-Saharan Africa, I find that the effect of international commodity price shocks on civil war risk is negative and statistically significant for countries with commodity exports relative to GDP below the median but statistically insignificant for countries with commodity exports relative to GDP above the median. This is the case for the 1980-2009 period and the 1957-2009 period. This result does not conform with the prediction of the baseline scenario above, where aggregate commodity exports relative to GDP are assumed to affect the causal chain from commodity price shocks to civil war risk only in that they magnify the effect of commodity price shocks on income. For the wider sample including all larger countries in Africa, the Middle East, Latin America, and Asia, there is some weak evidence for a statistically significant effect of commodity price shocks on civil war risk for countries with commodity exports relative to GDP above the median for the 1957-2009 period. Hence, overall, there is no clear evidence that commodity price shocks have a stronger effect on civil war risk for countries with large commodity exports relative to GDP. This could indicate that income is not the only channel through which commodity price shocks affect civil war risk. Alternatively, the prediction of the baseline scenario could be invalidated by heterogeneity in the effect of commodity price shocks on income or the effect of income shocks on civil war risk (Fearon, 2005; Fearon, Kasara, and Laitin, 2007; Caselli and Tesei, 2016).

Appendix Table 10 explores whether the effect of international commodity price shocks on civil war risk varies with countries' income per capita, income inequality, or ethnic fragmentation. The approach is analogous to Appendix Table 9. Countries are first grouped by whether the relevant country characteristic is above or below the cross-country median. Then the effect of 3-year fixed-weight commodity price shocks on the risk of civil war outbreak is estimated separately in each subsample. The data for the sample split by income per capita comes from the Penn World Tables. The data for the other sample splits comes from Alesina, Michalopoulos, and Papaioannou (2016). The period of analysis is 1980-2009. Panels A and B look at crosscountry heterogeneity using two measures of living standards, light per capita and income per capita. Overall, there is evidence that negative international commodity price shocks sparked civil wars in countries with living standards below the median but not in countries with living variable in the Bazzi and Blattman dataset. I do not average over commodity exports relative to GDP directly as Bazzi and Blattman's (partly interpolated) dataset for commodity exports focuses on commodity exports relative to total exports. 
standards above the median. Panels $\mathrm{C}$ and D look at cross-country heterogeneity using two measures of income inequality within countries, the Gini coefficient and the income share of the top quintile of the income distribution. Both yield evidence that negative international commodity price shocks sparked civil wars in countries with inequality below the median but not in countries with inequality above the median. Finally, Panel D looks at cross-country heterogeneity in ethnic fragmentation using the Alesina et al. (2003) measure. This yields that negative commodity price shocks sparked civil wars in countries with ethnic fragmentation below the median but not in countries with fragmentation above the median. ${ }^{30}$ These findings have to be interpreted with great caution however. More work would be needed to see whether they can be rationalized theoretically or whether they may be driven by omitted country characteristics.

\section{Conclusion}

The new dataset put together by Bazzi and Blattman (2014) makes it possible to examine whether international commodity price downturns sparked civil wars with more comprehensive data than used previously. I find that international commodity price downturns sparked civil wars in Sub-Saharan Africa. Another finding with the new dataset is that since 1980, international commodity price downturns also sparked civil wars in a much wider sample of countries including all larger countries in Africa, the Middle East, Latin America, and Asia. The effect of a one-standard-deviation commodity price shock on the risk of civil war outbreak is between $40 \%$ and $70 \%$ of the baseline risk of civil war outbreak. When I differentiate between agricultural commodities on the one hand and minerals, oil, and gas on the other, I find stronger increases in the risk of civil war outbreak following downturns in agricultural commodity prices. In particular, I find that 3-year downturns in agricultural commodity prices raised the risk of civil war outbreak since 1980 and also since 1957 whether I consider countries in Sub-Saharan Africa or all larger countries in Africa, the Middle East, Latin America, and Asia.

My conclusions using the new dataset of Bazzi and Blattman contrast with the conclusions of Bazzi and Blattman. The key issue is whether the commodity export shares used to aggregate international commodity prices to country-specific indices are taken to be time-invariant or

\footnotetext{
${ }^{30}$ The Garcia-Montalvo and Reynal-Querol (2002) measure of ethnic polarization yields the same pattern of results in Sub-Saharan Africa. In the wider sample, effects are insignificant in both subsamples.
} 
time-varying. Bazzi and Blattman use time-varying commodity export shares. My empirical results are based on time-invariant commodity export shares. I argue that to uncover a causal effect of international commodity price shocks on civil war risk, time-invariant export shares are preferable as they ensure that differences in country-specific price shocks over time solely reflect (exogenous) changes in international commodity prices over time. Using time-varying export shares to construct commodity price shocks jeopardizes causal estimation, as such price shocks partly reflect changes in the type and quantity of commodity exports and these changes may be correlated with the underlying risk of civil war. I also show that using average commodity export shares over the sample period as time-invariant export weights, can be a remedy for attenuation bias due to measurement error in export shares. When I explore cross-country heterogeneity in the effect of commodity price shocks on civil war outbreak, I find no robust evidence of a stronger effect in countries with greater aggregate commodity exports relative to GDP. 


\section{$6 \quad$ References}

Amemiya, T. (1985). Advanced Econometrics. Basil Blackwell, Oxford, UK.

Acemoglu, D., S. Johnson, J.A. Robinson, and P. Yared (2008). Income and Democracy. The American Economic Review, 98(3): 808-842.

Alesina, A., A. Devleeschauwer, W. Easterly, S. Kurlat, and R. Wacziarg (2003). Fractionalization. Journal of Economic Growth, 8(2): 155-94.

Alesina, A., S. Michalopoulos, and E. Papaioannou (2016). Ethnic Inequality. Journal of Political Economy, 124(2): 428-488.

Bazzi, S. and C. Blattman (2014). Economic Shocks and Conflict: Evidence from Commodity Prices. American Economic Journal: Macroeconomics, 6(4): 1-38.

Berman, N. and M. Couttenier (2015). External Shocks, Internal Shots: The Geography of Civil Conflicts. Review of Economics and Statistics, 97(4): 758-776.

Berman, N., M. Couttenier, D. Rohner, and M. Thoenig (2017). This Mine is Mine! How Minerals Fuel Conflicts in Africa. American Economic Review, 107(6): 1564-1610.

Blattman, C. and E. Miguel (2010). Civil War. Journal of Economic Literature, 48(1): 3-57.

Bruckner, M. and A. Ciccone (2010). International Commodity Prices, Growth, and the Outbreak of Civil War in Sub-Saharan Africa. The Economic Journal, 120: 519-534.

Caselli, F. and A. Tesei (2016). Resource Windfalls, Political Regimes, and Political Stability. Review of Economics and Statistics, 98(3): 573-590.

Ciccone, A. (2011). Economic Shocks and Civil Conflict: A Comment. American Economic Journal: Applied Economics, 3(4): 215-227.

Collier, P. and A. Hoeffler (2004). Greed and Grievance in Civil War. Oxford Economic Papers, 56(4): 563-595.

Cotet, A. and K. Tsui (2013). Oil and Conflict: What Does the Cross Country Evidence Really Show? American Economic Journal: Macroeconomics, 5(1): 49-80.

Deaton, A. and R. I. Miller (1995). International Commodity Prices, Macroeconomic Performance, and Politics in Sub-Saharan Africa. International Finance Section, Department of Economics, Princeton University. 
Deaton, A. (1999). Commodity Prices and Growth in Africa. Journal of Economic Perspectives, 13(3): 23-40.

Djankov, S. and M. Reynal-Querol (2010). Poverty and Civil War: Revisiting the Evidence. The Review of Economics and Statistics, 92(4): 1035-1041.

Eck, K. and Hultman, L. (2007). One-Sided Violence Against Civilians in War: Insights from New Fatality Data. Journal of Peace Research, 44(2): 233-46.

Fearon, J. (2005). Primary Commodity Exports and Civil War. Journal of Conflict Resolution, 49(5): 483-507.

Fearon, J. and D. Laitin (2003). Ethnicity, Insurgency, and Civil War. American Political Science Review, 97(1): 75-90.

Fearon, J., K. Kasara, and D. Laitin (2007). Ethnic Minority Rule and Civil War Onset. American Political Science Review, 101(1): 187-193.

Fearon, J., M. Humphreys, and J. Weinstein (2009). Can Development Aid Contribute to Social Cohesion after Civil War? Evidence from a Field Experiment in Post-Conflict Liberia. American Economic Review, 99(2): 87-91.

Ghobhara, H.A., P. Huth, and B. Russet (2003). Civil Wars Kill and Maim People - Long After the Shooting Stops. American Political Science Review, 97(2): 189-202.

Maertens, R. (2016). Adverse Rainfall Shocks and Civil War: Myth or Reality? Households in Conflict Network (HiCN) Working Paper 212.

McGuirk, E. and M. Burke (2017). The Economic Origins of Conflict in Africa. NBER Working Paper 23056.

Miguel, E., S. Satyanath, and E. Sergenti (2004). Economic Shocks and Civil Conflict: An Instrumental Variables Approach. Journal of Political Economy, 112(41): 725-753.

Müller, H. (2016). Growth and Violence: Argument for a Per Capita Measure of Civil War. Economica, 83(331): 473-497.

Nunn, N. and N. Qian (2014). US Food Aid and Civil Conflict. American Economic Review, 104(6): 1630-1666.

Sandholt Jensen, P. and K. Skrede Gleditsch (2009). Rain, Growth, and Civil War: The Importance of Location. Defence and Peace Economics, 20(5): 359-72.

Sarkees, M.R. (2010). The COW Typology of War: Defining and Categorizing Wars (Version 4 of the Data). 
Commodity weights (time-invariant)

Price maker cutoff (\%)

Commodity price shock $\mathrm{t}(\%)$

Commodity price shock $\mathrm{t}-1(\%)$

Commodity price shock $\mathrm{t}-2(\%)$

Commodity weights (time-invariant)

Price maker cutoff (\%)

Commodity price shock $\mathrm{t}(\%)$

Commodity price shock $\mathrm{t}-1$ (\%)

Commodity price shock $\mathrm{t}-2(\%)$
PANEL A. Point estimates of the effect of annual commodity price shocks on civil war risk

\begin{tabular}{|c|c|c|c|c|c|c|c|c|}
\hline & & & & 200 & eriod & & & \\
\hline & $\begin{array}{l}\text { age } 1 \\
2007\end{array}$ & & & 1990 & & & 1980 & \\
\hline no & 10 & 3 & no & 10 & 3 & no & 10 & 3 \\
\hline-10 & -10 & -10 & -10 & -10 & -10 & -8 & -8 & -6 \\
\hline-4 & -4 & -3 & -4 & -4 & -3 & -3 & -4 & -3 \\
\hline-9 & -9 & -9 & -8 & -8 & -8 & -7 & -7 & -7 \\
\hline
\end{tabular}

\begin{tabular}{|c|c|c|c|c|c|c|c|c|}
\hline \multicolumn{9}{|c|}{ 1982-2007 period } \\
\hline \multicolumn{3}{|c|}{$\begin{array}{c}\text { average 1980- } \\
2007\end{array}$} & \multicolumn{3}{|c|}{1990} & \multicolumn{3}{|c|}{1980} \\
\hline no & 10 & 3 & no & 10 & 3 & no & 10 & 3 \\
\hline-10 & -10 & -10 & -10 & -10 & -10 & -8 & -8 & -7 \\
\hline-4 & -4 & -3 & -4 & -4 & -3 & -3 & -3 & -3 \\
\hline-9 & -9 & -9 & -8 & -8 & -8 & -7 & -7 & -6 \\
\hline
\end{tabular}

PANEL B. P-values of the effect of annual commodity price shocks on civil war risk

\begin{tabular}{|c|c|c|c|c|c|c|c|c|}
\hline \multicolumn{9}{|c|}{ 1980-2007 period } \\
\hline \multicolumn{3}{|c|}{$\begin{array}{c}\text { average 1980- } \\
2007\end{array}$} & \multicolumn{3}{|c|}{1990} & \multicolumn{3}{|c|}{1980} \\
\hline no & 10 & 3 & no & 10 & 3 & no & 10 & 3 \\
\hline 8 & 8 & 8 & 4 & 4 & 4 & 6 & 6 & 16 \\
\hline 33 & 32 & 53 & 30 & 30 & 40 & 30 & 27 & 41 \\
\hline 6 & 6 & 9 & 5 & 6 & 7 & 7 & 8 & 11 \\
\hline
\end{tabular}

\begin{tabular}{|c|c|c|c|c|c|c|c|c|}
\hline \multicolumn{9}{|c|}{ 1982-2007 period } \\
\hline \multicolumn{3}{|c|}{$\begin{array}{c}\text { average 1980- } \\
2007\end{array}$} & \multicolumn{3}{|c|}{1990} & \multicolumn{3}{|c|}{1980} \\
\hline no & 10 & 3 & no & 10 & 3 & no & 10 & 3 \\
\hline 8 & 9 & 9 & 4 & 4 & 4 & 7 & 7 & 15 \\
\hline 36 & 37 & 56 & 33 & 34 & 46 & 37 & 37 & 47 \\
\hline 7 & 8 & 10 & 7 & 7 & 9 & 11 & 12 & 16 \\
\hline
\end{tabular}

PANEL C. Cumulative effects of annual commodity price shocks and p-values of hypothesis that the cumulative effect is equal to zero

\begin{tabular}{|c|c|c|c|c|c|c|c|c|c|c|c|c|c|c|c|c|c|c|}
\hline \multirow{3}{*}{$\begin{array}{l}\text { Commodity weights (time-invariant) } \\
\text { Price maker cutoff (\%) }\end{array}$} & \multicolumn{9}{|c|}{ 1980-2007 period } & \multicolumn{9}{|c|}{ 1982-2007 period } \\
\hline & \multicolumn{3}{|c|}{$\begin{array}{l}\text { average 1980- } \\
2007 \\
\end{array}$} & \multicolumn{3}{|c|}{1990} & \multicolumn{3}{|c|}{1980} & \multicolumn{3}{|c|}{$\begin{array}{l}\text { average 1980- } \\
2007 \\
\end{array}$} & \multicolumn{3}{|c|}{1990} & \multicolumn{3}{|c|}{1980} \\
\hline & no & 10 & 3 & no & 10 & 3 & no & 10 & 3 & no & 10 & 3 & no & 10 & 3 & no & 10 & 3 \\
\hline $\begin{array}{l}\text { Cumulative effect of annual commodity } \\
\text { price shocks (\%) }\end{array}$ & -23 & -23 & -22 & -22 & -22 & -21 & -18 & -19 & -16 & -23 & -23 & -22 & -22 & -22 & -21 & -18 & -18 & -16 \\
\hline $\begin{array}{l}\text { P-value of hypothesis that the cumulative } \\
\text { effect is equal to zero }\end{array}$ & 3 & 4 & 5 & 1 & 2 & 2 & 2 & 3 & 5 & 5 & 5 & 6 & 2 & 2 & 3 & 4 & 4 & 6 \\
\hline
\end{tabular}

Note: The table reports point estimates (PANEL A) and p-values (PANEL B) when estimating equation (9) in the main text. The table also reports the cumulative effect of the three annual commodity price shocks and the $p$-value of the hypothesis that the cumulative effect is equal to zero (PANEL C). The left-hand-side variable is an indicator variable for civil war outbreak. Shaded cells refer to effects that are statistically significant at the 10\% level at least. The calculation of the shocks is explained in Sections 3.1.1-3.1.2. The $10 \%$ (3\%) price maker cutoff basically implies that commodity exports of country-years are not used to obtain export weights if the country's share of world exports exceeds $10 \%$ (3\%) and is explained in detail in Section 3.1.3. No price maker cutoff refers to results where all commodity export data is used. All data is from Bazzi and Blattman (2014). 


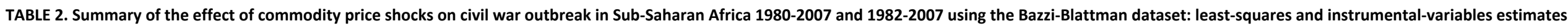

PANEL A. Point estimates of the effect of annual commodity price shocks on civil war risk: least-squares and instrumental-variables estimates compared

1980-2007 period

\begin{tabular}{|c|c|c|c|c|c|c|c|c|c|c|c|}
\hline \multicolumn{3}{|c|}{ LS (BB) } & \multicolumn{3}{|c|}{ IV } & \multicolumn{3}{|c|}{ IV } & \multicolumn{3}{|c|}{ IV } \\
\hline & & & \multicolumn{3}{|c|}{ average 1980-2007 } & \multicolumn{3}{|c|}{1990} & \multicolumn{3}{|c|}{1980} \\
\hline no & 10 & 3 & no & 10 & 3 & no & 10 & 3 & no & 10 & 3 \\
\hline-6.6 & -6.1 & -6.7 & -9.4 & -9.3 & -9.6 & -10.7 & -10.9 & -11.5 & -9.6 & -10.3 & -8.3 \\
\hline-2.3 & -2.1 & -1.2 & -3.8 & -3.8 & -2.6 & -4.4 & -4.7 & -4.0 & -4.2 & -4.7 & -3.0 \\
\hline-5.6 & -4.5 & -4.2 & -8.9 & -9.1 & -9.0 & -9.5 & -9.8 & -10.0 & -8.2 & -9.1 & -9.1 \\
\hline
\end{tabular}

1982-2007 period

\begin{tabular}{|c|c|c|c|c|c|c|c|c|c|c|c|}
\hline \multicolumn{3}{|c|}{ LS (BB) } & \multicolumn{3}{|c|}{ IV } & \multicolumn{3}{|c|}{ IV } & \multicolumn{3}{|c|}{ IV } \\
\hline & & & aver & se 19 & -2007 & & 1990 & & & 1980 & \\
\hline no & 10 & 3 & no & 10 & 3 & no & 10 & 3 & no & 10 & 3 \\
\hline-7.2 & -6.6 & -7.2 & -9.7 & -9.6 & -10.0 & -11.3 & -11.5 & -12.3 & -10.0 & -10.5 & -9.1 \\
\hline-2.7 & -2.2 & -1.8 & -4.0 & -4.0 & -2.8 & -4.4 & -4.6 & -3.8 & -3.8 & -4.3 & -2.8 \\
\hline-5.5 & -4.9 & -4.6 & -8.8 & -9.0 & -9.0 & -9.1 & -9.4 & -9.3 & -7.7 & -8.3 & -8.2 \\
\hline
\end{tabular}

PANEL B. P-values of the effect of annual commodity price shocks on civil war risk

Commodity price shock $\mathrm{t}(\%)$

Commodity price shock t-1 (\%)

Commodity price shock t-2 (\%)
1980-2007 period

\begin{tabular}{|c|c|c|c|c|c|c|c|c|c|c|c|}
\hline \multicolumn{12}{|c|}{ 1980-2007 period } \\
\hline & \multicolumn{2}{|c|}{ LS (BB) } & \multicolumn{3}{|c|}{ IV } & \multicolumn{3}{|c|}{ IV } & \multicolumn{3}{|c|}{ IV } \\
\hline & & & avera & 198 & 2007 & & 1990 & & & 1980 & \\
\hline no & 10 & 3 & no & 10 & 3 & no & 10 & 3 & no & 10 & 3 \\
\hline 14 & 15 & 9.3 & 5.8 & 6.0 & 5.7 & 5.8 & 2.9 & 2.5 & 4.3 & 4.8 & 14.4 \\
\hline 50 & 47 & 58 & 30 & 31 & 52 & 30 & 25 & 36 & 26 & 24 & 48 \\
\hline 21 & 21 & 22 & 4.3 & 4.6 & 6.3 & 4.3 & 3.4 & 4.1 & 5.2 & 5.5 & 8.6 \\
\hline
\end{tabular}

1982-2007 period

\begin{tabular}{|c|c|c|c|c|c|c|c|c|c|c|c|}
\hline \multicolumn{3}{|c|}{ LS (BB) } & \multicolumn{3}{|c|}{ IV } & \multicolumn{3}{|c|}{ IV } & \multicolumn{3}{|c|}{ IV } \\
\hline & & & aver & e 198 & 2007 & & 1990 & & & 1980 & \\
\hline no & 10 & 3 & no & 10 & 3 & no & 10 & 3 & no & 10 & 3 \\
\hline 13.8 & 14.4 & 8.6 & 6.3 & 6.5 & 6.3 & 6.3 & 3.1 & 2.7 & 5.1 & 5.7 & 13.2 \\
\hline 47 & 53 & 60 & 33 & 34 & 53 & 33 & 28 & 41 & 34 & 31 & 55 \\
\hline 24.7 & 27.9 & 26.8 & 5.2 & 5.5 & 7.1 & 5.2 & 4.7 & 6.2 & 8.6 & 9.2 & 13.5 \\
\hline
\end{tabular}

PANEL C. Cumulative effects of annual commodity price shocks and p-values of hypothesis that the cumulative effect is equal to zero

Time-invariant commodity weights used for fixed-weight price-shock instruments

Price maker cutoff (\%)

Commodity price shock t $(\%)$

Commodity price shock t-1 (\%)

Commodity price shock t-2 (\%)

PANEL C. Cumulative effects of annual com
1980-2007 period

\begin{tabular}{|c|c|c|c|c|c|c|c|c|c|c|c|}
\hline \multicolumn{12}{|c|}{ 1980-2007 period } \\
\hline \multicolumn{3}{|c|}{ LS (BB) } & \multicolumn{3}{|c|}{ IV } & \multicolumn{3}{|c|}{ IV } & \multicolumn{3}{|c|}{ IV } \\
\hline & & & avera & 198 & 007 & & 1990 & & & 1980 & \\
\hline no & 10 & 3 & no & 10 & 3 & no & 10 & 3 & no & 10 & 3 \\
\hline-14 & -13 & -12 & -22 & -22 & -21 & -25 & -25 & -26 & -22 & -24 & -20 \\
\hline 10.9 & 11.3 & 11.1 & 2.7 & 2.8 & 3.7 & 0.9 & 0.9 & 1.0 & 1.4 & 1.6 & 3.3 \\
\hline
\end{tabular}

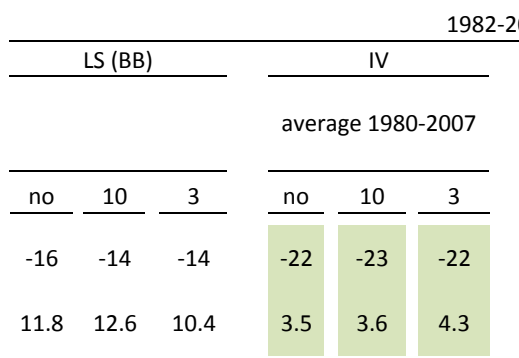

1982

82-2007 period

\begin{tabular}{|c|c|c|c|c|c|}
\hline \multicolumn{3}{|c|}{ IV } & \multicolumn{3}{|c|}{ IV } \\
\hline \multicolumn{3}{|c|}{1990} & \multicolumn{3}{|c|}{1980} \\
\hline no & 10 & 3 & no & 10 & 3 \\
\hline-25 & -25 & -25 & -22 & -23 & -20 \\
\hline 1.2 & 1.3 & 1.5 & 2.2 & 2.6 & 4.3 \\
\hline
\end{tabular}

effect is equal to zero

政

Note: The table reports point estimates (PANEL

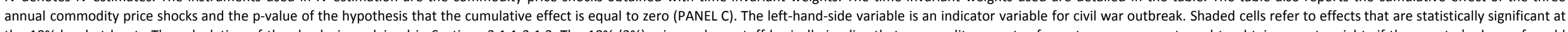

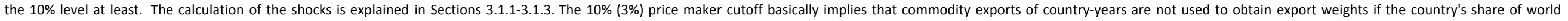
exports exceeds $10 \%(3 \%)$ and is explained in detail in Section 3.1.4. No price maker cutoff refers to results where all commodity export data is used. All data is from Bazzi and Blattman (2014). 
TABLE 3. Summary of the effect of 3-year commodity price shocks on civil war outbreak in Sub-Saharan Africa 1980-2007 using the Bazzi-Blattman dataset

PANEL A. Point estimates of effect of 3-year commodity price shocks on civil war risk

Commodity weights (time-invariant)

\begin{tabular}{|c|c|c|c|c|c|c|c|c|}
\hline & & & \multicolumn{3}{|c|}{ 1980-2007 period } & & & \\
\hline \multicolumn{3}{|c|}{$\begin{array}{c}\text { average 1980- } \\
2007 \\
\end{array}$} & \multicolumn{3}{|c|}{1990} & \multicolumn{3}{|c|}{1980} \\
\hline no & 10 & 3 & no & 10 & 3 & no & 10 & 3 \\
\hline-7 & -7 & -7 & -7 & -7 & -7 & -6 & -6 & -5 \\
\hline
\end{tabular}

\begin{tabular}{|c|c|c|c|c|c|c|c|c|}
\hline \multicolumn{9}{|c|}{ 1982-2007 period } \\
\hline \multicolumn{3}{|c|}{$\begin{array}{c}\text { average 1980- } \\
2007\end{array}$} & \multicolumn{3}{|c|}{1990} & \multicolumn{3}{|c|}{1980} \\
\hline no & 10 & 3 & no & 10 & 3 & no & 10 & 3 \\
\hline-8 & -8 & -7 & -8 & -7 & -7 & -6 & -6 & -5 \\
\hline
\end{tabular}

PANEL B. P-values of the effect of 3-year commodity price shocks on civil war risk

\begin{tabular}{|c|c|c|c|c|c|c|c|c|c|c|c|c|c|c|c|c|c|}
\hline \multicolumn{9}{|c|}{ 1980-2007 period } & \multicolumn{9}{|c|}{ 1982-2007 period } \\
\hline \multicolumn{3}{|c|}{$\begin{array}{c}\text { average 1980- } \\
2007 \\
\end{array}$} & \multicolumn{3}{|c|}{1990} & \multicolumn{3}{|c|}{1980} & \multicolumn{3}{|c|}{$\begin{array}{c}\text { average 1980- } \\
2007 \\
\end{array}$} & \multicolumn{3}{|c|}{1990} & \multicolumn{3}{|c|}{1980} \\
\hline no & 10 & 3 & no & 10 & 3 & no & 10 & 3 & no & 10 & 3 & no & 10 & 3 & no & 10 & 3 \\
\hline 4 & 4 & 5 & 2 & 2 & 2 & 2 & 3 & 5 & 5 & 5 & 7 & 2 & 2 & 3 & 4 & 4 & 6 \\
\hline
\end{tabular}

Note: The table reports point estimates (PANEL A) and p-values (PANEL B) when estimating equation (10) in the main text. The left-hand-side variable is an indicator variable for civil war outbreak. Shaded cells refer to effects that are statistically significant at the $10 \%$ level at least. The calculation of the shocks is explained in Sections $3.1 .1-3.1 .3$. The $10 \%(3 \%)$ price maker cutoff basically implies that commodity exports of country-years are not used to obtain export weights if the country's share of world exports exceeds $10 \%(3 \%)$ and is explained in detail in Section 3.1.3. No price maker cutoff refers to results where all commodity export data is used. All data is from Bazzi and Blattman (2014). 
TABLE 4. Summary of the effect of 3-year commodity price shocks on civil war outbreak in SubSaharan Africa for the 1957-2007 period using the Bazzi-Blattman dataset

PANEL A. Point estimates of the effect of 3-year commodity price shocks on civil war risk

Commodity weights (time-invariant)
Price maker cutoff (\%)
3-year commodity price shock t (\%)

\begin{tabular}{|c|c|c|}
\hline \multicolumn{3}{|c|}{$\begin{array}{c}\text { average 1957- } \\
2007\end{array}$} \\
\hline no & 10 & 3 \\
\hline-3 & -4 & -4 \\
\hline
\end{tabular}

\begin{tabular}{|c|c|c|}
\hline \multicolumn{3}{|c|}{1990} \\
\hline no & 10 & 3 \\
\hline-3 & -3 & -3 \\
\hline
\end{tabular}

$\overline{\overline{\frac{\text { no }}{\mathrm{A}}}} \frac{\overline{10}}{\frac{\overline{10}}{-3}} \frac{\overline{3}}{\frac{-2}{-2}}$

PANEL B. P-values of the effect of 3-year commodity price shocks on civil war risk

Commodity weights (time-invariant)

Price maker cutoff (\%)

3-year commodity price shock $\mathrm{t}(\%)$

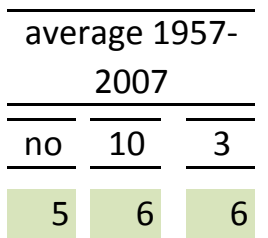

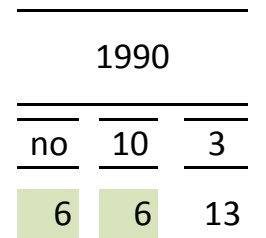

Note: The table reports point estimates (PANEL A) and p-values (PANEL B) when estimating equation (10) in the main text. The left-hand-side variable is an indicator variable for civil war outbreak. Shaded cells refer to effects that are significant at the $10 \%$ level at least. The calculation of the shocks is explained in Sections $3.1 .1-3.1 .3$. The $10 \%(3 \%)$ price maker cutoff basically implies that commodity exports of country-years are not used to obtain export weights if the country's share of world exports exceeds $10 \%$ (3\%) and is explained in detail in Section 3.1.3. No price maker cutoff refers to results where all commodity export data is used. All data is from Bazzi and Blattman (2014). 


\section{TABLE 5. Summary of the effect of annual commodity price shocks on civil war outbreak beyond Sub- Saharan Africa for the 1980-2007 period using the Bazzi-Blattman dataset}

PANEL A. Point estimates of the effect of annual commodity price shocks on civil war risk

Commodity weights (time-invariant)

Price maker cutoff (\%)

Commodity price shock $\mathrm{t}(\%)$

Commodity price shock t-1 (\%)

Commodity price shock t-2 (\%)

\begin{tabular}{|c|c|c|}
\hline \multicolumn{3}{|c|}{$\begin{array}{c}\text { average 1980- } \\
2007 \\
\end{array}$} \\
\hline no & 10 & 3 \\
\hline-6 & -6 & -7 \\
\hline-1 & -1 & -1 \\
\hline-4 & -4 & -4 \\
\hline
\end{tabular}

\begin{tabular}{rrrr}
\hline \multicolumn{3}{c}{1980} & \\
\cline { 1 - 1 }$\overline{\text { no }}$ & $\frac{10}{10}$ & $\frac{3}{3}$ \\
\cline { 1 - 1 }-5 & -4 & -5 \\
-2 & -1 & -2 \\
-4 & -4 & -3
\end{tabular}

PANEL B. P-values of the effect of annual commodity price shocks on civil war risk

Commodity weights (time-invariant)

Price maker cutoff (\%)

Commodity price shock $\mathrm{t}(\%)$

Commodity price shock t-1 (\%)

Commodity price shock t-2 (\%)

\begin{tabular}{|c|c|c|}
\hline \multicolumn{3}{|c|}{$\begin{array}{c}\text { average } 1980- \\
2007\end{array}$} \\
\hline no & 10 & 3 \\
\hline 2 & 3 & 2 \\
\hline 52 & 75 & 55 \\
\hline 12 & 18 & 20 \\
\hline
\end{tabular}

\begin{tabular}{|c|c|c|}
\hline \multicolumn{3}{|c|}{1990} \\
\hline no & 10 & 3 \\
\hline 2 & 2 & 1 \\
\hline 67 & 92 & 60 \\
\hline 11 & 15 & 25 \\
\hline
\end{tabular}

\begin{tabular}{|c|c|c|}
\hline \multicolumn{3}{|c|}{1980} \\
\hline no & 10 & 3 \\
\hline 1 & 3 & 2 \\
\hline 20 & 43 & 16 \\
\hline 3 & 6 & 11 \\
\hline
\end{tabular}

Note: The table reports point estimates (PANEL A) and p-values (PANEL B) when estimating equation (9) in the main text. The left-hand-side variable is an indicator variable for civil war outbreak. Shaded cells refer to effects that are significant at the $10 \%$ level at least. The calculation of the shocks is explained in Sections 3.1.1-3.1.3. The $10 \%$ (3\%) price maker cutoff basically implies that commodity exports of country-years are not used to obtain export weights if the country's share of world exports exceeds $10 \%$ (3\%) and is explained in detail in Section 3.1.3. No price maker cutoff refers to results where all commodity export data is used. All data is from Bazzi and Blattman (2014) and includes all larger countries in Africa, the Middle East, Latin America, and Asia. 
TABLE 6. Summary of the effect of 3-year commodity price shocks on civil war outbreak beyond SubSaharan Africa for the 1980-2007 period using the Bazzi-Blattman dataset

PANEL A. Point estimates of the effect of 3-year commodity price shocks on civil war risk

Commodity weights (time-invariant)

\begin{tabular}{|c|c|c|}
\hline \multicolumn{3}{|c|}{$\begin{array}{c}\text { average } 1980- \\
2007 \\
\end{array}$} \\
\hline 0 & 10 & 3 \\
\hline-4 & -3 & -4 \\
\hline
\end{tabular}

\begin{tabular}{|c|c|c|}
\hline \multicolumn{3}{|c|}{1990} \\
\hline no & 10 & 3 \\
\hline-3 & -3 & -3 \\
\hline
\end{tabular}

\begin{tabular}{|c|c|c|}
\hline & 1980 & \\
\hline no & 10 & 3 \\
\hline-4 & -3 & -4 \\
\hline
\end{tabular}

PANEL B. P-values of the effect of 3-year commodity price shocks on civil war risk

Commodity weights (time-invariant)

$\begin{aligned} & \text { average 1980- } \\ & \frac{2007}{\mathrm{no}} \frac{\frac{10}{5}}{\frac{10}{10}} \frac{-3}{6}\end{aligned}$
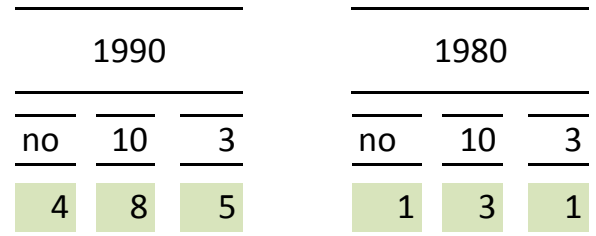

Note: The table reports point estimates (PANEL A) and p-values (PANEL B) when estimating equation (10) in the main text. The left-hand-side variable is an indicator variable for civil war outbreak. Shaded cells refer to effects that are significant at the $10 \%$ level at least. The left-hand-side variable is civil war onset. The calculation of the shocks is explained in Sections 3.1.1-3.1.3. The 10\% (3\%) price maker cutoff basically implies that commodity exports of country-years are not used to obtain export weights if the country's share of world exports exceeds $10 \%(3 \%)$ and is explained in detail in Section 3.1.3. No price maker cutoff refers to results where all commodity export data is used. All data is from Bazzi and Blattman (2014) and includes all larger countries in Africa, the Middle East, Latin America, and Asia. 
TABLE 7. Annual commodity price shocks and civil war outbreak in Sub-Saharan Africa: Bazzi-Blattman dataset with updated civil war data 1980-2009 period, $10 \%$ and $3 \%$ price maker cutoff

Price maker cutoff

Commodity price shock $\mathrm{t}$

Commodity price shock $\mathrm{t}-1$

Commodity price shock $\mathrm{t}-2$

OECD export growth $t$

Rainfall (GPCP) t

Rainfall (GPCP) squared $t$

Test equality of coefficients on three shocks ( $p$-value)

Test sum of the coefficients on three shocks equal zero ( $p$ value)

Year fixed effects

Country specific linear time trends

Observations

Countries

$\mathrm{R}$ squared
Country fixed effects

\begin{tabular}{lll}
\hline \multicolumn{3}{c}{$10 \%$} \\
\hline$(1)$ & $(2)$
\end{tabular}

$-0.068 *-0.067 *-0.072 * *$

$(-1.88) \quad(-1.87)$

$(-2.00)$

[0.066] [0.068]

[0.051]

$-0.062 *-0.063^{*} \quad-0.061^{*}$

$(-1.73)$

$(-1.72)$

$(-1.71)$

[0.093]

[0.093]

[0.09]

$\begin{array}{ll}-0.042 & -0.043\end{array}$

(-1.2)

$(-1.2)$

[0.24]

[0.24]

$-0.041$

$(-1.15)$

[0.26]

$\begin{array}{cc}-0.005 * * * & -0.006 * * * \\ (-3.17) & (-4.00) \\ {[0.003]} & {[0.00]}\end{array}$

[0.003]

[0.00]

$-0.386 * * *$

$(-2.71)$

[0.01]

$0.179 * * *$

(2.86)

[0.007]

0.78

0.79

0.72

0.024

0.035

0.035

0.030

Note: The commodity price and export data is from Bazzi and Blattman (2014). The civil war data is from the same source used by Bazzi and Blattman but updated using the latest version (UCPD 2016 version 4). The estimating equation is (9) in the main text. The left-hand-side variable is an indicator variable for civil war outbreak. The calculation of the shocks is explained in Sections 3.1.1-3.1.3. Time-invariant countrycommodity weights are set equal to country-commodity export shares averaged over the sample period. The 10\% (3\%) price maker cutoff basically implies that commodity exports of country-years are not used to obtain export weights if the country's share of world exports exceeds $10 \%(3 \%)$ and is explained in Section 3.1.3. Standard errors in parentheses and p-values of the hypothesis that the effect is zero in square brackets. ${ }^{*}$ denotes significance at the $10 \%$ level; ${ }^{* *}$ significance at the $5 \%$ level; and $* * *$ significance at the $1 \%$ level. 
TABLE 8. 3-year commodity price shocks and civil war outbreak in Sub-Saharan Africa: Bazzi-Blattman dataset with updated civil war data $1980-2009$ period, $10 \%$ and $3 \%$ price maker cutoff

Price maker cutoff

3-year commodity price shock t

OECD export growth $t$

Rainfall (GPCP) t

Rainfall (GPCP) squared $t$

$10 \%$

$(1)$

$-0.058 *$

$(-2.28)$

[0.028]

$-0.058 * *$

$(-2.27)$

[0.028]

$-0.005^{* * *}$

$(-3.21)$

[0.003]

(n)

Country fixed effects

Year fixed effects

Country specific linear time trends

Observations

Countries

$\mathrm{R}$ squared

$\begin{array}{cc}Y & Y \\ Y & Y \\ Y & Y \\ 1099 & 1099 \\ 45 & 45 \\ 0.097 & 0.098\end{array}$

(3)

\begin{tabular}{cc} 
& $3 \%$ \\
\hline$(4)$ & $(5)$ \\
$-0.058^{* *}$ & $-0.058^{* *}$ \\
$(-2.2)$ & $(-2.2)$ \\
{$[0.033]$} & {$[0.033]$} \\
& $-0.005^{* *}$ \\
& $(-3.3)$ \\
& {$[0.002]$}
\end{tabular}

$-0.385^{* *}$

$0.178 * * *$

[0.007]

$-0.387^{* *}$
$(-2.69)$
$[0.01]$
$0.178 * * *$
$(2.82)$
$[0.007]$

$Y$
$Y$
$Y$
1099
45
0.12

$Y$
$Y$
$Y$
1099
45
0.097

$Y$
$Y$
$Y$
1099
45
0.098

Y

Y

Y

1099

45

0.12

Note: The commodity price and export data is from Bazzi and Blattman (2014). The civil war data is from the same source used by Bazzi and Blattman but updated using the latest version (UCPD 2016 version 4). The estimating equation is (10) in the main text. The left-hand-side variable is an indicator variable for civil war outbreak. The calculation of the shocks is explained in Sections 3.1.1-3.1.3. Time-invariant countrycommodity weights are set equal to country-commodity export shares averaged over the sample period. The 10\% (3\%) price maker cutoff basically implies that commodity exports of country-years are not used to obtain export weights if the country's share of world exports exceeds $10 \%$ (3\%) and is explained in Section 3.1.3. Standard errors in parentheses and p-values of the hypothesis that the effect is zero in square brackets. ${ }^{*}$ denotes significance at the $10 \%$ level; ${ }^{* *}$ significance at the $5 \%$ level; and $* * *$ significance at the $1 \%$ level. 
TABLE 9. 3-year commodity price shocks and civil war outbreak in Sub-Saharan Africa: Bazzi-Blattman dataset with updated civil war data 1957-2009 period, 10\% and 3\% price maker cutoff

Price maker cutoff

3-year commodity price

shock t

OECD export growth $\mathrm{t}$

Rainfall (GPCC) $\mathrm{t}$

Rainfall (GPCC) squared t

Test equality of

coefficients on three

shocks ( $p$-value)

Test sum of the

coefficients on three

shocks equal zero ( $p$-value)

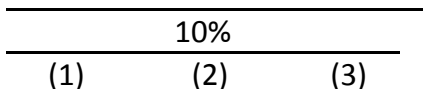

$\begin{array}{lll}(-2.32) & (-2.35) \quad(-2.43)\end{array}$

[0.025]

[0.023] [0.019]

$-0.003 * *-0.003 * *$

$(-2.44) \quad(-2.66)$

[0.019] [0.011]

$-0.124 *$

$(-1.74)$

[0.09]

$0.056 * *$

(2.22)

[0.031]

\begin{tabular}{ccc}
\multicolumn{3}{c}{$3 \%$} \\
\hline$(4)$ & $(5)$ & $(6)$ \\
$-0.037^{* *}$ & $-0.037^{* *}$ & $-0.039 * * *$ \\
$(-2.59)$ & $(-2.62)$ & $(-2.65)$ \\
{$[0.013]$} & {$[0.012]$} & {$[0.011]$} \\
& $-0.003^{* *}$ & $-0.003^{* *}$ \\
& $(-2.46)$ & $(-2.68)$ \\
& {$[0.018]$} & {$[0.01]$} \\
& & $-0.125^{*}$ \\
& & $(-1.75)$ \\
& & {$[0.087]$} \\
& & $0.057^{* *}$ \\
& & $(2.22)$ \\
& & {$[0.032]$}
\end{tabular}

0.54

0.52

0.59

0.56

0.54

0.62

0.021

0.018

0.01

0.011

0.011

Country fixed effects

Year fixed effects

Country specific linear

time trends

Observations

Countries

$\mathrm{R}$ squared

$\begin{array}{ccc}Y & Y & Y \\ Y & Y & Y \\ Y & Y & Y \\ 1897 & 1897 & 1897 \\ 45 & 45 & 45 \\ 0.099 & 0.099 & 0.105\end{array}$

Y

Y

Y

1897

45

0.099

$\begin{array}{cc}Y & Y \\ Y & Y \\ Y & Y \\ 1897 & 1897 \\ 45 & 45 \\ 0.1 & 0.106\end{array}$

Note: The commodity price and export data is from Bazzi and Blattman (2014). The civil war data is from the same source used by Bazzi and Blattman but updated using the latest version (UCPD 2016 version 4). The estimating equation is (10) in the main text. The lefthand-side variable is an indicator variable for civil war outbreak. The calculation of the shocks is explained in Sections 3.1.1-3.1.3. Time-invariant country-commodity weights are set equal to country-commodity export shares averaged over the sample period. The $10 \%$ (3\%) price maker cutoff basically implies that commodity exports of country-years are not used to obtain export weights if the country's share of world exports exceeds $10 \%$ (3\%) and is explained in Section 3.1.3. Standard errors in parentheses and p-values of the hypothesis that the effect is zero in square brackets. ${ }^{*}$ denotes significance at the $10 \%$ level; ** significance at the $5 \%$ level; and ${ }^{* * *}$ significance at the $1 \%$ level. 
TABLE 10. Annual commodity price shocks and civil war outbreak beyond SubSaharan Africa: Bazzi-Blattman dataset with updated civil war data 1980-2009 period, $10 \%$ and $3 \%$ price maker cutoff

Price maker cutoff

Commodity price shock

Commodity price shock t-1

Commodity price shock t-2

OECD export growth $t$

\begin{tabular}{c}
\hline \multicolumn{2}{c}{$10 \%$} \\
\hline$(1) \quad(2)$
\end{tabular}

$-0.034 * \quad-0.034 *$

$(-1.92) \quad(-1.91)$

[0.058] [0.059]

$-0.024 \quad-0.024$

$(-1.24) \quad(-1.23)$

[0.216]

$-0.019$

[0.298]

Test equality of coefficients on three shocks ( $p$-value)

Test sum of the coefficients on three shocks equal zero ( $p$ value)

\section{Country fixed effects}

Year fixed effects

Country specific linear time trends

Observations

Countries

R squared

$Y$
$Y$
$Y$
2901
118
0.119

[0.22]

$-0.019$

$(-1.05) \quad(-1.04)$

[0.299]

$-0.004^{* *}$

(-2.19)

[0.030]

0.63

0.057

0.040

0.43

$-0.043^{* *}$
$(-2.24)$

$-0.023$

$-0.026$

$(-1.30)$

[0.195]

(-1.30)

[0.197]

$.0 .004 * *$

(-2.21)

[0.029]

0.62

0.056

0.057

$Y$
$Y$
$Y$
2901

$\begin{array}{cc}2901 & 2901 \\ 118 & 118 \\ 0.119 & 0.119\end{array}$

$\begin{array}{cc}Y & Y \\ Y & Y \\ Y & Y \\ 2901 & 2901 \\ 118 & 118 \\ 0.119 & 0.120\end{array}$

Note: The analysis includes all larger countries in Africa, the Middle East, Latin America, and Asia. The commodity price and export data is from Bazzi and Blattman (2014). The civil war data is from the same source used by Bazzi and Blattman but updated using the latest version (UCPD 2016 version 4). The estimating equation is (9) in the main text. The left-hand-side variable is an indicator variable for civil war outbreak. The calculation of the shocks is explained in Sections 3.1.1-3.1.3. Time-invariant country-commodity weights are set equal to country-commodity export shares averaged over the sample period. The $10 \%$ (3\%) price maker cutoff basically implies that commodity exports of country-years are not used to obtain export weights if the country's share of world exports exceeds $10 \%(3 \%)$ and is explained in Section 3.1.3. Standard errors in parentheses and $p$-values of the hypothesis that the effect is zero in square brackets. * denotes significance at the $10 \%$ level; ${ }^{* *}$ significance at the $5 \%$ level; and $* * *$ significance at the $1 \%$ level. 
TABLE 11. 3-year commodity price shocks and civil war outbreak beyond SubSaharan Africa: Bazzi-Blattman dataset with updated civil war data, 1980-2009 period, $10 \%$ and $3 \%$ price maker cutoff

Price maker cutoff

3-year commodity price shock $\mathrm{t}$

OECD export growth $t$

\begin{tabular}{ccccc}
\hline \multicolumn{2}{c}{$10 \%$} & & \multicolumn{2}{c}{$3 \%$} \\
\cline { 5 - 5 }$(1)$ & $(2)$ & & $(3)$ & $(4)$ \\
& & & \\
$-0.026^{*}$ & $-0.026^{*}$ & & $-0.031^{* *}$ & $-0.031^{* *}$ \\
$(-1.95)$ & $(-1.93)$ & & $(-2.09)$ & $(-2.08)$ \\
{$[0.055]$} & {$[0.056]$} & & {$[0.039]$} & {$[0.04]$} \\
& & & $-0.004 * *$ \\
& $-0.004^{* *}$ & & $(-2.23)$ \\
& $(-2.21)$ & & $0.028]$
\end{tabular}

Country fixed effects

Year fixed effects

Country specific linear time trends

Observations

Countries

R squared

$Y$
$Y$
$Y$

$2901 \quad 2901$

$118 \quad 118$

$Y$
$Y$
$Y$
2901
118
0.119

Y

Y

Y

$2901 \quad 2901$
0.119

$118 \quad 118$

$0.119 \quad 0.119$

Note: The analysis includes all larger countries in Africa, the Middle East, Latin America, and Asia. The commodity price and export data is from Bazzi and Blattman (2014). The civil war data is from the same source used by Bazzi and Blattman but updated using the latest version (UCPD 2016 version 4). The estimating equation is (10) in the main text. The lefthand-side variable is an indicator variable for civil war outbreak. The calculation of the shocks is explained in Sections 3.1.1-3.1.3. Timeinvariant country-commodity weights are set equal to countrycommodity export shares averaged over the sample period. The $10 \%$ (3\%) price maker cutoff basically implies that commodity exports of countryyears are not used to obtain export weights if the country's share of world exports exceeds $10 \%(3 \%)$ and is explained in Section 3.1.3. Standard errors in parentheses and p-values of the hypothesis that the effect is zero in square brackets. * denotes significance at the $10 \%$ level; ${ }^{* *}$ significance at the $5 \%$ level; and $* * *$ significance at the $1 \%$ level. 


\title{
Appendix A. Dealing with Mismeasured Export Shares
}

\author{
for
}

\section{International Commodity Prices and Civil War Outbreak: New Evidence for Sub- Saharan Africa and Beyond}

\author{
Antonio Ciccone
}

January 2018 


\section{Appendix A. Dealing with Mismeasured Export Shares}

Suppose the risk of civil war is determined by

$$
y_{c, t}=\alpha_{c}+\alpha_{t}+\beta\left(\sum_{i} s_{i, c, t-1}^{*} \pi_{i, t}\right)+u_{c, t}
$$

where $y_{c, t}$ is the risk of civil war in country $c$ in years $t=1, \ldots, T ; s_{i, c, t-1}^{*}$ is the share of commodity $i$ in total commodity exports of country $c$ in year $t-1$; and $\pi_{i, t}=\log p_{i, t}-\log p_{i, t-1}$ the log-change in the international price of commodity $i$. The summation is across all possible commodities $i$. The true commodity export shares entering the commodity price shock on the right-hand side of (A1) are taken to be the export shares in $t-1$ (which results in the commodity price shock being equal to the log growth rate of a Laspeyres price index). But the results below would remain unchanged if the relevant export shares were the shares in $t$ or the average of the export shares in $t-1$ and $t$ (which would result in the commodity price shock being equal to, respectively, the log growth rates of a Paasche or Fisher price index). The $\alpha$-terms capture the country-specific and time-specific risk of civil war, and $u_{c, t}$ captures other factors affecting the risk of civil war. I take $u_{c, t}$ to be independent of the international commodity price shocks $\pi_{i, t}$ and of the average true export shares over the sample period. International commodity price shocks are assumed to be exogenous and bounded, $\left|\pi_{i, t} \pi_{j, t}\right| \leq \mu$ for some $0<\mu<\infty$. The parameter of interest in (A1) is $\beta$, the causal effect of the true commodity price shock $\sum_{i} s_{i, c, t-1}^{*} \pi_{i, t}$ on the risk of civil war.

The model for the risk of civil war in (A1) assumes that the risk of civil war only depends on the contemporaneous commodity price shock. It is therefore simpler than the model in (11) in the main text, which also includes lagged and twice-lagged commodity price shocks. As the main issues do not depend on whether or not the risk of civil war also depends on lagged commodity price shocks, it is convenient to proceed with (A1) above as it avoids having to use matrix notation in the proofs below. Another simplifying assumption I make compared to the main text, is that I take the risk of civil war on the left-hand side of (A1) to be observable. In practice it isn't and researchers instead use indicator variables that capture whether a civil war has broken out or not (as I do in the main text). I simplify here as the issues around this 
approach are well understood and unrelated to what I want to discuss here.

Suppose the researcher does not observe the true commodity export shares $s_{i, c, t}^{*}$ but export shares measured with some error

$$
s_{i, c, t}^{m}=s_{i, c, t}^{*}+\varepsilon_{i, c, t}
$$

where $\varepsilon_{i, c, t}$ is a measurement error that is independent of all the elements of the true model in (A1), has bounded moments of all orders across commodities and over time, and satisfies $E\left(\varepsilon_{i, c, t} \mid i, c\right)=0$ and $E\left(\varepsilon_{i, c, t} \mid i, t\right)=0$. The measurement error is also assumed to be independent across countries, but $\varepsilon_{i, c, t}$ may be serially correlated and correlated across different commodities $i, j$ for a given country $c$.

As is well understood, estimating the model in (A1) using the mismeasured export shares in (A2) instead of the true export shares gives rise to measurement error bias. The issue I want to examine here is whether mismeasured export shares can still be used to obtain a consistent estimator of the causal effect of commodity price shocks on civil war risk, $\beta$ in (A1). Intuitively, this might be possible as long as the mismeasured export shares averaged over time

$$
\bar{s}_{i, c}^{m}=\frac{1}{T} \sum_{t=0}^{T} s_{i, c, t}^{m}
$$

converge in probability to the average over time of the true export shares $\bar{s}_{i, c}^{*}=\frac{1}{T} \sum s_{i, c, t}^{*}$. The remainder of this appendix shows that consistent estimation of $\beta$ in (A1) is in fact possible as long as the serial correlation in the measurement error is, loosely formulated, limited.

There are several ways to make statements about limited serial correlation precise. The specific condition I will use is so-called K-dependence (Amemiya, 1985, p.175).

Definition 1 (K-dependence of a single stochastic process) A stochastic process $\omega_{t}$ is K-dependent if $\left(\omega_{t_{1}}, \omega_{t_{2}}, \ldots, \omega_{t_{n}}\right)$ is independent of $\left(\omega_{\tau_{1}}, \omega_{\tau_{2}}, \ldots, \omega_{\tau_{m}}\right)$ for any set of integers satisfying $t_{1}<t_{2} \ldots<t_{n}<\tau_{1}<\tau_{2} \ldots<\tau_{m}$ and $t_{n}+K<\tau_{1}$.

Intuitively, K-dependence allows for correlation within time windows of width $K$ but not outside time windows of width $K$, that is $\operatorname{Cov}\left(\omega_{\tau}, \omega_{t}\right) \neq 0$ if $|t-\tau| \leq K$ but $\operatorname{Cov}\left(\omega_{\tau}, \omega_{t}\right)=0$ if $|t-\tau|>K$. For example, a moving-average process of order smaller or equal $K$ based in i.i.d. shocks is K-dependent. An advantage of the K-dependence condition is that it does 
not impose restrictions on the functional form of serial correlation. Such conditions would be unlikely to capture the measurement error in the Bazzi and Blattman dataset as missing data is interpolated.

The next definition is a generalization of K-dependence to the case of multiple stochastic processes. This definition will be useful as the mismeasured commodity price shocks for a country will generally involve the commodity export shares, and hence measurement errors, of more than one commodity.

Definition 2 (K-dependence with multiple stochastic processes) The D stochastic processes $\omega_{t}^{1}, \omega_{t}^{2}, \ldots, \omega_{t}^{D}$ are $K$-dependent if $\left(\omega_{t_{1}}^{i}, \omega_{t_{2}}^{i}, \ldots, \omega_{t_{n}}^{i}\right)$ is independent of $\left(\omega_{\tau_{1}}^{j}, \omega_{\tau_{2}}^{j}, \ldots, \omega_{\tau_{m}}^{j}\right)$ for any two stochastic processes $i, j$ and any set of integers satisfying $t_{1}<t_{2} \ldots<t_{n}<\tau_{1}<$ $\tau_{2} \ldots<\tau_{m}$ and $t_{n}+K<\tau_{1}$.

Intuitively, for any two of the $D$ stochastic processes, this generalization of K-dependence allows for correlation within time windows of width $K$ but not outside time windows of width $K$. That is, $\operatorname{Cov}\left(\omega_{\tau}^{i}, \omega_{t}^{j}\right) \neq 0$ if $|t-\tau| \leq K$ but $\operatorname{Cov}\left(\omega_{\tau}^{i}, \omega_{t}^{j}\right)=0$ if $|t-\tau|>K$ for any $i, j$. For example, the moving-average processes $\omega_{t}^{i}=\left(\varepsilon_{t}^{i}+\eta_{t}\right)+\theta_{1}\left(\varepsilon_{t-1}^{i}+\eta_{t-1}\right)+. .+\theta_{K}\left(\varepsilon_{t-K}^{i}+\eta_{t-K}\right)$ and with all the $\varepsilon$ and $\eta$ i.i.d. would satisfy K-dependence as defined above.

The next proposition presents an instrumental-variables estimator that relies on mismeasured export shares only but still converges to the parameter $\beta$ in (A1) if the measurement errors for any country are K-dependent.

Proposition 1 Suppose that measurement errors $\varepsilon_{i, c, t}$ are $K$-dependent for any country c. Consider the following model obtained by replacing the true time-varying export shares on the righthand side of (A1) by the mismeasured time-varying export shares

$$
y_{c, t}=a_{c}+a_{t}+b\left(\sum_{i} s_{i, c, t-1}^{m} \pi_{i, t}\right)+v_{c, t} .
$$

Estimating this model with an instrumental-variables approach using as an instrument the fixedweight price shock $\sum_{i} \bar{s}_{i, c}^{m} \pi_{i, t}$, with the time-averaged mismeasured export shares $\bar{s}_{i, c}^{m}$ defined in (A3), yields a consistent estimate of $\beta$ in (11) as $T$ goes to infinity. 
The proposition is proven further below. To get an intuitive idea of what is driving this result, note that the mismeasured commodity price shock employed as instrument uses the average mismeasured export shares over the sample period as commodity weights. The measurement error in these time-averaged mismeasured export shares goes to zero as the sample period goes to infinity. As a result, the measurement error in the fixed-weight price-shock instrument ends up being uncorrelated with the measurement error in the mismeasured commodity price shock on the right-hand-side of (A4) as the sample period goes to infinity.

It is also interesting to examine the reduced-form approach corresponding to the instrumentalvariables approach in Proposition 1. The next proposition summarizes the key result.

Proposition 2 Suppose that measurement errors $\varepsilon_{i, c, t}$ are $K$-dependent for any country c. Consider the following model obtained by replacing the true time-varying export shares on the righthand side of (A1) by the mismeasured time-averaged export shares $\bar{s}_{i, c}^{m}$ defined in (A3)

$$
y_{c, t}=a_{c}+a_{t}+b^{r}\left(\sum_{i} \bar{s}_{i, c}^{m} \pi_{i, t}\right)+v_{c, t} .
$$

The least-squares slope estimate of this model satisfies

$$
\operatorname{plim}_{T \rightarrow \infty} \widehat{b^{r}}=\beta(1+\gamma)
$$

where $\beta$ is defined in (11) and $\gamma$ is

$$
\gamma=\operatorname{plim}_{T \rightarrow \infty} \frac{\frac{1}{T} \frac{1}{N} \sum_{t} \sum_{c} z_{c, t}\left(x_{c, t}^{m}-\bar{x}_{c}^{m}-\bar{x}_{t}^{m}+\bar{x}^{m}\right)}{\frac{1}{T} \frac{1}{N} \sum_{t} \sum_{c}\left(x_{c, t}^{m}-\bar{x}_{c}^{m}-\bar{x}_{t}^{m}+\bar{x}^{m}\right)^{2}}
$$

with $x_{c, t}^{m}=\sum_{i} \bar{s}_{i, c}^{m} \pi_{i, t}$ and $z_{c, t}=\sum_{i}\left(s_{i, c, t-1}^{m}-\bar{s}_{i, c}^{m}\right) \pi_{i, t}$. The variables with upper bars in (A 7$)$ denote averages. The upper bar with subscript $c$ denotes the average over time for country c; the upper bar with subscript $t$ denotes the average across countries for year $t$; and the upper bar without any subscript is the average both over time and across countries.

This proposition is also proven further below. The intuition is that there are two issues with the reduced-form model in (A5) compared to the true model in (A1). First, there is measurement error in the right-hand-side variable $x_{c, t}^{m}=\sum_{i} \bar{s}_{i, c}^{m} \pi_{i, t}$ as the export shares used as 
commodity weights are mismeasured. Second, while the model in (A1) implies that the true risk of civil war also reflects the time variation in the export shares, the reduced-form model in (A5) only captures the effect of average export shares over the sample period. This generally leads to an omitted-variable bias when estimating (A5). When measurement errors in mismeasured export shares are K-dependent, the measurement error issue is resolved as the sample period goes to infinity (because the measurement error in the time-averaged mismeasured export shares used as commodity weights in the right-hand-side variable $x_{c, t}^{m}=\sum_{i} \bar{s}_{i, c}^{m} \pi_{i, t}$ in (A5) goes to zero as the sample period goes to infinity). But the omitted-variable issue remains. This is why the probability limit of the least-squares slope in (A6) is equal to $\beta(1+\gamma)$ with $\gamma$ capturing the omitted-variable bias in percent of $\beta$ when estimating the reduced-form model in (A5).

Proposition 2 also characterizes $\gamma$ in terms of mismeasured observables. The expression on the right-hand side of (A7) is the probability limit of the least-squares slope when regressing $z_{c, t}=\sum_{i}\left(s_{i, c, t-1}^{m}-\bar{s}_{i, c}^{m}\right) \pi_{i, t}$ on $x_{c, t}^{m}=\sum_{i} \bar{s}_{i, c}^{m} \pi_{i, t}$ and country plus year fixed effects. Hence, $\gamma$ can be estimated consistently as the least-squares slope $\widehat{\gamma}$ when regressing $z_{c, t}$ on $x_{c, t}^{m}$ and country plus year fixed effects. Intuitively, $z_{c, t}=\sum_{i}\left(s_{i, c, t-1}^{m}-\bar{s}_{i, c}^{m}\right) \pi_{i, t}$ is the mismeasured version of the omitted variable, that is, the mismeasured difference between the commodity price shock using time-varying export shares and the commodity price shock using time-averaged export shares. When measurement errors in mismeasured export shares are K-dependent, this mismeasured version of the omitted variable can be used to obtain a consistent estimate of $\gamma$ and hence the omitted-variable bias.

An interesting special case of Proposition 2 is when $\gamma=0$. In this case, the reduced-form estimate obtained by applying least squares to (A5) converges to $\beta$ in probability. The reason is that there is no omitted-variable bias asymptotically in this case, because the omitted variable is uncorrelated with the fixed-weight commodity price shock using time-averaged export shares as the sample period goes to infinity. The condition $\gamma=0$ can be checked by testing the hypothesis $\widehat{\gamma}=0$.

When the risk of civil war in (A1) depends on lagged and twice-lagged commodity price shocks also, as assumed in the main text in equation (11), (A6) has to be replaced by equation (15) in the main text. The intuition and proof remain unchanged however. 
Proof of Proposition 1 To prove Proposition 1 it is useful to write the true model in (A1) in terms of the mismeasured commodity price shock, which using (A2) implies that the measurement error becomes part of the residual

$$
y_{c, t}=\alpha_{c}+\alpha_{t}+\beta\left(\sum_{i} s_{i, c, t-1}^{m} \pi_{i, t}\right)-\beta\left(\sum_{i} \varepsilon_{i, c, t-1} \pi_{i, t}\right)+u_{c, t} .
$$

The standard measurement error bias arises when (A8) is estimated using least squares because the measurement error enters both the mismeasured commodity price shock $\sum_{i} s_{i, c, t-1}^{m} \pi_{i, t}$ and the residual.

When the mismeasured commodity price shock in (A8) is instrumented with $\sum_{i} \bar{s}_{i, c}^{m} \pi_{i, t}$, the resulting instrumental-variables estimator will be consistent as $T$ goes to infinity, $\operatorname{plim}_{T \rightarrow \infty} \widehat{b}_{I V}=$ $\beta$, if and only if the residual $-\beta\left(\sum_{i} \varepsilon_{i, c, t-1} \pi_{i, t}\right)+u_{c, t}$ is uncorrelated with the instrument $\sum_{i} \bar{s}_{i, c}^{m} \pi_{i, t}$ as $T$ goes to infinity. As $u_{c, t}$ is taken to be independent of the instrument, this condition is equivalent to $\sum_{i} \varepsilon_{i, c, t-1} \pi_{i, t}$ being uncorrelated with the instrument $\sum_{i} \bar{s}_{i, c}^{m} \pi_{i, t}$ as $T$ goes to infinity. Formally

$$
\operatorname{plim}_{T \rightarrow \infty} \frac{1}{T} \frac{1}{N} \sum_{c} \sum_{t}\left(\sum_{i} \varepsilon_{i, c, t-1} \pi_{i, t}\right)\left(\sum_{i} \bar{s}_{i, c}^{m} \pi_{i, t}\right)=0 .
$$

Writing the time-averaged mismeasured export share in (A9) as the true time-averaged export share plus the time-averaged measurement error yields

$$
A=\frac{1}{T} \frac{1}{N} \sum_{c} \sum_{t}\left(\sum_{i} \varepsilon_{i, c, t-1} \pi_{i, t}\right)\left(\sum_{i} \bar{s}_{i, c}^{*} \pi_{i, t}+\bar{\varepsilon}_{i, c} \pi_{i, t}\right) .
$$

The term $A$ in (A10) can be written as the sum of the two following terms

$$
B=\sum_{i, j}\left(\frac{1}{N T} \sum_{c} \sum_{t} \bar{s}_{j, c}^{*} \varepsilon_{i, c, t-1} \pi_{i, t} \pi_{j, t}\right)=\sum_{i, j} B_{i, j}
$$

and

$$
C=\sum_{i, j}\left(\frac{1}{N T} \sum_{c} \sum_{t} \varepsilon_{i, c, t-1} \bar{\varepsilon}_{j, c} \pi_{i, t} \pi_{j, t}\right)=\sum_{i, j} C_{i, j} .
$$


Both terms go to zero in probability as $T$ goes to infinity if the measurement errors $\varepsilon_{i, c, t}$ are K-dependent for any country $c$ and independent across countries.

To see this, start with $B$. It follows from (A11) that this term goes to zero in probability as $T$ goes to infinity if $B_{i, j}$ goes to zero for all $i, j$. The zero-expectation properties of the measurement error implies that

$$
E B_{i, j}=0
$$

Moreover, the assumption that $\varepsilon_{i, c, t}$ is $\mathrm{K}$-dependent implies that there is a positive, finite $\phi_{1}$ such that

$$
E B_{i, j}^{2} \leq \frac{1}{N T}(2 K+1) \mu \phi_{1}
$$

where $\mu$ is the bound on $\left|\pi_{i, t} \pi_{j, t}\right|$ and I have used that export shares are bounded above by one. For example, in the case where the measurement error is i.i.d., $\phi_{1}$ could be set equal to the variance of the measurement error. As $E B_{i, j}=0$ and $E B_{i, j}^{2}$ goes to zero as $T$ goes to infinity, the probability limit of $B_{i, j}$ goes to zero as $T$ goes to infinity. This implies that the probability limit of $B$ in (A11) goes to zero as $T$ goes to infinity.

The $C$ term in (A12) goes to zero in probability as $T$ goes to infinity if $C_{i, j}$ goes to zero for all $i, j$. To examine the $C_{i, j}$ terms it is useful to rewrite them as

$$
C_{i, j}=\frac{1}{N T^{2}} \sum_{c} \sum_{t, \tau} \varepsilon_{i, c, t-1} \varepsilon_{j, c, \tau} \pi_{i, t} \pi_{j, t}
$$

where $\sum_{t, \tau} \equiv \sum_{t} \sum_{\tau}$. The K-dependence assumption implies that there are finite $\phi_{2}$, $\phi_{3}$ with $\phi_{2} \leq 0<\phi_{3}$ such that

$$
\frac{1}{T}(2 K+1) \mu \phi_{2} \leq E C_{i, j} \leq \frac{1}{T}(2 K+1) \mu \phi_{3}
$$

For example, in the case where the measurement error is i.i.d., $\phi_{2}$ could be set equal zero and $\phi_{3}$ equal to the variance of the measurement error. More generally, $\phi_{2}$ could be picked to be the minimum of zero and the smallest possible value of the $E\left(\varepsilon_{i, c, t-1} \varepsilon_{j, c, \tau}\right)$ across all commodities and years, and $\phi_{3}$ could be picked to be the largest possible value of $E\left(\varepsilon_{i, c, t-1} \varepsilon_{j, c, \tau}\right)$. An immediate implication of (A16) is that the expectation of $C_{i, j}$ in (A15) goes to zero as $T$ goes to infinity. 
The next step is to examine $E C_{i, j}^{2}$. To do so, it is useful to write this term as

$$
E C_{i, j}^{2}=\frac{1}{N^{2} T^{4}} \sum_{c, q} \sum_{t, \tau, p, w} E\left(\varepsilon_{i, c, t-1} \varepsilon_{j, c, \tau} \pi_{i, t} \pi_{j, t} \varepsilon_{i, q, p-1} \varepsilon_{j, q, w} \pi_{i, p} \pi_{j, p}\right)
$$

where $\sum_{t, \tau, p, w} \equiv \sum_{t} \sum_{\tau} \sum_{p} \sum_{w}$. The K-dependence assumption implies that there are positive, finite numbers $\phi_{4}, \phi_{5}$ such that

$$
E C_{i, j}^{2} \leq \frac{1}{T^{2}}(2 K+1)^{2} \mu^{2} \phi_{4}+\frac{1}{N T^{2}}(2 K+1)^{2} \mu^{2} \phi_{5}
$$

where $\mu^{2}$ is the squared bound on $\left|\pi_{i, t} \pi_{j, t}\right|$. For example, in the case where the measurement errors are i.i.d., $\phi_{4}$ and $\phi_{5}$ could be picked to be the maximum of $\left(E \varepsilon^{2}\right)^{2}$ and $E \varepsilon^{4}$. More generally, $\phi_{4}$ and $\phi_{5}$ could be picked to be the largest possible value of the $E\left(\varepsilon_{i, c, t-1} \varepsilon_{j, c, \tau} \varepsilon_{i, q, r-1} \varepsilon_{j, q, s}\right)$ across all countries, commodities, and years. The inequality in (A18) implies that $E C_{i, j}^{2}$ goes to zero as $T$ goes to infinity. Hence, both $E C_{i, j}$ and $E C_{i, j}^{2}$ go to zero as $T$ goes to infinity, which implies that the probability limit of $C_{i, j}$ goes to zero as $T$ goes to infinity. As a result, the probability limit of $C$ in (A12) goes to zero as $T$ goes to infinity, which completes the proof that the probability limit of $A$ in (A10) goes to zero as $T$ goes to infinity. Hence, (A9) holds and $\operatorname{plim}_{T \rightarrow \infty} \widehat{b}_{I V}=\beta$.

Proof of Proposition 2 To prove Proposition 2 it is useful to express the least-squares estimator of $b^{r}$ in (A5) in terms of demeaned data

$$
\widehat{b^{r}}=\frac{\frac{1}{T} \frac{1}{N} \sum_{c} \sum_{t}\left(y_{c, t}-\bar{y}_{c}-\bar{y}_{t}+\bar{y}\right)\left(x_{c, t}^{m}-\bar{x}_{c}^{m}-\bar{x}_{t}^{m}+\bar{x}^{m}\right)}{\frac{1}{T} \frac{1}{N} \sum_{c} \sum_{t}\left(x_{c, t}^{m}-\bar{x}_{c}^{m}-\bar{x}_{t}^{m}+\bar{x}^{m}\right)^{2}}
$$

where $x_{c, t}^{m}=\sum_{i} \bar{s}_{i, c}^{m} \pi_{i, t}$ and the variables with upper bars denote averages. The upper bar with subscript $c$ denotes the average over time for country $c$, the upper bar with subscript $t$ denotes the average across countries for year $t$, and the upper bar without any subscript denotes the average both over time and across countries.

The true model in (A1) implies that the demeaned risk of civil war can also be written in 
terms of demeaned variables

$$
y_{c, t}-\bar{y}_{c}-\bar{y}_{t}+\bar{y}=\beta\left(x_{c, t}-\bar{x}_{c}-\bar{x}_{t}+\bar{x}\right)+\left(u_{c, t}-\bar{u}_{c}-\bar{u}_{t}+\bar{u}\right)
$$

where $x_{c, t}=\sum_{i} s_{i, c, t-1}^{*} \pi_{i, t}$ is the true commodity price shock. The true commodity price shock can be written as the commodity price shock using mismeasured time-averaged commodity weights, $s_{c, t}^{m}=\sum_{i} \bar{s}_{i, c}^{m} \pi_{i, t}$, plus two additional terms

$$
x_{c, t}=x_{c, t}^{m}+z_{c, t}+e_{c, t}
$$

where $z_{c, t}$ is the differences between the commodity price shock using mismeasured time-varying commodity weights and mismeasured time-averaged commodity weights

$$
z_{c, t}=\sum_{i}\left(s_{i, c, t-1}^{m}-\bar{s}_{c}^{m}\right) \pi_{i, t}
$$

and $e_{c, t}$ captures the difference between the commodity price shock using true and mismeasured time-varying commodity weights

$$
e_{c, t}=\sum_{i}\left(s_{i, c, t-1}^{*}-s_{i, c, t-1}^{m}\right) \pi_{i, t}=-\sum_{i} \varepsilon_{i, c, t-1} \pi_{i, t} .
$$

Substituting (A21) in (A20) yields that the least-squares estimator in (A19) can be written as

$$
\widehat{b^{r}}=\beta+\beta \widehat{\gamma}+\beta \widehat{b_{e}^{r}}+\widehat{b_{u}^{r}}
$$

where

$$
\begin{aligned}
& \widehat{\gamma}=\frac{\frac{1}{T} \frac{1}{N} \sum_{c} \sum_{t} z_{c, t}\left(x_{c, t}^{m}-\bar{x}_{c}^{m}-\bar{x}_{t}^{m}+\bar{x}^{m}\right)}{\frac{1}{T} \frac{1}{N} \sum_{c} \sum_{t}\left(x_{c, t}^{m}-\bar{x}_{c}^{m}-\bar{x}_{t}^{m}+\bar{x}^{m}\right)^{2}} \\
& \widehat{b_{e}^{r}}=\frac{\frac{1}{T} \frac{1}{N} \sum_{c} \sum_{t} e_{c, t}\left(x_{c, t}^{m}-\bar{x}_{c}^{m}-\bar{x}_{t}^{m}+\bar{x}^{m}\right)}{\frac{1}{T} \frac{1}{N} \sum_{c} \sum_{t}\left(x_{c, t}^{m}-\bar{x}_{c}^{m}-\bar{x}_{t}^{m}+\bar{x}^{m}\right)^{2}}
\end{aligned}
$$

and

$$
\widehat{b_{u}^{r}}=\frac{\frac{1}{T} \frac{1}{N} \sum_{c} \sum_{t} u_{c, t}\left(x_{c, t}^{m}-\bar{x}_{c}^{m}-\bar{x}_{t}^{m}+\bar{x}^{m}\right)}{\frac{1}{T} \frac{1}{N} \sum_{c} \sum_{t}\left(x_{c, t}^{m}-\bar{x}_{c}^{m}-\bar{x}_{t}^{m}+\bar{x}^{m}\right)^{2}} .
$$


As $u_{c, t}$ is independent of true export shares, international commodity price shocks, and measurement errors, $\widehat{b_{u}^{r}}$ goes to zero in probability as $T$ goes to infinity, $\operatorname{plim}_{T \rightarrow \infty} \widehat{b_{u}^{r}}=0$. Moreover, the K-dependence assumption implies that $\widehat{b_{e}^{r}}$ goes to zero in probability as $T$ goes to infinity. To see this, note that using (A23) and $x_{c, t}^{m}=\sum_{i} \bar{s}_{i, c}^{m} \pi_{i, t}$, the term $\frac{1}{T} \frac{1}{N} \sum_{c} \sum_{t} e_{c, t} x_{c, t}^{m}$ in the numerator of $\widehat{b_{e}^{r}}$ can be written as

$$
E=-\frac{1}{T} \frac{1}{N} \sum_{c} \sum_{t} \sum_{i} \varepsilon_{i, c, t-1} \pi_{i, t}\left(\sum_{i} \bar{s}_{i, c}^{*} \pi_{i, t}+\bar{\varepsilon}_{i, c} \pi_{i, t}\right)
$$

This term is equal to the negative of $A$ in (A10) which I have shown to go to zero in probability as $T$ goes to infinity. The terms $\frac{1}{T} \frac{1}{N} \sum_{c} \sum_{t} e_{c, t} \bar{x}_{c}^{m}$ and $\frac{1}{T} \frac{1}{N} \sum_{c} \sum_{t} e_{c, t} \bar{x}_{t}^{m}$ in the numerator of $\widehat{b_{e}^{r}}$ in (A26) can be shown to be equal, respectively, to $-\frac{1}{T} \frac{1}{N} \sum_{c} \sum_{t} \sum_{i} \varepsilon_{i, c, t-1} \pi_{i, t}\left(\sum_{i} \bar{s}_{i, c}^{*} \bar{\pi}_{i}+\bar{\varepsilon}_{i, c} \bar{\pi}_{i}\right)$ and to $-\frac{1}{T} \frac{1}{N} \sum_{c} \sum_{t} \sum_{i} \varepsilon_{i, c, t-1} \pi_{i, t}\left(\sum_{i} \bar{s}_{i}^{*} \pi_{i, t}+\overline{\bar{\varepsilon}}_{i} \pi_{i, t}\right)$ where $\bar{\pi}_{i}=\frac{1}{T} \sum_{t} \pi_{i, t}, \overline{\bar{s}}_{i}^{*}=\frac{1}{N} \sum_{c} \bar{s}_{i, c}^{*}$, and $\bar{\varepsilon}_{i}=\frac{1}{N} \sum_{c} \bar{\varepsilon}_{i, c}$. As a result, they can be shown go to zero in probability as $T$ goes to infinity using the same type of argument used for $E$ in (A28) (and $A$ in (A10)). Hence, $p \lim _{T \rightarrow \infty} \widehat{b_{e}^{r}}=0$ and (A24) implies that

$$
\operatorname{plim}_{T \rightarrow \infty} \widehat{b^{r}}=\beta+\beta p l i m_{T \rightarrow \infty} \widehat{\gamma} .
$$




\title{
Appendix B. Figures and Tables
}

for

\section{International Commodity Prices and Civil War Outbreak: New Evidence for Sub- Saharan Africa and Beyond}

\author{
Antonio Ciccone
}

January 2018 


\begin{tabular}{|c|c|}
\hline $\begin{array}{c}\text { Time } \\
\text { period }\end{array}$ & $\begin{array}{c}\text { Export } \\
\text { weights }\end{array}$ \\
\hline
\end{tabular}
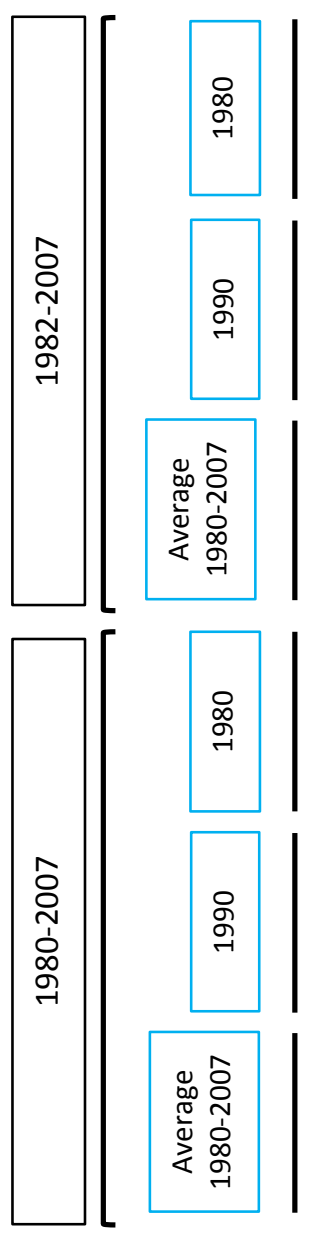

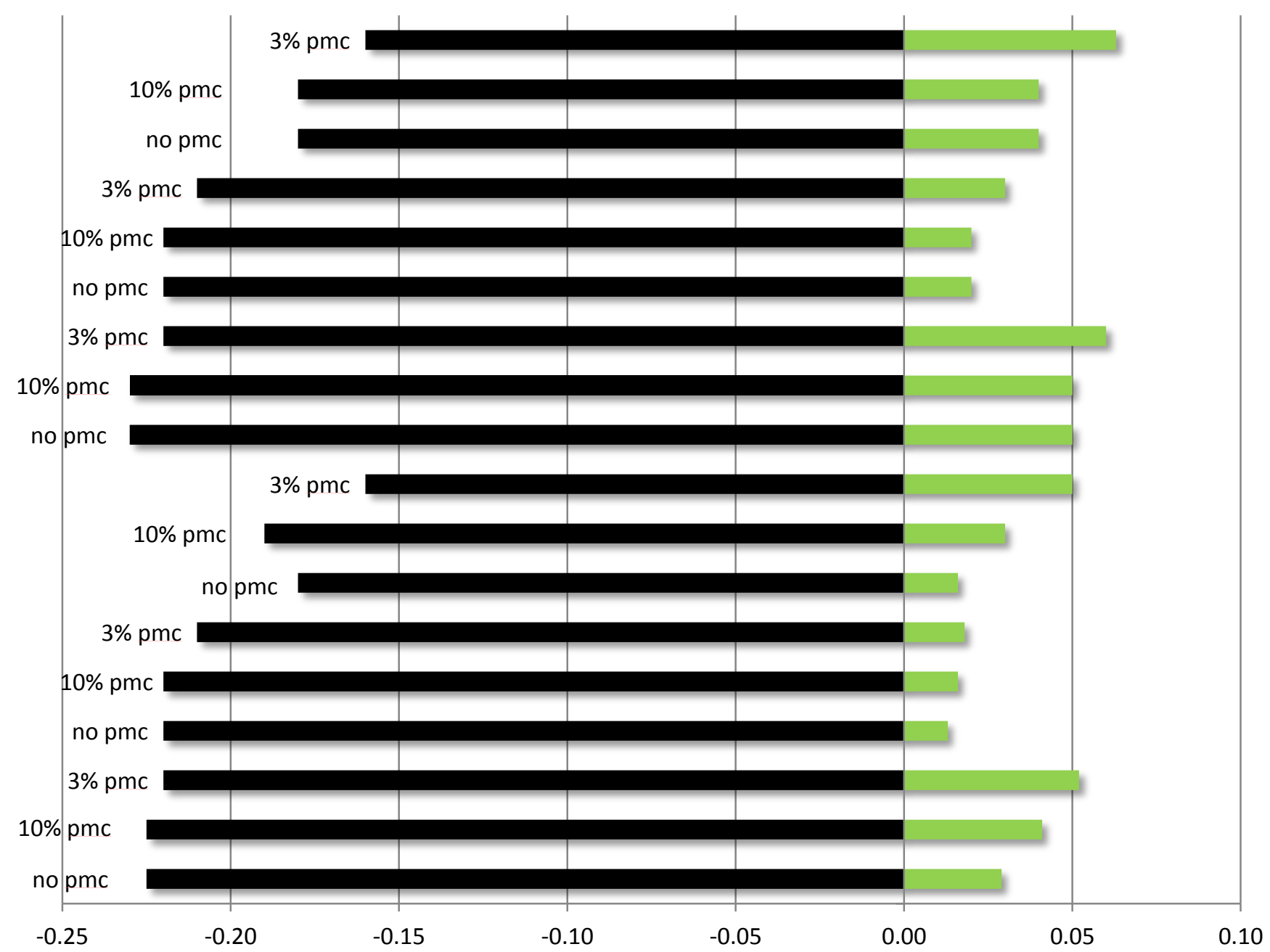

P-value of the hypothesis that the cumulative effect of commodity price

shocks is equal to zero

- Cumulative effect of commodity price shocks in TABLE 1, PANEL C (sum of the three point estimates on commodity price shocks in $t, t-1$, and $t-2)$

Note: The abbreviation pmc stands for price maker cutoff. The data comes from TABLE 1, PANEL C. Black bars taking negative values denote the cumulative effect of annual commodity price shocks (the sum of the point estimates on the commodity price shocks in $\mathrm{t}, \mathrm{t}-1$, and $\mathrm{t}-2$ ) for all 18 specifications in TABLE 1 . Green bars taking positive values denote the $\mathrm{p}$-values of the hypothesis that the cumulative effect is zero. The estimating equation is (9) in the main text. All data is from Bazzi and Blattman (2014). 


\section{APPENDIX FIGURE 2. Bazzi and Blattman shocks against reconstructed shocks with and without export weights normalized to unity}

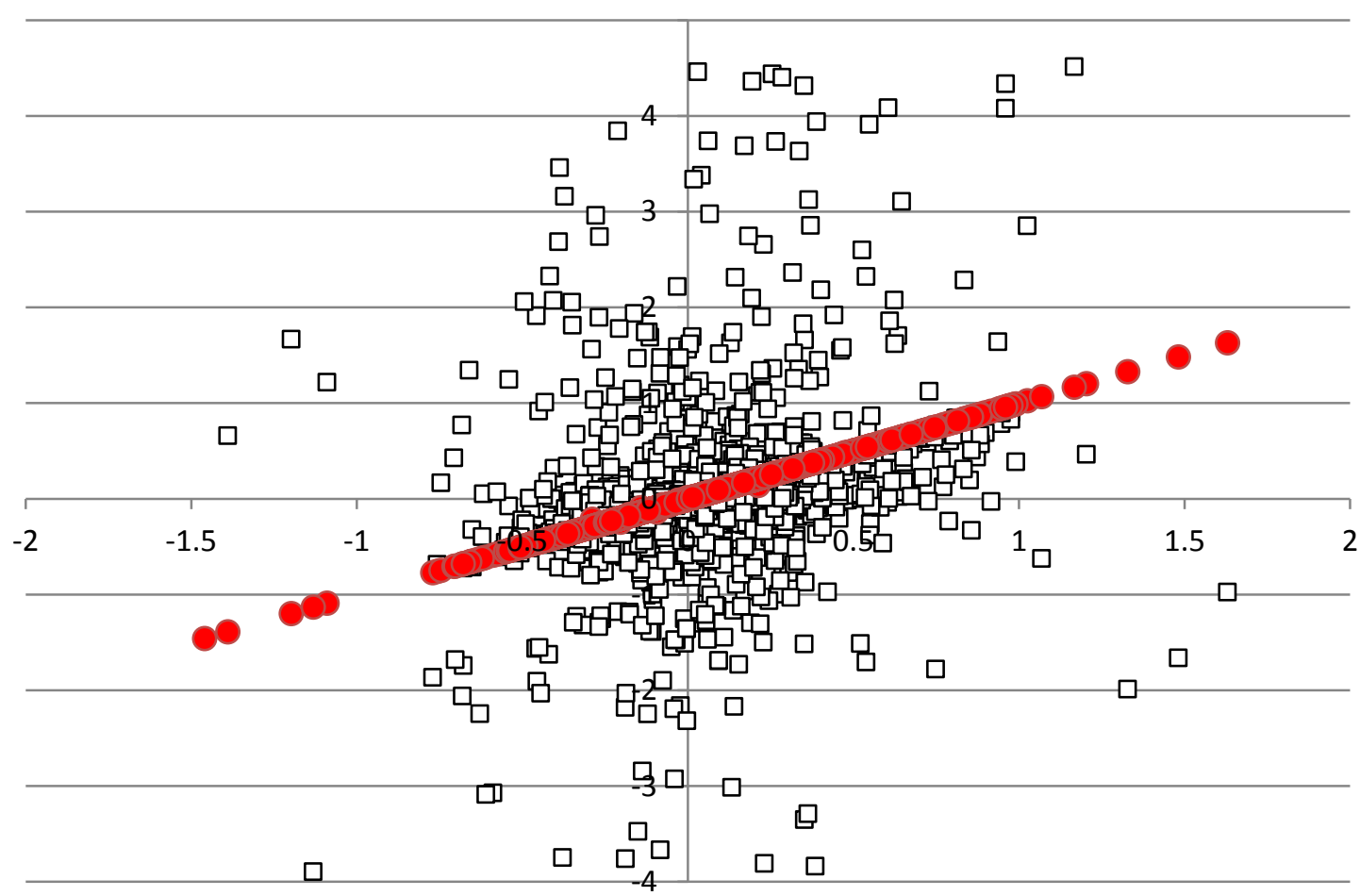

\section{$\square$ Reconstructed BB shocks with}

weights not normalized to unity (vertical axis) plotted against actual Bazzi and Blattman shocks without US CPI (horizontal axis)

- Reconstructed BB shocks with weights normalized to unity (vertical axis) plotted against actual Bazzi and Blattman shocks without US CPI (horizontal axis)

Note: See footnote 10 on page 13 in the main text for details on this figure. The Bazzi and Blattman shocks are the non-standardized version of the shocks used in their Online Appendix Table 11, column 2, without the US CPI. 


\section{APPENDIX TABLE 1. Annual commodity price shocks and civil war outbreak in Sub-Saharan Africa: Bazzi-Blattman dataset,}

1980-2007 period, $10 \%$ price maker cutoff

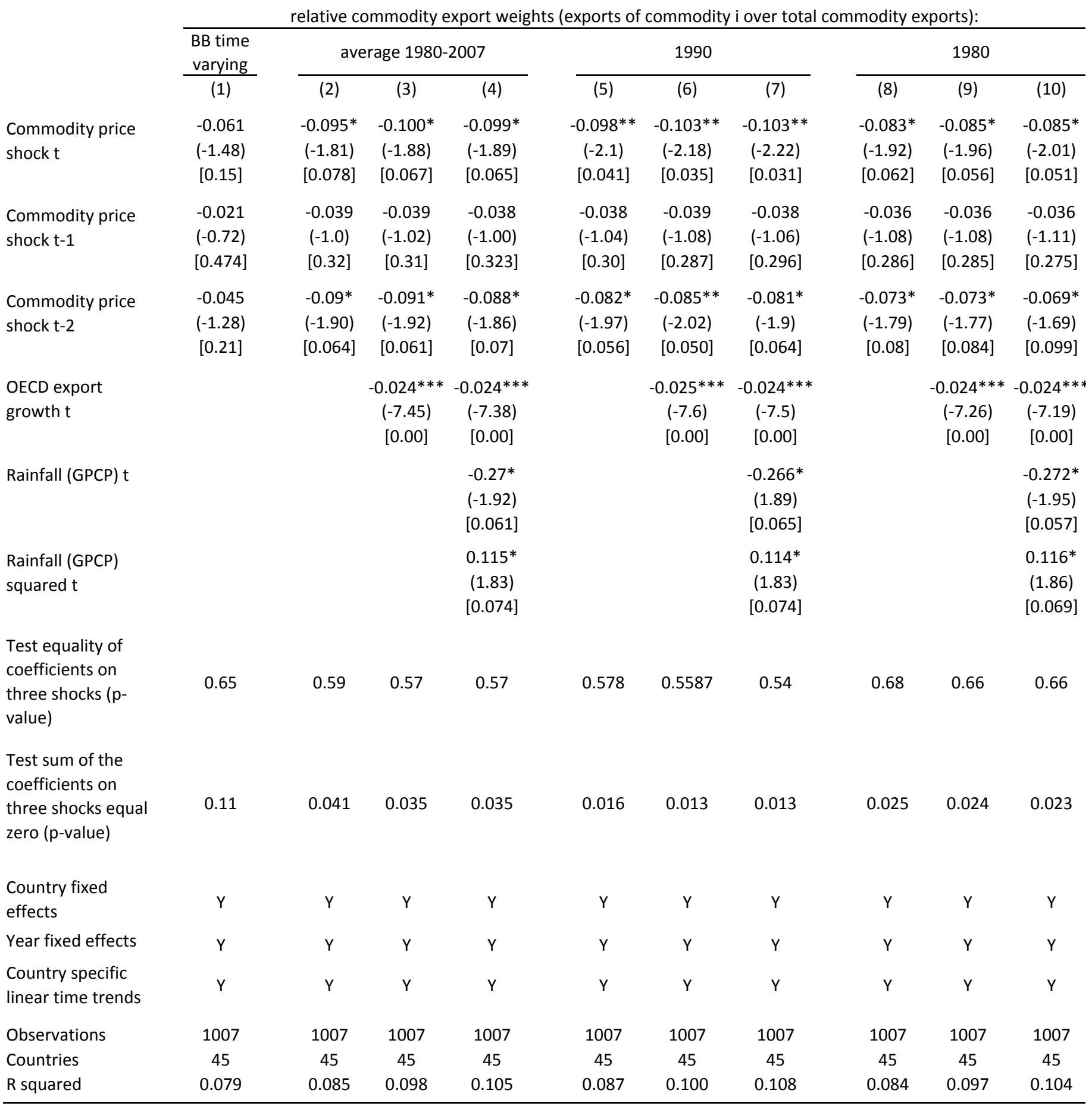

Note: All data in columns (1), (2), (5), and (8) is from Bazzi and Blattman (2014). The estimating equation is (9) in the main text. The lefthand-side variable is an indicator variable for civil war outbreak. The calculation of the shocks is explained in Sections 3.1.1-3.1.3. Column (1) calculates shocks using time-varying export weights as in Bazzi and Blattman (BB), and columns (2)-(10) calculate shocks using time-invariant export weights. The $10 \%$ price maker cutoff basically implies that commodity exports of country-years are not used to obtain export weights if the country's share of world exports exceeds $10 \%$ and is explained in Section 3.1.3. Standard errors in parentheses and $\mathrm{p}$-values of the hypothesis that the effect is zero in square brackets. ${ }^{*}$ denotes significance at the $10 \%$ level; $* *$ significance at the $5 \%$ level; and $* * *$ significance at the $1 \%$ level. 


\section{APPENDIX TABLE 2. 3-year commodity price shocks and civil war outbreak in Sub-Saharan Africa: Bazzi-Blattman dataset, $1980-2007$ period, $10 \%$ price maker cutoff}

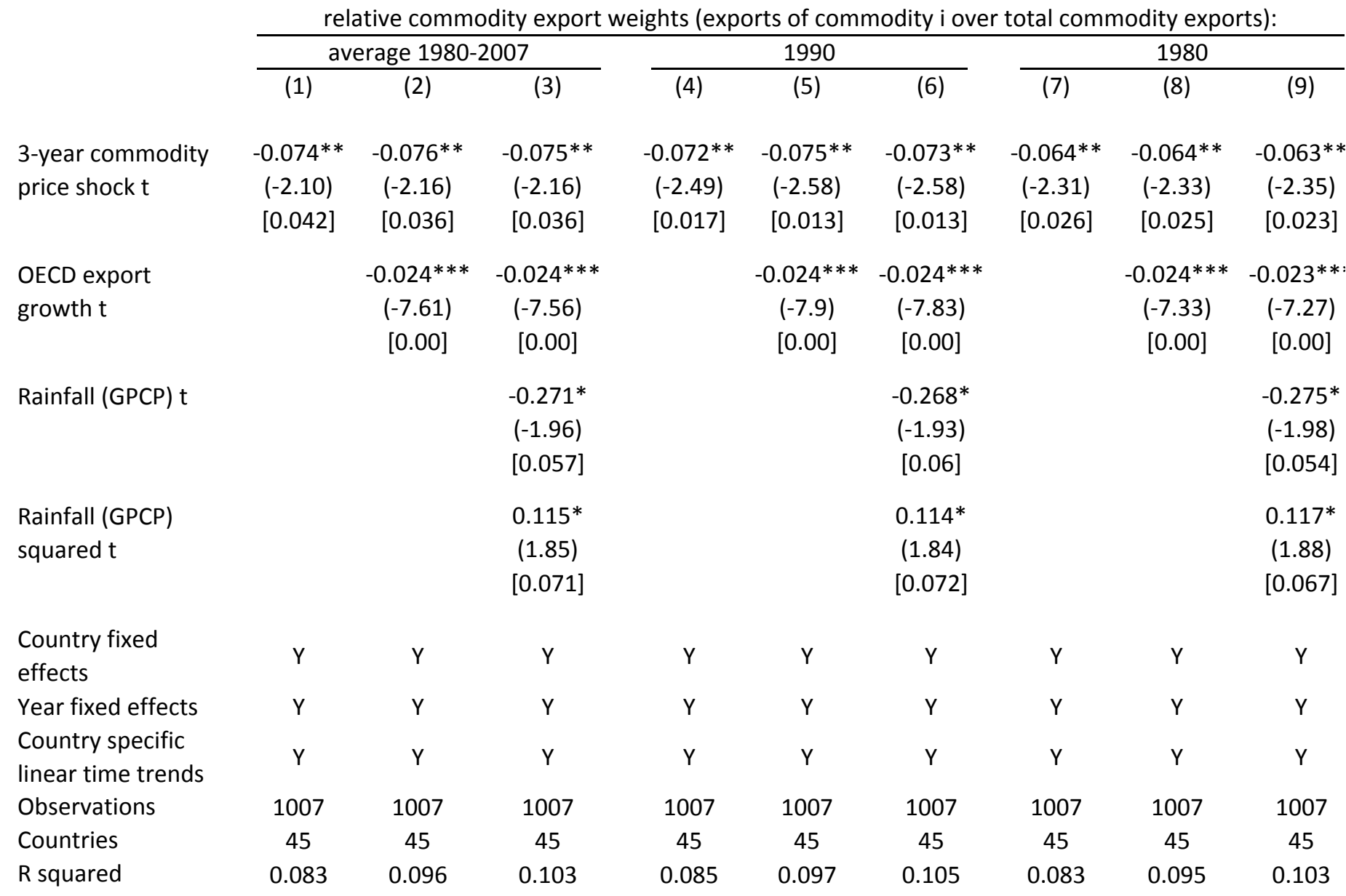

Note: All data in columns (1), (4), and (7) is from Bazzi and Blattman (2014). The estimating equation is (10) in the main text. The left-hand-side variable is an indicator variable for civil war outbreak. The calculation of the shocks is explained in Sections 3.1.1-3.1.3. The $10 \%$ price maker cutoff basically implies that commodity exports of country-years are not used to obtain export weights if the country's share of world exports exceeds $10 \%$ and is explained in detail in Section 3.1.3. Standard errors in parentheses and p-values of the hypothesis that the effect is zero in square brackets. * denotes significance at the $10 \%$ level; ${ }^{* *}$ significance at the $5 \%$ level; and ${ }^{* * *}$ significance at the $1 \%$ level. 


\section{APPENDIX TABLE 3. 3-year commodity price shocks and civil war outbreak in Sub-Saharan Africa: Bazzi and Blattman dataset, $1957-2007$ period, $10 \%$ price maker cutoff}

relative commodity export weights (exports of commodity i over total commodity exports):

\begin{tabular}{|c|c|c|c|c|c|c|c|c|c|}
\hline & \multirow{2}{*}{\multicolumn{3}{|c|}{ average $1957-2007$}} & \multirow{2}{*}{\multicolumn{3}{|c|}{1990}} & \multirow{2}{*}{\multicolumn{3}{|c|}{1980}} \\
\hline & & & & & & & & & \\
\hline & $(1)$ & $(2)$ & (3) & (4) & $(5)$ & (6) & (7) & $(8)$ & (9) \\
\hline \multirow{3}{*}{$\begin{array}{l}\text { 3-year commodity } \\
\text { price shock } t\end{array}$} & $-0.036 *$ & $-0.037^{* *}$ & $-0.037 * *$ & $-0.028^{*}$ & $-0.03 * *$ & $-0.029 * *$ & $-0.027^{*}$ & $-0.028 *$ & $-0.028 *$ \\
\hline & $(-1.97)$ & $(-2.05)$ & $(-2.07)$ & $(-1.93)$ & $(-2.02)$ & $(-2.02)$ & $(-1.81)$ & $(-1.87)$ & $(-1.93)$ \\
\hline & {$[0.055]$} & {$[0.046]$} & [0.045] & {$[0.06]$} & [0.049] & {$[0.05]$} & [0.077] & {$[0.068]$} & {$[0.06]$} \\
\hline \multirow{3}{*}{$\begin{array}{l}\text { OECD export } \\
\text { growth } t\end{array}$} & & $-0.007 * * *$ & $-0.007 * * *$ & & $-0.007 * * *$ & $-0.007 * * *$ & & $-0.007 * * *$ & $-0.007 * *$ \\
\hline & & $(-4.06)$ & $(-4.07)$ & & $(-4.17)$ & $(-4.18)$ & & $(-3.96)$ & $(-3.98)$ \\
\hline & & {$[0.00]$} & {$[0.00]$} & & {$[0.00]$} & {$[0.00]$} & & {$[0.00]$} & {$[0.00]$} \\
\hline \multirow[t]{3}{*}{ Rainfall (GPCC) t } & & & $-0.132 *$ & & & $-0.131 *$ & & & $-0.134 *$ \\
\hline & & & $(-1.82)$ & & & $(-1.8)$ & & & $(-1.84)$ \\
\hline & & & {$[0.075]$} & & & {$[0.078]$} & & & [0.072] \\
\hline \multirow{3}{*}{$\begin{array}{l}\text { Rainfall (GPCC) } \\
\text { squared } t\end{array}$} & & & $0.048 *$ & & & $0.047^{*}$ & & & $0.048 *$ \\
\hline & & & $(1.86)$ & & & $(1.84)$ & & & $(1.88)$ \\
\hline & & & {$[0.07]$} & & & {$[0.073]$} & & & {$[0.066]$} \\
\hline $\begin{array}{l}\text { Country fixed } \\
\text { effects }\end{array}$ & $\mathrm{Y}$ & $Y$ & $Y$ & Y & Y & $Y$ & $Y$ & $Y$ & $Y$ \\
\hline Year fixed effects & $Y$ & $Y$ & $Y$ & $\mathrm{Y}$ & $\mathrm{Y}$ & $\mathrm{Y}$ & $\mathrm{Y}$ & $Y$ & $\mathrm{Y}$ \\
\hline $\begin{array}{l}\text { Country specific } \\
\text { linear time trends }\end{array}$ & Y & $Y$ & $Y$ & Y & $\mathrm{Y}$ & Y & Y & Y & Y \\
\hline Observations & 1805 & 1805 & 1805 & 1805 & 1805 & 1805 & 1805 & 1805 & 1805 \\
\hline Countries & 45 & 45 & 45 & 45 & 45 & 45 & 45 & 45 & 45 \\
\hline R squared & 0.104 & 0.106 & 0.109 & 0.104 & 0.106 & 0.109 & 0.104 & 0.105 & 0.109 \\
\hline
\end{tabular}

Note: All data in columns (1), (4), and (7) is from Bazzi and Blattman (2014). The estimating equation is (10) in the main text. The left-hand-side variable is an indicator variable for civil war outbreak. The calculation of the shocks is explained in Sections 3.1.1-3.1.3. The $10 \%$ price maker cutoff basically implies that commodity exports of country-years are not used to obtain export weights if the country's share of world exports exceeds $10 \%$ and is explained in detail in Section 3.1 .3 . Standard errors in parentheses and p-values of the hypothesis that the effect is zero in square brackets. ${ }^{*}$ denotes significance at the $10 \%$ level; ${ }^{* *}$ significance at the $5 \%$ level; and ${ }^{* * *}$ significance at the $1 \%$ level. 


\section{APPENDIX TABLE 4. Annual commodity price shocks and civil war outbreak beyond Sub- Saharan Africa: Bazzi-Blattman dataset, 1980-2007 period, 10\% price maker cutoff}

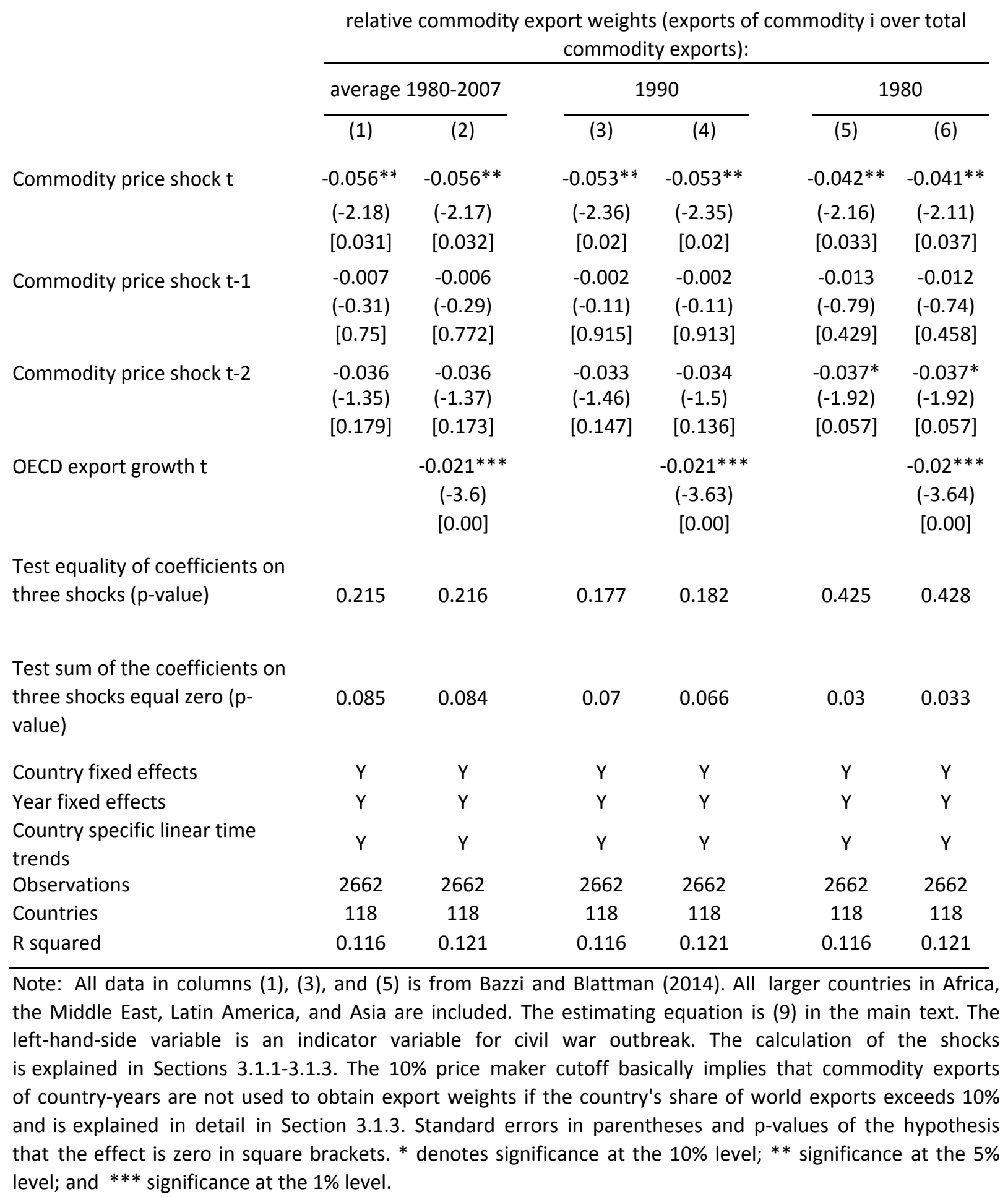




\section{APPENDIX TABLE 5. 3-year commodity price shocks and civil war outbreak beyond Sub- Saharan Africa: Bazzi-Blattman dataset, 1980-2007 period, 10\% price maker cutoff}

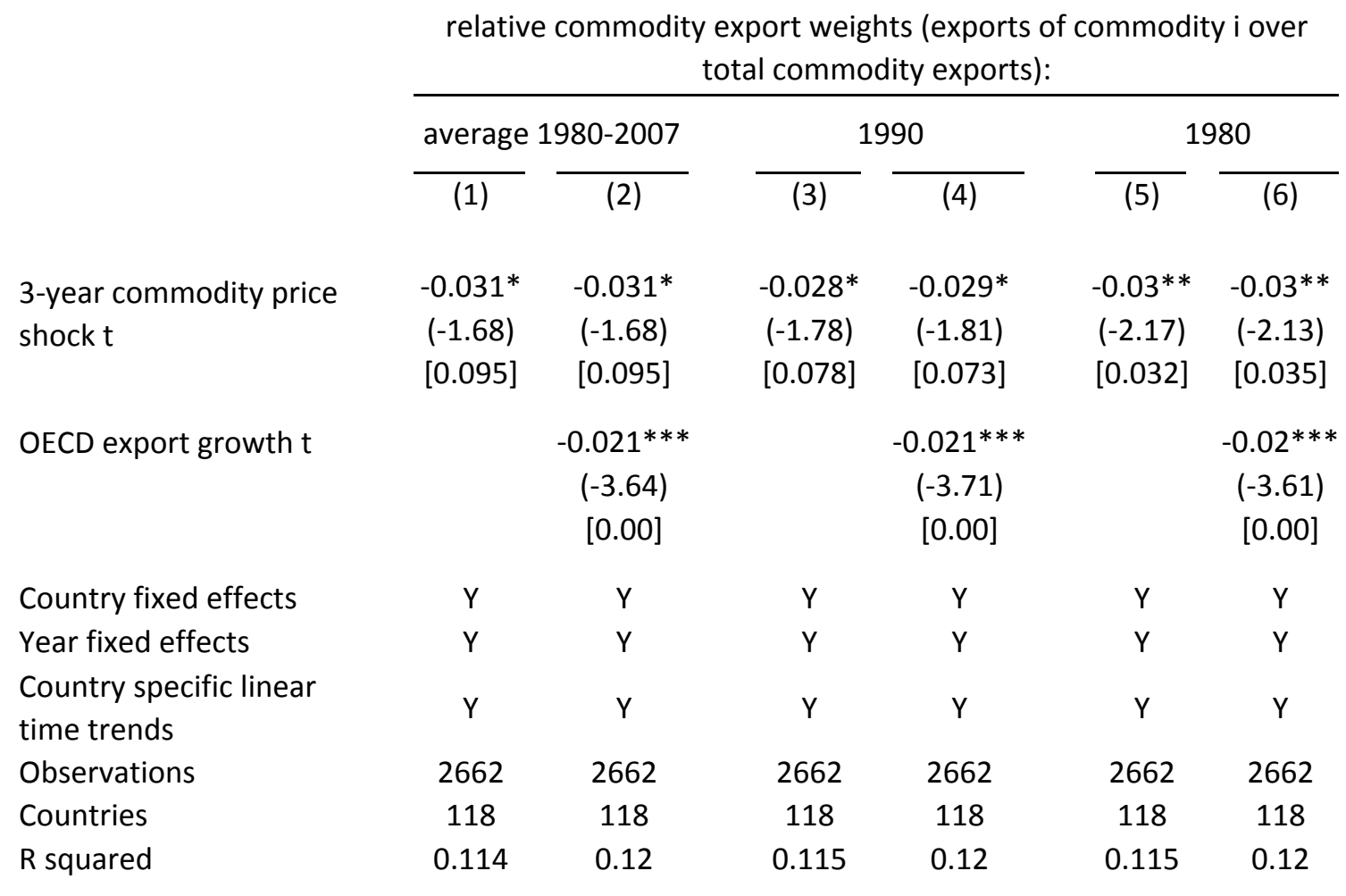

Note: All data in columns (1), (3), and (5) is from Bazzi and Blattman (2014). All larger countries in Africa, the Middle East, Latin America, and Asia are included. The estimating equation is (10) in the main text. The left-hand-side variable is an indicator variable for civil war outbreak. The calculation of the shocks is explained in Sections 3.1.1-3.1.3. The 10\% price maker cutoff basically implies that commodity exports of country-years are not used to obtain export weights if the country's share of world exports exceeds $10 \%$ and is explained in detail in Section 3.1.3. Standard errors in parentheses and $p$-values of the hypothesis that the effect is zero in square brackets. ${ }^{*}$ denotes significance at the $10 \%$ level; ${ }^{* *}$ significance at the $5 \%$ level; and $* * *$ significance at the $1 \%$ level. 


\section{APPENDIX TABLE 6. 3-year commodity price shocks and civil war outbreak beyond Sub- Saharan Africa: Bazzi-Blattman dataset, 1957-2007 period, 10\% price maker cutoff}

\begin{tabular}{|c|c|c|c|c|c|c|}
\hline & \multicolumn{6}{|c|}{$\begin{array}{l}\text { relative commodity export weights (exports of commodity i over } \\
\text { total commodity exports): }\end{array}$} \\
\hline & \multicolumn{2}{|c|}{$\begin{array}{l}\text { average 1957- } \\
\quad 2007\end{array}$} & \multicolumn{2}{|c|}{1990} & \multicolumn{2}{|c|}{1980} \\
\hline & (1) & $(2)$ & (3) & (4) & (5) & (6) \\
\hline \multirow{3}{*}{$\begin{array}{l}\text { 3-year commodity price } \\
\text { shock } t\end{array}$} & -0.014 & -0.014 & -0.009 & -0.009 & -0.013 & -0.013 \\
\hline & $(-1.28)$ & $(-1.34)$ & $(-0.95)$ & $(-1.01)$ & $(-1.47)$ & $(-1.52)$ \\
\hline & {$[0.20]$} & {$[0.18]$} & [0.344] & {$[0.312]$} & [0.143] & {$[0.131]$} \\
\hline \multirow[t]{3}{*}{ OECD export growth $t$} & & $-0.005 * *$ & & $-0.005 * *$ & & $-0.005^{* *}$ \\
\hline & & $(-2.4)$ & & $(-2.4)$ & & $(-2.41)$ \\
\hline & & {$[0.018]$} & & {$[0.018]$} & & [0.017] \\
\hline Country fixed effects & $\mathrm{Y}$ & $Y$ & Y & Y & Y & $\mathrm{Y}$ \\
\hline Year fixed effects & $\mathrm{Y}$ & $\mathrm{Y}$ & Y & Y & $Y$ & Y \\
\hline $\begin{array}{l}\text { Country specific linear time } \\
\text { trends }\end{array}$ & $Y$ & $\mathrm{Y}$ & Y & Y & Y & $\mathrm{Y}$ \\
\hline Observations & 4781 & 4781 & 4781 & 4781 & 4781 & 4781 \\
\hline Countries & 118 & 118 & 118 & 118 & 118 & 118 \\
\hline R squared & 0.086 & 0.087 & 0.086 & 0.086 & 0.086 & 0.087 \\
\hline
\end{tabular}

Note: All data in columns (1), (3), and (5) is from Bazzi and Blattman (2014). All larger countries in Africa, the Middle East, Latin America, and Asia are included. The estimating equation is (10) in the main text. The left-hand-side variable is an indicator variable for civil war outbreak. The calculation of the shocks is explained in Sections 3.1 .1-3.1.3. The $10 \%$ price maker cutoff basically implies that commodity exports of country-years are not used to obtain export weights if the country's share of world exports exceeds $10 \%$ and is explained in detail in Section 3.1.3. Standard errors in parentheses and $p$-values of the hypothesis that the effect is zero in square brackets. ${ }^{*}$ denotes significance at the $10 \%$ level; ${ }^{* *}$ significance at the $5 \%$ level; and ${ }^{* * *}$ significance at the $1 \%$ level. 


\section{APPENDIX TABLE 7: Summary of the effect of 3-year commodity price shocks on civil war outbreak beyond Sub-Saharan Africa for the 1957-2007 period using the Bazzi-Blattman dataset}

PANEL A. Point estimates of the effect of 3-year commodity price shocks on civil war risk

Commodity weights (time-invariant)

Price maker cutoff (\%)

3-year commodity price shock $\mathrm{t}(\%)$

\begin{tabular}{|c|c|c|}
\hline \multicolumn{3}{|c|}{$\begin{array}{c}\text { average 1957- } \\
2007 \\
\end{array}$} \\
\hline no & 10 & 3 \\
\hline-1 & -1 & -2 \\
\hline
\end{tabular}

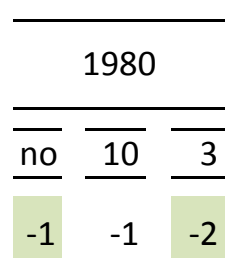

PANEL B. P-values of the effect of 3-year commodity price shocks on civil war risk

\begin{tabular}{|c|c|c|c|c|c|c|c|c|c|}
\hline \multirow{2}{*}{$\begin{array}{l}\text { Commodity weights (time-invariant) } \\
\text { Price maker cutoff (\%) }\end{array}$} & \multicolumn{3}{|c|}{$\begin{array}{c}\text { average 1957- } \\
2007\end{array}$} & \multicolumn{3}{|c|}{1990} & \multicolumn{3}{|c|}{1980} \\
\hline & no & 10 & 3 & no & 10 & 3 & $\overline{\text { no }}$ & 10 & 3 \\
\hline 3-year commodity price shock t (\%) & 12 & 20 & 8 & 24 & 34 & 25 & 9 & 14 & 5 \\
\hline
\end{tabular}

Note: The table reports point estimates (PANEL A) and p-values (PANEL B) when estimating equation (10) in the main text. The left-hand-side variable is an indicator variable for civil war outbreak. Shaded cells refer to effects that are significant at the $10 \%$ level at least. The calculation of the shocks is explained in Sections 3.1.1-3.1.3. The $10 \%$ (3\%) price maker cutoff basically implies that commodity exports of country-years are not used to obtain export weights if the country's share of world exports exceeds $10 \%(3 \%)$ and is explained in detail in Section 3.1.3. No price maker cutoff refers to results where all commodity export data is used. All data is from Bazzi and Blattman (2014) and includes all larger countries in Africa, the Middle East, Latin America, and Asia. 
APPENDIX TABLE 8. 3-year commodity price shocks and civil war outbreak beyond Sub-Saharan Africa: Bazzi-Blattman dataset with updated civil war data, 1957-2009 period, $10 \%$ and $3 \%$ price maker cutoff

Price maker cutoff

3-year commodity price shock $t$

OECD export growth $t$

Test sum of the coefficients on three shocks equal zero ( $p$ value)

Country fixed effects
Year fixed effects
Country specific linear time
trends
Observations
Countries
R squared

Test equality of coefficients on three shocks ( $p$-value)

10\%

$-0.01$

[0.202]

0.011

$(-1.30)$

[0.195]

$-0.002^{*}$

$(-1.87)$

[0.063]

\footnotetext{
Note: The analysis includes all larger countries in Africa, the Middle East, Latin America, and Asia. The commodity price and export data is from Bazzi and Blattman (2014). The civil war data is from the same source used by Bazzi and Blattman but updated using the latest version (UCPD 2016 version 4). The estimating equation is (10) in the main text. The left-hand-side variable is an indicator variable for civil war outbreak. The calculation of the shocks is explained in Sections 3.1.1-3.1.3. Timeinvariant country-commodity weights are set equal to country-commodity export shares averaged over the sample period. The $10 \%$ (3\%) price maker cutoff basically implies that commodity exports of country-years are not used to obtain export weights if the country's share of world exports exceeds $10 \%(3 \%)$ and is explained in Section 3.1.3. Standard errors in parentheses and $p$-values of the hypothesis that the effect is zero in square brackets. * denotes significance at the $10 \%$ level; ** significance at the $5 \%$ level; and *** significance at the $1 \%$ level.
} 
APPENDIX TABLE 9. 3-year commodity price shocks and civil war outbreak: estimates for countries with commodity exports relative to GDP below and above the median, Bazzi-Blattman dataset with updated civil war data

\begin{tabular}{|c|c|c|c|}
\hline \multirow[b]{2}{*}{ Sample } & \multirow[b]{2}{*}{ price shock measure } & \multicolumn{2}{|c|}{ commodity exports relative to GDP } \\
\hline & & below median & above median \\
\hline \multirow{3}{*}{$\begin{array}{l}\text { Sub-Saharan Africa, } \\
\text { 1980-2009 period }\end{array}$} & \multirow{3}{*}{$\begin{array}{c}\text { 3-year commodity price } \\
\text { shock } \mathrm{t}\end{array}$} & $-0.12^{* *}$ & 0.001 \\
\hline & & $(-2.44)$ & $(0.03)$ \\
\hline & & [0.024] & [0.97] \\
\hline \multirow{3}{*}{$\begin{array}{l}\text { Sub-Saharan Africa, } \\
\text { 1957-2009 period }\end{array}$} & \multirow{3}{*}{$\begin{array}{c}\text { 3-year commodity price } \\
\text { shock } \mathrm{t}\end{array}$} & $-0.063 * * *$ & -0.007 \\
\hline & & $(-2.28)$ & $(-1.37)$ \\
\hline & & [0.033] & {$[0.18]$} \\
\hline \multirow{3}{*}{$\begin{array}{l}\text { Beyond Sub-Saharan } \\
\text { Africa, 1980-2009 } \\
\text { period }\end{array}$} & \multirow{3}{*}{$\begin{array}{c}\text { 3-year commodity price } \\
\text { shock } \mathrm{t}\end{array}$} & -0.028 & -0.012 \\
\hline & & $(-0.90)$ & $(-1.13)$ \\
\hline & & {$[0.37]$} & {$[0.26]$} \\
\hline \multirow{3}{*}{$\begin{array}{l}\text { Beyond Sub-Saharan } \\
\text { Africa, 1957-2009 } \\
\text { period }\end{array}$} & \multirow{3}{*}{$\begin{array}{c}\text { 3-year commodity price } \\
\text { shock } t\end{array}$} & -0.001 & $-0.012 *$ \\
\hline & & $(-0.05)$ & $(-1.73)$ \\
\hline & & {$[0.96]$} & [0.089] \\
\hline \multicolumn{4}{|c|}{$\begin{array}{l}\text { Note: The table splits countries in the sample listed in the left-most column at the median value of } \\
\text { commodity exports relative to GDP and estimates the effect of } 3 \text {-year commodity price shocks on civil } \\
\text { war risk using equation (10) in the main text separately for the two subsamples. The 'beyond } \\
\text { Sub-Saharan Africa' sample includes all larger countries in Africa, the Middle East, Latin America, and } \\
\text { Asia. The commodity price and export data is from Bazzi and Blattman (2014). The civil war data is } \\
\text { from the same source used by Bazzi and Blattman but updated using the latest version (UCPD } 2016 \text { version } \\
\text { 4). The left-hand-side variable is an indicator variable for civil war outbreak. The calculation of } \\
\text { the shocks is explained in Sections } 3.1 .1-3.1 .3 \text {. Time-invariant country-commodity weights are } \\
\text { set equal to country-commodity export shares averaged over the sample period. Standard errors in } \\
\text { parentheses and p-values of the hypothesis that the effect is zero in square brackets. * denotes } \\
\text { significance at the } 10 \% \text { level; }{ }^{* *} \text { significance at the } 5 \% \text { level; and *** significance at the } 1 \% \text { level. }\end{array}$} \\
\hline
\end{tabular}


APPENDIX TABLE 10. 3-year commodity price shocks and civil war outbreak: sample splits by income/light per capita, income inequality, and ethnic fragmentation; Bazzi-Blattman dataset with updated civil war data

PANEL A. Light per capita in 2000

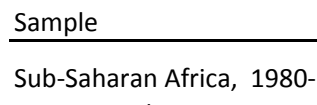

2009 period

Beyond Sub-Saharan

Africa, 1980-2009 period
Sub-Saharan Africa, 19802009 period

Beyond Sub-Saharan Africa, 1980-2009 period

\author{
price shock measure \\ 3-year commodity price \\ shock $\mathrm{t}$
}

3-year commodity price

shock $\mathrm{t}$

\begin{tabular}{c} 
below median \\
\hline$-0.121^{* *}$ \\
$(-2.31)$ \\
{$[0.031]$} \\
$-0.048^{* *}$ \\
$(-1.99)$ \\
{$[0.051]$}
\end{tabular}

PANEL B. Real GDP per capita in 1980

\begin{tabular}{cc} 
& below median \\
\cline { 2 - 2 } 3-year commodity price & $-0.07^{* *}$ \\
shock t & $(-2.04)$ \\
& {$[0.055]$} \\
3-year commodity price & -0.024 \\
shock t & $(-1.27)$ \\
& {$[0.21]$}
\end{tabular}

PABEL C. Inequality measured by Gini coefficient

Sub-Saharan Africa, 1980-
2009 period
Beyond Sub-Saharan
Africa, 1980-2009 period

3-year commodity price shock t

3-year commodity price shock $\mathrm{t}$

\begin{tabular}{c} 
below median \\
\hline$-0.074^{* *}$ \\
$(-2.13)$ \\
{$[0.052]$} \\
$-0.051^{* *}$ \\
$(-2.04)$ \\
{$[0.048]$}
\end{tabular}

\begin{tabular}{c} 
above median \\
\hline-0.005 \\
$(-0.60)$ \\
{$[0.56]$} \\
\\
0.004 \\
$(0.38)$ \\
{$[0.71]$}
\end{tabular}

\begin{tabular}{c} 
above median \\
\hline-0.002 \\
$(-0.37)$ \\
{$[0.71]$} \\
-0.001 \\
$(-0.04)$ \\
{$[0.14]$}
\end{tabular}

$[0.14]$

\begin{tabular}{c} 
above median \\
\hline 0.01 \\
$(0.96)$ \\
{$[0.36]$} \\
\\
0.006 \\
$(0.31)$ \\
{$[0.76]$}
\end{tabular}

PANEL D. Inequality measured by top quintile income share

\begin{tabular}{lccc} 
& & below median & above median \\
\cline { 3 - 4 } Sub-Saharan Africa, 1980- & 3-year commodity price & $-0.074^{*}$ & 0.013 \\
2009 period & shock t & $(-2.03)$ & $(1.08)$ \\
& & {$[0.063]$} & {$[0.29]$} \\
Beyond Sub-Saharan & 3-year commodity price & $-0.045^{*}$ & 0.007 \\
Africa, 1980-2009 period & shock t & $(-1.86)$ & $(0.31)$ \\
& & {$[0.07]$} & {$[0.76]$}
\end{tabular}

PANEL E. Ethnic fragmentation measured by Alesina et al. (2003) index

\begin{tabular}{lccc} 
& & below median & above median \\
\cline { 3 - 4 } Sub-Saharan Africa, 1980- & 3-year commodity price & $-0.097^{*}$ & -0.037 \\
2009 period & shock t & $(-1.88)$ & $(-1.46)$ \\
& & {$[0.075]$} & {$[0.16]$} \\
Beyond Sub-Saharan & 3-year commodity price & $-0.044^{*}$ & -0.015 \\
Africa, 1980-2009 period & shock t & $(-1.69)$ & $(-0.87)$ \\
& & {$[0.097]$} & {$[0.38]$}
\end{tabular}

Note: The table splits countries in the sample listed in the left-most column at the median value of the variable listed in the panel headings and estimates the effect of 3-year commodity price shocks on civil war risk using equation (10) in the main text separately for the two subsamples. The 'beyond Sub-Saharan Africa' sample includes all larger countries in Africa, the Middle East, Latin America, and Asia. The commodity price and export data is from Bazzi and Blattman (2014). The civil war data is from the same source used by Bazzi and Blattman but updated using the latest version (UCPD 2016 version 4). The left-hand-side variable is an indicator variable for civil war outbreak. The calculation of the shocks is explained in Sections 3.1.1-3.1.3. Time-invariant country-commodity weights are set equal to country-commodity export shares averaged over the sample period. Standard errors in parentheses and $p$-values of the hypothesis that the effect is zero in square brackets. ${ }^{*}$ denotes significance at the $10 \%$ level; ${ }^{* *}$ significance at the $5 \%$ level; and ${ }^{* * *}$ significance at the $1 \%$ level. 


\section{APPENDIX TABLE 11. Annual commodity price shocks and civil war outbreak in Sub-Saharan Africa: Bazzi-Blattman data only, $1980-2007$ period, $3 \%$ price maker cutoff}

relative commodity export weights (exports of commodity i over total commodity exports):

\begin{tabular}{l} 
BB time \\
varying \\
\hline
\end{tabular}

(1)

Commodity price

shock $\mathrm{t}$

Commodity price

shock t-1

Commodity price

shock t-2

OECD export

growth $t$

Rainfall (GPCP) t

Rainfall (GPCP)

squared $t$

Test equality of coefficients on

three shocks ( $p$ -

value)

Test sum of the coefficients on three shocks equal zero ( $p$-value)

Country fixed

effects

Year fixed effects

Country specific

linear time trends

Observations

Countries

$\mathrm{R}$ squared

\section{$-0.067$ \\ $(-1.72)$ \\ [0.093]}

$-0.016$

$(-0.56)$

[0.575]

$-0.042$

$(-1.23)$

[0.22]

0.40

0.11

(2)
average 1980-2007

(3)

(4)

-0.097
$(-1.78)$
$[0.082]$

(3)

(4)

[0.082]

$(-1.87) \quad(-1.93)$

[0.068]

[0.06]

$-0.026$

$-0.027$

$(-0.64)$

(-0.66)

$-0.024$

[0.527]

[0.51]

$(-0.59)$

$-0.088^{*}$

$-0.090 *$

[0.56]

(1.76)

$(-1.78)$

$-0.086 *$

[0.086]

[0.081]

$(-1.71)$

[0.094]

$-0.024 * * *-0.024 * * *$

$(-7.62) \quad(-7.55)$

[0.00]

[0.00]

$-0.278 *$

$(-1.99)$

[0.053]

$0.117^{*}$

(1.89)

[0.066]

0.53

0.43

0.47

0.54

0.50

0.44

0.76

0.76

0.78

0.052

0.051

0.044

0.018

0.014

0.014

0.049

0.0445

0.047

$(-7.74) \quad(-7.66)$

[0.00] [0.00]

$-0.276 *$

$(-1.97)$

[0.055]

$0.116^{*}$

(1.88)

[0.067]

[0.061]

(0.0

$\begin{array}{ccc}(5) & (6) & (7) \\ & & \\ -099^{* *} & -0.105^{* *} & -0.108^{* *} \\ (-2.11) & (-2.20) & (-2.29) \\ 0.041] & {[0.033]} & {[0.027]} \\ -0.032 & -0.033 & -0.031 \\ (-0.85) & (-0.88) & (-0.82) \\ {[0.40]} & {[0.38]} & {[0.415]} \\ -0.078^{*} & -0.08^{*} & -0.077^{*} \\ (1.89) & (-1.93) & (-1.83) \\ 0.066] & {[0.06]} & {[0.074]} \\ & -0.025^{* * *} & -0.025^{* * *} \\ & (-7.77) & (-7.70) \\ & {[0.00]} & {[0.00]} \\ & & -0.278^{*} \\ & & (-2.01) \\ & & {[0.051]} \\ & & 0.118^{*} \\ & & (1.93) \\ & & {[0.061]}\end{array}$

(8) (9) (10)

$\begin{array}{lll}-0.061 & -0.064 & -0.064 \\ (-1.42) & (-1.49) & (-1.55)\end{array}$

[0.16] [0.14] [0.13]

$\begin{array}{lll}-0.027 & -0.027 & -0.026\end{array}$

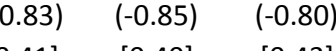

$\begin{array}{lll}-0.068 & -0.067 & -0.063\end{array}$

$(-1.63) \quad(-1.52)$

$0.14]$

\section{6)}

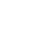




\section{APPENDIX TABLE 12. Annual commodity price shocks and civil war outbreak in Sub-Saharan Africa: Bazzi-Blattman data only, 1982-2007 period, $10 \%$ price maker cutoff}

\begin{tabular}{|c|c|c|c|c|c|c|c|c|c|c|}
\hline & & & & & & & & & & \\
\hline & varying & & erage 1980- & 2007 & & 1990 & & & 1980 & \\
\hline & $(1)$ & (2) & (3) & (4) & (5) & (6) & (7) & (8) & (9) & (10) \\
\hline $\begin{array}{l}\text { Commodity price } \\
\text { shock t }\end{array}$ & $\begin{array}{c}-0.066 \\
(-1.49) \\
{[0.14]}\end{array}$ & $\begin{array}{c}-0.097^{*} \\
(-1.76) \\
{[0.086]}\end{array}$ & $\begin{array}{c}-0.101^{*} \\
(-1.82) \\
{[0.075]}\end{array}$ & $\begin{array}{c}-0.101^{*} \\
(-1.83) \\
{[0.074]}\end{array}$ & $\begin{array}{c}-0.102 * * \\
(-2.07) \\
{[0.044]}\end{array}$ & $\begin{array}{c}-0.107^{* *} \\
(-2.13) \\
{[0.038]}\end{array}$ & $\begin{array}{c}-0.108 * * \\
(-2.18) \\
{[0.35]}\end{array}$ & $\begin{array}{c}-0.084 * \\
(-1.84) \\
{[0.072]}\end{array}$ & $\begin{array}{c}-0.087^{*} \\
(-1.89) \\
{[0.065]}\end{array}$ & $\begin{array}{c}-0.086 * \\
(-1.92) \\
{[0.062]}\end{array}$ \\
\hline $\begin{array}{l}\text { Commodity price } \\
\text { shock t-1 }\end{array}$ & $\begin{array}{c}-0.022 \\
(-0.64) \\
{[0.53]}\end{array}$ & $\begin{array}{c}-0.04 \\
(-0.91) \\
{[0.366]}\end{array}$ & $\begin{array}{c}-0.04 \\
(-0.91) \\
{[0.368]}\end{array}$ & $\begin{array}{c}-0.04 \\
(-0.91) \\
{[0.366]}\end{array}$ & $\begin{array}{l}-0.039 \\
(-0.97) \\
{[0.335]}\end{array}$ & $\begin{array}{l}-0.039 \\
(-0.98) \\
{[0.333]}\end{array}$ & $\begin{array}{c}-0.039 \\
(-0.98) \\
{[0.333]}\end{array}$ & $\begin{array}{c}-0.032 \\
(-0.91) \\
{[0.37]}\end{array}$ & $\begin{array}{c}-0.032 \\
(-0.89) \\
{[0.378]}\end{array}$ & $\begin{array}{c}-0.034 \\
(-0.95) \\
{[0.348]}\end{array}$ \\
\hline $\begin{array}{l}\text { Commodity price } \\
\text { shock t-2 }\end{array}$ & $\begin{array}{c}-0.048 \\
(-1.10) \\
{[0.279]}\end{array}$ & $\begin{array}{c}-0.091 * \\
(1.80) \\
{[0.078]}\end{array}$ & $\begin{array}{c}-0.093^{*} \\
(-1.84) \\
{[0.073]}\end{array}$ & $\begin{array}{c}-0.09 * \\
(-1.77) \\
{[0.083]}\end{array}$ & $\begin{array}{c}-0.081^{*} \\
(1.84) \\
{[0.072]}\end{array}$ & $\begin{array}{c}-0.084^{*} \\
(-1.9) \\
{[0.064]}\end{array}$ & $\begin{array}{c}-0.08 * \\
(-1.79) \\
{[0.081]}\end{array}$ & $\begin{array}{l}-0.067 \\
(-1.58) \\
{[0.122]}\end{array}$ & $\begin{array}{l}-0.067 \\
(-1.57) \\
{[0.123]}\end{array}$ & $\begin{array}{l}-0.064 \\
(-1.49) \\
{[0.144]}\end{array}$ \\
\hline $\begin{array}{l}\text { OECD export } \\
\text { growth } t\end{array}$ & & & $\begin{array}{c}-0.025 * * * \\
(-7.21) \\
{[0.00]}\end{array}$ & $\begin{array}{c}-0.024 * * * \\
(-6.82) \\
{[0.00]}\end{array}$ & & $\begin{array}{c}-0.025^{* * *} \\
(-7.3) \\
{[0.00]}\end{array}$ & $\begin{array}{c}-0.025^{* * *} \\
(-6.89) \\
{[0.00]}\end{array}$ & & $\begin{array}{c}-0.024 * * * \\
(-7.04) \\
{[0.00]}\end{array}$ & $\begin{array}{c}-0.024 * * * \\
(-6.66) \\
{[0.00]}\end{array}$ \\
\hline Rainfall (GPCP) $t$ & & & & $\begin{array}{c}-0.266^{*} \\
(-1.77) \\
{[0.084]}\end{array}$ & & & $\begin{array}{c}-0.262^{*} \\
(-1.74) \\
{[0.089]}\end{array}$ & & & $\begin{array}{c}-0.271^{*} \\
(-1.81) \\
{[0.077]}\end{array}$ \\
\hline $\begin{array}{l}\text { Rainfall (GPCP) } \\
\text { squared } t\end{array}$ & & & & $\begin{array}{c}0.116^{*} \\
(1.71) \\
{[0.094]}\end{array}$ & & & $\begin{array}{c}0.115^{*} \\
(1.71) \\
{[0.094]}\end{array}$ & & & $\begin{array}{c}0.117^{*} \\
(1.74) \\
{[0.088]}\end{array}$ \\
\hline $\begin{array}{l}\text { Test equality of } \\
\text { coefficients on } \\
\text { three shocks ( } p \text { - } \\
\text { value) }\end{array}$ & 0.65 & 0.63 & 0.60 & 0.62 & 0.57 & 0.5494 & 0.527 & 0.655 & 0.63 & 0.637 \\
\hline $\begin{array}{l}\text { Test sum of the } \\
\text { coefficients on } \\
\text { three shocks equal } \\
\text { zero ( } p \text {-value) }\end{array}$ & 0.13 & 0.052 & 0.046 & 0.045 & 0.021 & 0.018 & 0.018 & 0.039 & 0.037 & 0.036 \\
\hline $\begin{array}{l}\text { Country fixed } \\
\text { effects }\end{array}$ & Y & $Y$ & Y & $Y$ & $Y$ & $Y$ & $\mathrm{Y}$ & $Y$ & $\mathrm{Y}$ & $\mathrm{Y}$ \\
\hline Year fixed effects & $\mathrm{Y}$ & $\mathrm{Y}$ & $\mathrm{Y}$ & $\mathrm{Y}$ & $\mathrm{Y}$ & $\mathrm{Y}$ & $\mathrm{Y}$ & $\mathrm{Y}$ & $\mathrm{Y}$ & $\mathrm{Y}$ \\
\hline $\begin{array}{l}\text { Country specific } \\
\text { linear time trends }\end{array}$ & $\mathrm{Y}$ & $\mathrm{Y}$ & $\mathrm{Y}$ & $\mathrm{Y}$ & $\mathrm{Y}$ & $\mathrm{Y}$ & $\mathrm{Y}$ & $\mathrm{Y}$ & $\mathrm{Y}$ & Y \\
\hline Observations & 932 & 932 & 932 & 932 & 932 & 932 & 932 & 932 & 932 & 932 \\
\hline Countries & 45 & 45 & 45 & 45 & 45 & 45 & 45 & 45 & 45 & 45 \\
\hline R squared & 0.089 & 0.095 & 0.107 & 0.115 & 0.097 & 0.11 & 0.117 & 0.093 & 0.106 & 0.113 \\
\hline
\end{tabular}

Note: The civil war data and the commodity price and export data is from Bazzi and Blattman (2014). The estimating equation is (9) in the main text. The left-hand-side variable is an indicator variable civil war outbreak. The calculation of the shocks is explained in Sections 3.1.13.1.3. Column (1) calculates shocks using time-varying export weights as in Bazzi and Blattman (BB), and columns (2)-(10) calculate shocks using time-invariant export weights. The $10 \%$ price maker cutoff basically implies that commodity exports of country-years are not used to obtain export weights if the country's share of world exports exceeds $10 \%$ and is explained in detail in Section 3.1 .3 . Standard errors in parentheses and $p$-values of the hypothesis that the effect is zero in square brackets. ${ }^{*}$ denotes significance at the $10 \%$ level; ${ }^{* *}$ significance at the $5 \%$ level; and *** significance at the $1 \%$ level. 


\section{APPENDIX TABLE 13. Annual commodity price shocks and civil war outbreak in Sub-Saharan Africa: Bazzi-Blattman data only, 1982-2007 period, 3\% price maker cutoff}

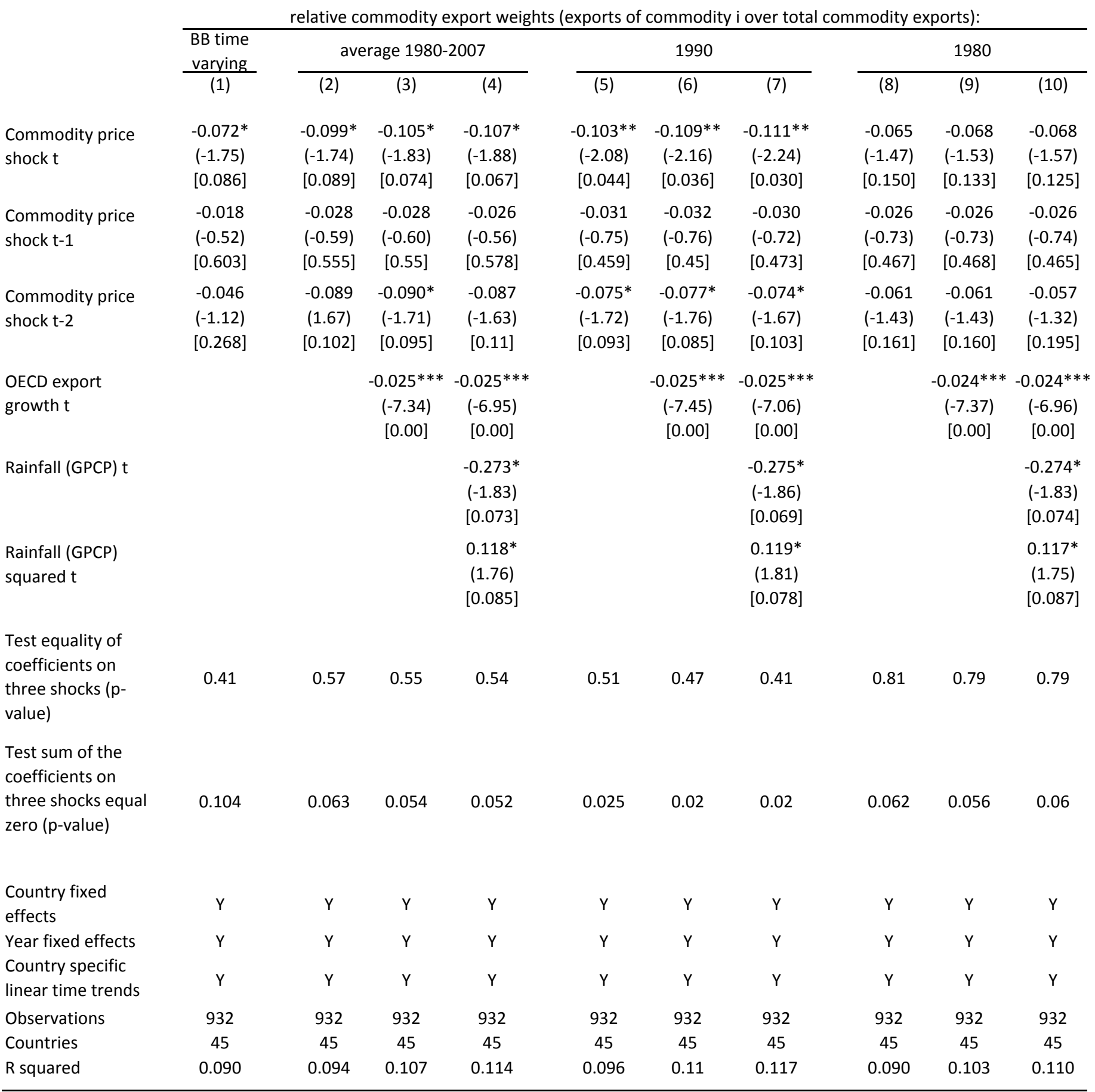

Note: The civil war data and the commodity price and export data is from Bazzi and Blattman (2014). The estimating equation is (9) in the main text. The left-hand-side variable is an indicator variable civil war outbreak. The calculation of the shocks is explained in Sections 3.1.1-3.1.3. Column (1) calculates shocks using time-varying export weights as in Bazzi and Blattman (BB), and columns (2)-(10) calculate shocks using time-invariant export weights. The $3 \%$ price maker cutoff basically implies that commodity exports of country-years are not used to obtain export weights if the country's share of world exports exceeds $3 \%$ and is explained in detail in Section 3.1.3. Standard errors in parentheses and p-values of the hypothesis that the effect is zero in square brackets. $*$ denotes significance at the $10 \%$ level; ${ }^{* *}$ significance at the $5 \%$ level; and ${ }^{* * *}$ significance at the $1 \%$ level. 


\section{APPENDIX TABLE 14. 3-year commodity price price shocks and civil war outbreak in Sub-Saharan Africa: Bazzi-Blattman data only, 1980-2007 period, 3\% price maker cutoff}

relative commodity export weights (exports of commodity i over total commodity exports):

\begin{tabular}{|c|c|c|c|c|c|c|c|c|c|}
\hline & & erage 1980- & 007 & & 1990 & & & 1980 & \\
\hline & (1) & $(2)$ & (3) & (4) & $(5)$ & (6) & (7) & $(8)$ & (9) \\
\hline $\begin{array}{l}\text { 3-year commodity } \\
\text { price shock } t\end{array}$ & $\begin{array}{c}-0.069 * \\
(-1.98) \\
{[0.054]}\end{array}$ & $\begin{array}{c}-0.072 * * \\
(-2.06) \\
{[0.045]}\end{array}$ & $\begin{array}{c}-0.07^{* *} \\
(-2.05) \\
{[0.046]}\end{array}$ & $\begin{array}{c}-0.068 * * \\
(-2.43) \\
{[0.019]}\end{array}$ & $\begin{array}{c}-0.072^{* *} \\
(-2.54) \\
{[0.015]}\end{array}$ & $\begin{array}{c}-0.071^{* *} \\
(-2.54) \\
{[0.015]}\end{array}$ & $\begin{array}{c}-0.052 * * \\
(-2.02) \\
{[0.049]}\end{array}$ & $\begin{array}{c}-0.053^{* *} \\
(-2.07) \\
{[0.045]}\end{array}$ & $\begin{array}{c}-0.051 * * \\
(-2.04) \\
{[0.047]}\end{array}$ \\
\hline $\begin{array}{l}\text { OECD export } \\
\text { growth } t\end{array}$ & & $\begin{array}{c}-0.024 * * * \\
(-7.79) \\
{[0.00]}\end{array}$ & $\begin{array}{c}-0.024 * * * \\
(-7.73) \\
{[0.00]}\end{array}$ & & $\begin{array}{c}-0.024 * * * \\
(-8.05) \\
{[0.00]}\end{array}$ & $\begin{array}{c}-0.024 * * * \\
(-7.98) \\
{[0.00]}\end{array}$ & & $\begin{array}{c}-0.024 * * * \\
(-7.67) \\
{[0.00]}\end{array}$ & $\begin{array}{c}-0.024^{* *} \\
(-7.61) \\
{[0.00]}\end{array}$ \\
\hline Rainfall (GPCP) t & & & $\begin{array}{c}-0.274^{*} \\
(-1.97) \\
{[0.055]}\end{array}$ & & & $\begin{array}{c}-0.274^{*} \\
(-1.98) \\
{[0.053]}\end{array}$ & & & $\begin{array}{c}-0.275 * \\
(-1.98) \\
{[0.055]}\end{array}$ \\
\hline $\begin{array}{l}\text { Rainfall (GPCP) } \\
\text { squared } t\end{array}$ & & & $\begin{array}{l}0.116^{*} \\
(1.86) \\
{[0.07]}\end{array}$ & & & $\begin{array}{c}0.116^{*} \\
(1.88) \\
{[0.067]}\end{array}$ & & & $\begin{array}{c}0.116^{*} \\
(1.87) \\
{[0.068]}\end{array}$ \\
\hline $\begin{array}{l}\text { Country fixed } \\
\text { effects }\end{array}$ & $\mathrm{Y}$ & $Y$ & $Y$ & $Y$ & $Y$ & $Y$ & $Y$ & $Y$ & $Y$ \\
\hline Year fixed effects & $\mathrm{Y}$ & $\mathrm{Y}$ & $\mathrm{Y}$ & $\mathrm{Y}$ & $\mathrm{Y}$ & $\mathrm{Y}$ & $\mathrm{Y}$ & $\mathrm{Y}$ & $Y$ \\
\hline $\begin{array}{l}\text { Country specific } \\
\text { linear time trends }\end{array}$ & $Y$ & $\mathrm{Y}$ & $\mathrm{Y}$ & $\mathrm{Y}$ & $Y$ & $Y$ & $\mathrm{Y}$ & $\mathrm{Y}$ & $Y$ \\
\hline Observations & 1007 & 1007 & 1007 & 1007 & 1007 & 1007 & 1007 & 1007 & 1007 \\
\hline Countries & 45 & 45 & 45 & 45 & 45 & 45 & 45 & 45 & 45 \\
\hline R squared & 0.082 & 0.094 & 0.102 & 0.084 & 0.097 & 0.104 & 0.08 & 0.092 & 0.10 \\
\hline
\end{tabular}

Note: The civil war data and the commodity price and export data is from Bazzi and Blattman (2014). The estimating equation is (10) in the main text. The left-hand-side variable is an indicator variable for civil war outbreak. The calculation of the shocks is explained in Sections 3.1.1-3.1.3. The 3\% price maker cutoff basically implies that commodity exports of country-years are not used to obtain export weights if the country in the world exports of the commodity exceeded $3 \%$ and is explained in Section 3.1.3. Standard errors in parentheses and p-values of the hypothesis that the effect is zero in square brackets. * denotes significance at the $10 \%$ level; ${ }^{* *}$ significance at the $5 \%$ level; and ${ }^{* * *}$ significance at the $1 \%$ level. 


\section{APPENDIX TABLE 15. 3-year commodity price price shocks and civil war outbreak in Sub-Saharan Africa: Bazzi-Blattman data only, 1982-2007 period, 10\% price maker cutoff}

relative commodity export weights (exports of commodity i over total commodity exports):

\begin{tabular}{|c|c|c|c|c|c|c|c|c|c|}
\hline & & erage $1980-$ & 007 & & 1990 & & & 1980 & \\
\hline & (1) & $(2)$ & (3) & (4) & $(5)$ & (6) & (7) & (8) & (9) \\
\hline $\begin{array}{l}\text { 3-year commodity } \\
\text { price shock } \mathrm{t}\end{array}$ & $\begin{array}{c}-0.075^{*} \\
(-1.98) \\
{[0.054]}\end{array}$ & $\begin{array}{c}-0.077^{* *} \\
(-2.04) \\
{[0.048]}\end{array}$ & $\begin{array}{c}-0.076 * * \\
(-2.04) \\
{[0.047]}\end{array}$ & $\begin{array}{c}-0.073 * * \\
(-2.36) \\
{[0.023]}\end{array}$ & $\begin{array}{c}-0.076^{* *} \\
(-2.44) \\
{[0.019]}\end{array}$ & $\begin{array}{c}-0.075^{* *} \\
(-2.44) \\
{[0.019]}\end{array}$ & $\begin{array}{c}-0.061 * * \\
(-2.11) \\
{[0.041]}\end{array}$ & $\begin{array}{c}-0.061^{* *} \\
(-2.13) \\
{[0.038]}\end{array}$ & $\begin{array}{c}-0.061 * * \\
(-2.15) \\
{[0.037]}\end{array}$ \\
\hline $\begin{array}{l}\text { OECD export } \\
\text { growth } t\end{array}$ & & $\begin{array}{c}-0.025 * * * \\
(-7.34) \\
{[0.00]}\end{array}$ & $\begin{array}{c}-0.024 * * * \\
(-6.97) \\
{[0.00]}\end{array}$ & & $\begin{array}{c}-0.025^{* * *} \\
(-7.58) \\
{[0.00]}\end{array}$ & $\begin{array}{c}-0.024^{* * *} \\
(-7.17) \\
{[0.00]}\end{array}$ & & $\begin{array}{c}-0.024 * * * \\
(-7.11) \\
{[0.00]}\end{array}$ & $\begin{array}{c}-0.024^{* *} \\
(-6.76) \\
{[0.00]}\end{array}$ \\
\hline Rainfall (GPCP) t & & & $\begin{array}{c}-0.271 * \\
(-1.83) \\
{[0.074]}\end{array}$ & & & $\begin{array}{c}-0.267^{*} \\
(-1.8) \\
{[0.079]}\end{array}$ & & & $\begin{array}{c}-0.277^{*} \\
(-1.87) \\
{[0.068]}\end{array}$ \\
\hline $\begin{array}{l}\text { Rainfall (GPCP) } \\
\text { squared } t\end{array}$ & & & $\begin{array}{c}0.117^{*} \\
(1.74) \\
{[0.088]}\end{array}$ & & & $\begin{array}{l}0.116^{*} \\
(1.73) \\
{[0.09]}\end{array}$ & & & $\begin{array}{c}0.119 * \\
(1.78) \\
{[0.082]}\end{array}$ \\
\hline $\begin{array}{l}\text { Country fixed } \\
\text { effects }\end{array}$ & $\mathrm{Y}$ & $\mathrm{Y}$ & $\mathrm{Y}$ & $\mathrm{Y}$ & $\mathrm{Y}$ & $\mathrm{Y}$ & $\mathrm{Y}$ & $\mathrm{Y}$ & $\mathrm{Y}$ \\
\hline Year fixed effects & $\mathrm{Y}$ & $\mathrm{Y}$ & $\mathrm{Y}$ & $\mathrm{Y}$ & $\mathrm{Y}$ & $\mathrm{Y}$ & $\mathrm{Y}$ & $\mathrm{Y}$ & $\mathrm{Y}$ \\
\hline $\begin{array}{l}\text { Country specific } \\
\text { linear time trends }\end{array}$ & $Y$ & $Y$ & $Y$ & $Y$ & $\mathrm{Y}$ & $Y$ & $Y$ & $Y$ & Y \\
\hline Observations & 932 & 932 & 932 & 932 & 932 & 932 & 932 & 932 & 932 \\
\hline Countries & 45 & 45 & 45 & 45 & 45 & 45 & 45 & 45 & 45 \\
\hline R squared & 0.093 & 0.105 & 0.113 & 0.094 & 0.107 & 0.115 & 0.092 & 0.104 & 0.112 \\
\hline
\end{tabular}

Note: The civil war data and the commodity price and export data is from Bazzi and Blattman (2014). The estimating equation is (10) in the main text. The left-hand-side variable is an indicator variable for civil war outbreak. The calculation of the shocks is explained in Sections 3.1.1-3.1.3. The $10 \%$ price maker cutoff basically implies that commodity exports of country-years are not used to obtain export weights if the country in the world exports of the commodity exceeded $10 \%$ and is explained in Section 3.1.3. Standard errors in parentheses and p-values of the hypothesis that the effect is zero in square brackets. ${ }^{*}$ denotes significance at the $10 \%$ level; ${ }^{* *}$ significance at the $5 \%$ level; and ${ }^{* * *}$ significance at the $1 \%$ level. 


\section{APPENDIX TABLE 16. 3-year commodity price price shocks and civil war outbreak in Sub-Saharan Africa: Bazzi-Blattman data only, 1982-2007 period, 3\% price maker cutoff}

\begin{tabular}{|c|c|c|c|c|c|c|c|c|c|}
\hline & & ive & dity export & eights (exp & rts of comr & nodity i ovel & total com & hodity expor & ts): \\
\hline & & erage $1980-2$ & 2007 & & 1990 & & & 1980 & \\
\hline & (1) & $(2)$ & (3) & (4) & (5) & (6) & (7) & $(8)$ & (9) \\
\hline 3-year commodity & $-0.071^{*}$ & $-0.074 *$ & $-0.072^{*}$ & $-0.069 * *$ & $-0.072^{* *}$ & $-0.071^{* *}$ & $-0.051^{*}$ & $-0.052^{*}$ & $-0.050 * *$ \\
\hline price shock t & $(-1.88)$ & $(-1.96)$ & $(-1.95)$ & $(-2.28)$ & $(-2.38)$ & $(-2.37)$ & $(-1.91)$ & $(-1.96)$ & $(-1.93)$ \\
\hline & {$[0.067]$} & {$[0.057]$} & {$[0.058]$} & [0.027] & {$[0.022]$} & [0.022] & {$[0.062]$} & {$[0.056]$} & {$[0.06]$} \\
\hline OECD export & & $-0.025^{* * *}$ & $-0.024 * * *$ & & $-0.025^{* * *}$ & $-0.024 * * *$ & & $-0.024 * * *$ & $-0.024^{* *:}$ \\
\hline growth t & & $(-7.52)$ & $(-7.13)$ & & $(-7.74)$ & $(-7.32)$ & & $(-7.37)$ & $(-6.99)$ \\
\hline & & {$[0.00]$} & {$[0.00]$} & & {$[0.00]$} & {$[0.00]$} & & {$[0.00]$} & {$[0.00]$} \\
\hline Rainfall (GPCP) $t$ & & & $-0.273^{*}$ & & & $-0.274^{*}$ & & & $-0.277^{*}$ \\
\hline & & & $(-1.85)$ & & & $(-1.86)$ & & & $(-1.86)$ \\
\hline & & & {$[0.072]$} & & & {$[0.07]$} & & & [0.07] \\
\hline Rainfall (GPCP) & & & $0.117^{*}$ & & & $0.117^{*}$ & & & $0.118^{*}$ \\
\hline squared t & & & (1.75) & & & (1.76) & & & (1.76) \\
\hline & & & {$[0.087]$} & & & {$[0.085]$} & & & {$[0.085]$} \\
\hline $\begin{array}{l}\text { Country fixed } \\
\text { effects }\end{array}$ & $\mathrm{Y}$ & $\mathrm{Y}$ & $\mathrm{Y}$ & $\mathrm{Y}$ & $\mathrm{Y}$ & $\mathrm{Y}$ & $\mathrm{Y}$ & $\mathrm{Y}$ & $\mathrm{Y}$ \\
\hline Year fixed effects & $\mathrm{Y}$ & $\mathrm{Y}$ & $\mathrm{Y}$ & $\mathrm{Y}$ & Y & Y & $\mathrm{Y}$ & Y & Y \\
\hline $\begin{array}{l}\text { Country specific } \\
\text { linear time trends }\end{array}$ & $\mathrm{Y}$ & $\mathrm{Y}$ & $\mathrm{Y}$ & $\mathrm{Y}$ & $\mathrm{Y}$ & $\mathrm{Y}$ & $\mathrm{Y}$ & $\mathrm{Y}$ & Y \\
\hline Observations & 932 & 932 & 932 & 932 & 932 & 932 & 932 & 932 & 932 \\
\hline Countries & 45 & 45 & 45 & 45 & 45 & 45 & 45 & 45 & 45 \\
\hline R squared & 0.092 & 0.104 & 0.112 & 0.093 & 0.106 & 0.114 & 0.089 & 0.101 & 0.109 \\
\hline
\end{tabular}

Note: The civil war data and the commodity price and export data is from Bazzi and Blattman (2014). The estimating equation is (10) in the main text. The left-hand-side variable is an indicator variable for civil war outbreak. The calculation of the shocks is explained in Sections 3.1.1-3.1.3. The 3\% price maker cutoff basically implies that commodity exports of country-years are not used to obtain export weights if the country in the world exports of the commodity exceeded $10 \%$ and is explained in Section 3.1.3. Standard errors in parentheses and p-values of the hypothesis that the effect is zero in square brackets. ${ }^{*}$ denotes significance at the $3 \%$ level; ${ }^{* *}$ significance at the $5 \%$ level; and ${ }^{* * *}$ significance at the $1 \%$ level. 


\section{APPENDIX TABLE 17. 3-year commodity price shocks and civil war outbreak in Sub-Saharan Africa: Bazzi and Blattman data only, 1957-2007 period, 3\% price maker cutoff}

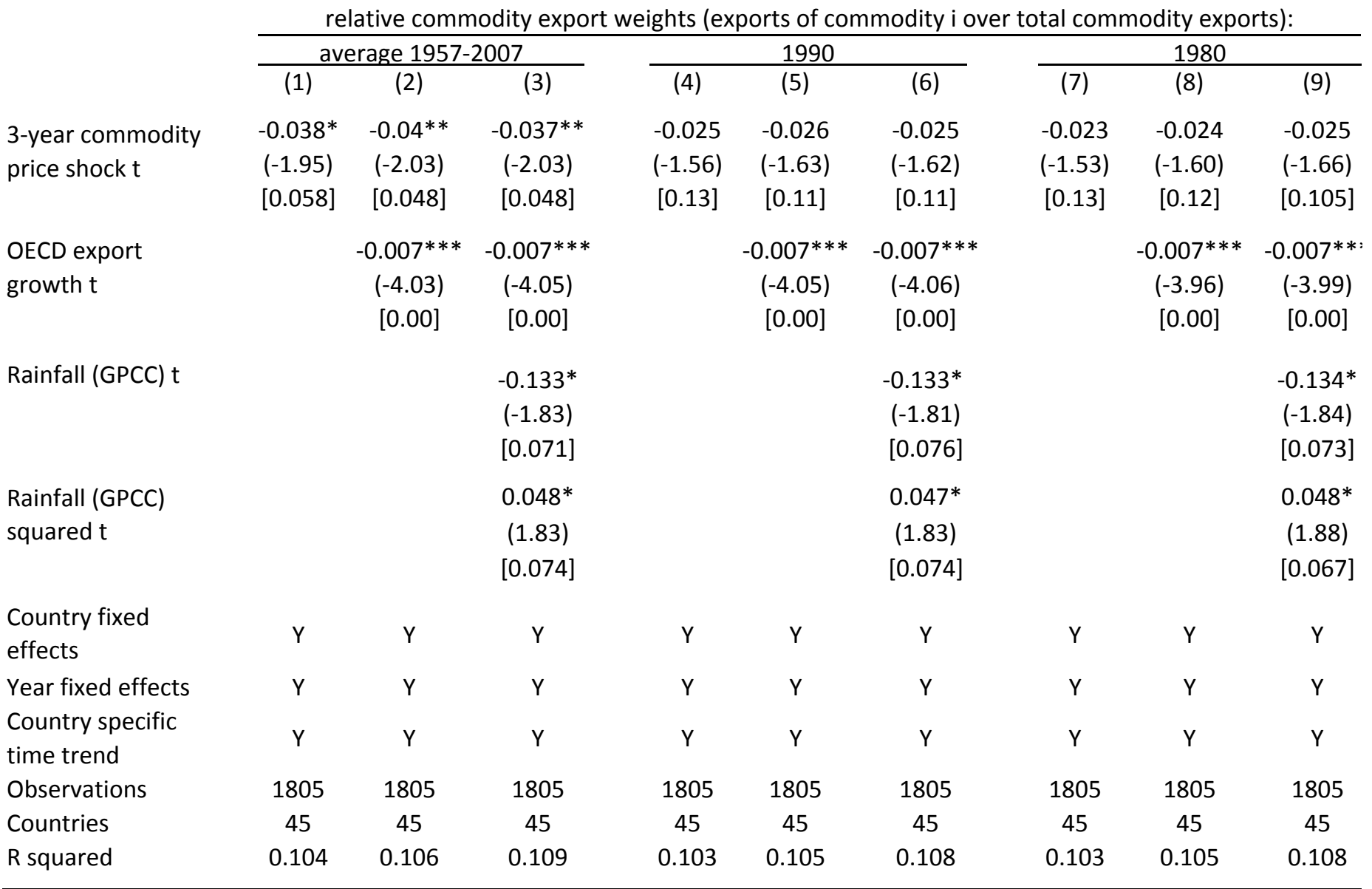

Note: The civil war data and the commodity price and export data is from Bazzi and Blattman (2014). The estimating equation is (10) in the main text. The left-hand-side variable is an indicator variable for civil war outbreak. The calculation of the shocks is explained in Sections 3.1.1-3.1.3. The 3\% price maker cutoff basically implies that commodity exports of country-years are not used to obtain export weights if the country in the world exports of the commodity exceeded $3 \%$ and is explained in Section 3.1.3. Standard errors in parentheses and p-values of the hypothesis that the effect is zero in square brackets. * denotes significance at the $3 \%$ level; ${ }^{* *}$ significance at the $5 \%$ level; and $* * *$ significance at the $1 \%$ level. 


\section{APPENDIX TABLE 18. Annual commodity price shocks and civil war outbreak in Sub-Saharan Africa 1980-2009: minerals, oil, and gas versus agricultural commodity prices}

\begin{tabular}{|c|c|c|}
\hline \multirow[t]{2}{*}{ Price maker cutoff } & $10 \%$ & $3 \%$ \\
\hline & $(1)$ & (2) \\
\hline \multirow{3}{*}{$\begin{array}{l}\text { Minerals, oil, gas price } \\
\text { shock t }\end{array}$} & $-0.078 * *$ & $-0.09 * *$ \\
\hline & $(-2.04)$ & $(-2.22)$ \\
\hline & {$[0.047]$} & [0.032] \\
\hline \multirow{3}{*}{$\begin{array}{l}\text { Minerals, oil, gas price } \\
\text { shock t-1 }\end{array}$} & -0.039 & -0.036 \\
\hline & $(-1.1)$ & $(-0.9)$ \\
\hline & {$[0.28]$} & {$[0.37]$} \\
\hline \multirow{3}{*}{$\begin{array}{l}\text { Minerals, oil, gas price } \\
\text { shock t-2 }\end{array}$} & -0.011 & -0.009 \\
\hline & $(-0.42)$ & $(-0.31)$ \\
\hline & {$[0.68]$} & {$[0.76]$} \\
\hline \multirow{3}{*}{$\begin{array}{l}\text { Agricultural commodity } \\
\text { price shock } t\end{array}$} & -0.053 & -0.049 \\
\hline & $(-0.96)$ & $(-0.88)$ \\
\hline & {$[0.34]$} & {$[0.38]$} \\
\hline \multirow{3}{*}{$\begin{array}{l}\text { Agricultural commodity } \\
\text { price shock t-1 }\end{array}$} & -0.087 & -0.087 \\
\hline & $(-1.36)$ & $(-1.33)$ \\
\hline & {$[0.18]$} & {$[0.19]$} \\
\hline \multirow{3}{*}{$\begin{array}{l}\text { Agricultural commodity } \\
\text { price shock t-2 }\end{array}$} & -0.07 & -0.069 \\
\hline & $(-1.38)$ & $(-1.29)$ \\
\hline & {$[0.17]$} & {$[0.20]$} \\
\hline Country fixed effects & $Y$ & Y \\
\hline Year fixed effects & $\mathrm{Y}$ & Y \\
\hline $\begin{array}{l}\text { Country specific linear } \\
\text { time trends }\end{array}$ & Y & Y \\
\hline Observations & 1099 & 1099 \\
\hline Countries & 45 & 45 \\
\hline R squared & 0.1 & 0.1 \\
\hline
\end{tabular}

Note: The commodity price and export data is from Bazzi and Blattman (2014). The civil war data is from the same source used by Bazzi and Blattman but updated using the latest version (UCPD 2016 version 4). The estimating equation is (9) in the main text. The left-hand-side variable is an indicator variable for civil war outbreak. The calculation of the shocks is explained in Sections 3.1.1-3.1.3. Time-invariant country-commodity weights are set equal to country-commodity export shares averaged over the sample period. The minerals, oil, and gas shock is defined as in (7) but with the summation only over commodities classified as minerals, oil, and gas. The agricultural commodity shock is defined as in (7) but with the summation only over agricultural commodities. (Hence, the two types of shocks sum to the fixed-weight commodity shock involving all commodities.) The $10 \%$ (3\%) price maker cutoff basically implies that commodity exports of country-years are not used to obtain export weights if the country's share of world exports exceeds $10 \%(3 \%)$ and is explained in Section 3.1.3. Standard errors in parentheses and $p$-values of the hypothesis that the effect is zero in square brackets. ${ }^{*}$ denotes significance at the $10 \%$ level; ${ }^{* *}$ significance at the $5 \%$ level; and *** significance at the $1 \%$ level 


\section{APPENDIX TABLE 19. 3-year commodity price shocks and civil war outbreak in Sub-Saharan Africa 1980-2009: minerals, oil, and gas versus agricultural commodity prices}

\begin{tabular}{|c|c|c|}
\hline \multirow[t]{2}{*}{ Price maker cutoff } & $10 \%$ & $3 \%$ \\
\hline & (1) & (2) \\
\hline 3-year minerals, oil, gas & $-0.046 *$ & $-0.049 *$ \\
\hline \multirow[t]{2}{*}{ price shock t } & $(-1.78)$ & $(-1.73)$ \\
\hline & [0.082] & {$[0.09]$} \\
\hline 3-year agricultural & $-0.068 * *$ & $-0.066^{*}$ \\
\hline \multirow[t]{2}{*}{ commodity price shock $\mathrm{t}$} & $(-2.05)$ & $(-1.96)$ \\
\hline & {$[0.046]$} & {$[0.056]$} \\
\hline Country fixed effects & $Y$ & $Y$ \\
\hline Year fixed effects & $\mathrm{Y}$ & $\mathrm{Y}$ \\
\hline $\begin{array}{l}\text { Country specific linear time } \\
\text { trends }\end{array}$ & $\mathrm{Y}$ & $\mathrm{Y}$ \\
\hline Observations & 1099 & 1099 \\
\hline Countries & 45 & 45 \\
\hline R squared & 0.1 & 0.1 \\
\hline
\end{tabular}

Note: The commodity price and export data is from Bazzi and Blattman (2014). The civil war data is from the same source used by Bazzi and Blattman but updated using the latest version (UCPD 2016 version 4). The estimating equation is (10) in the main text. The left-hand-side variable is an indicator variable for civil war outbreak. The calculation of the shocks is explained in Sections 3.1.1-3.1.3. Time-invariant country-commodity weights are set equal to country-commodity export shares averaged over the sample period. The minerals, oil, and gas shock is defined as in (7) but with the summation only over commodities classified as minerals, oil, and gas. The agricultural commodity shock is defined as in (7) but with the summation only over agricultural commodities. (Hence, the two types of shocks sum to the fixedweight commodity shock involving all commodities.) The $10 \%$ (3\%) price maker cutoff basically implies that commodity exports of country-years are not used to obtain export weights if the country's share of world exports exceeds $10 \%$ (3\%) and is explained in Section 3.1.3. Standard errors in parentheses and p-values of the hypothesis that the effect is zero in square brackets. * denotes significance at the $10 \%$ level; $* *$ significance at the $5 \%$ level; and $* * *$ significance at the $1 \%$ level 


\section{APPENDIX TABLE 20. 3-year commodity price shocks and civil war outbreak in Sub-Saharan Africa 1957-2009: minerals, oil, and gas versus agricultural commodity prices}

\begin{tabular}{lcc}
\cline { 2 - 2 } Price maker cutoff & $10 \%$ & $3 \%$ \\
\cline { 2 - 2 } & $(1)$ & $(2)$ \\
3-year minerals, oil, gas & -0.023 & $-0.033^{* *}$ \\
price shock t & $(-1.52)$ & $(-2.02)$ \\
& {$[0.14]$} & {$[0.049]$} \\
3-year agricultural & & \\
commodity price shock t & $-0.037^{* *}$ & $-0.039 * *$ \\
& $(-2.31)$ & $(-2.27)$ \\
Country fixed effects & {$[0.026]$} & {$[0.028]$} \\
Year fixed effects & & \\
Country specific linear time & $Y$ & $Y$ \\
trends & $Y$ & $Y$ \\
Observations & $Y$ & $Y$ \\
Countries & 1897 & 1897 \\
R squared & 45 & 45 \\
& 0.1 & 0.1
\end{tabular}

Note: The commodity price and export data is from Bazzi and Blattman (2014). The civil war data is from the same source used by Bazzi and Blattman but updated using the latest version (UCPD 2016 version 4). The estimating equation is (10) in the main text. The left-hand-side variable is an indicator variable for civil war outbreak. The calculation of the shocks is explained in Sections 3.1.1-3.1.2. Time-invariant country-commodity weights are set equal to country-commodity export shares averaged over the sample period. The minerals, oil, and gas shock is defined as in (7) but with the summation only over commodities classified as minerals, oil, and gas. The agricultural commodity shock is defined as in (7) but with the summation only over agricultural commodities. (Hence, the two types of shocks sum to the fixedweight commodity shock involving all commodities.) The $10 \%$ (3\%) price maker cutoff basically implies that commodity exports of country-years are not used to obtain export weights if the country's share of world exports exceeds $10 \%$ (3\%) and is explained in Section 3.1.3. * denotes significance at the $10 \%$ level; ** significance at the $5 \%$ level; and $* * *$ significance at the $1 \%$ level. 


\section{APPENDIX TABLE 21. Annual commodity price shocks and civil war outbreak beyond Sub-Saharan Africa 1980-2009: minerals, oil, and gas versus agricultural commodity prices}

\begin{tabular}{|c|c|c|}
\hline \multirow[t]{2}{*}{ Price maker cutoff } & $10 \%$ & $3 \%$ \\
\hline & (1) & $(2)$ \\
\hline $\begin{array}{l}\text { Minerals, oil, gas price } \\
\text { shock t }\end{array}$ & $\begin{array}{c}-0.033^{*} \\
(-1.87) \\
{[0.064]}\end{array}$ & $\begin{array}{c}-0.045^{* *} \\
(-2.21) \\
{[0.029]}\end{array}$ \\
\hline $\begin{array}{l}\text { Minerals, oil, gas price } \\
\text { shock t-1 }\end{array}$ & $\begin{array}{l}-0.013 \\
(-0.66) \\
{[0.51]}\end{array}$ & $\begin{array}{l}-0.014 \\
(-0.52) \\
{[0.601]}\end{array}$ \\
\hline $\begin{array}{l}\text { Minerals, oil, gas price } \\
\text { shock t-2 }\end{array}$ & $\begin{array}{c}0.014 \\
(-0.83) \\
{[0.41]}\end{array}$ & $\begin{array}{c}0.005 \\
(0.23) \\
{[0.818]}\end{array}$ \\
\hline $\begin{array}{l}\text { Agricultural commodity } \\
\text { price shock } t\end{array}$ & $\begin{array}{l}-0.034 \\
(-1.01) \\
{[0.31]}\end{array}$ & $\begin{array}{l}-0.038 \\
(-1.12) \\
{[0.27]}\end{array}$ \\
\hline $\begin{array}{l}\text { Agricultural commodity } \\
\text { price shock t-1 }\end{array}$ & $\begin{array}{c}-0.036 \\
(-0.9) \\
{[0.37]}\end{array}$ & $\begin{array}{l}-0.036 \\
(-0.87) \\
{[0.38]}\end{array}$ \\
\hline $\begin{array}{l}\text { Agricultural commodity } \\
\text { price shock } \mathrm{t}-2\end{array}$ & $\begin{array}{c}-0.065^{* *} \\
(-2.05) \\
{[0.042]}\end{array}$ & $\begin{array}{c}-0.066 * * \\
(-1.99) \\
{[0.049]}\end{array}$ \\
\hline Country fixed effects & $\mathrm{Y}$ & Y \\
\hline Year fixed effects & Y & Y \\
\hline $\begin{array}{l}\text { Country specific linear time } \\
\text { trends }\end{array}$ & $\mathrm{Y}$ & Y \\
\hline Observations & 2901 & 2901 \\
\hline Countries & 118 & 118 \\
\hline R squared & 0.119 & 0.119 \\
\hline
\end{tabular}

Note: The analysis includes all larger countries in Africa, the Middle East, Latin America, and Asia. The commodity price and export data is from Bazzi and Blattman (2014). The civil war data is from the same source used by Bazzi and Blattman but updated using the latest version (UCPD 2016 version 4). The estimating equation is (9) in the main text. The left-hand-side variable is an indicator variable for civil war outbreak. The calculation of the shocks is explained in Sections 3.1.1-3.1.2. Time-invariant country-commodity weights are set equal to country-commodity export shares averaged over the sample period. The minerals, oil, and gas shock is defined as in (7) but with the summation only over commodities classified as minerals, oil, and gas. The agricultural commodity shock is defined as in (7) but with the summation only over agricultural commodities. (Hence, the two types of shocks sum to the fixed-weight commodity shock involving all commodities.) The $10 \%$ (3\%) price maker cutoff basically implies that commodity exports of country-years are not used to obtain export weights if the country's share of world exports exceeds $10 \%(3 \%)$ and is explained in Section 3.1.3. * denotes significance at the $10 \%$ level; ** significance at the $5 \%$ level; and ${ }^{* * *}$ significance at the $1 \%$ level. 


\section{APPENDIX TABLE 22. 3-year commodity price shocks and civil war outbreak beyond Sub-Saharan Africa 1980-2009: minerals, oil, and gas versus agricultural commodity prices}

\begin{tabular}{|c|c|c|}
\hline \multirow[t]{2}{*}{ Price maker cutoff } & $10 \%$ & $3 \%$ \\
\hline & $(1)$ & $(2)$ \\
\hline \multirow{3}{*}{$\begin{array}{l}\text { 3-year minerals, oil, gas } \\
\text { price shock } t\end{array}$} & -0.013 & -0.02 \\
\hline & $(-0.99)$ & $(-1.25)$ \\
\hline & {$[0.32]$} & {$[0.21]$} \\
\hline \multirow{3}{*}{$\begin{array}{l}\text { 3-year agricultural } \\
\text { commodity price shock } \mathrm{t}\end{array}$} & $-0.044 * *$ & $-0.046 * *$ \\
\hline & $(-2.02)$ & $(-2.03)$ \\
\hline & {$[0.046]$} & {$[0.045]$} \\
\hline Country fixed effects & Y & $\mathrm{Y}$ \\
\hline Year fixed effects & $\mathrm{Y}$ & $\mathrm{Y}$ \\
\hline $\begin{array}{l}\text { Country specific linear time } \\
\text { trends }\end{array}$ & Y & $\mathrm{Y}$ \\
\hline Observations & 2901 & 2901 \\
\hline Countries & 118 & 118 \\
\hline R squared & 0.119 & 0.119 \\
\hline
\end{tabular}

Note: The analysis includes all larger countries in Africa, the Middle East, Latin America, and Asia. The commodity price and export data is from Bazzi and Blattman (2014). The civil war data is from the same source used by Bazzi and Blattman but updated using the latest version (UCPD 2016 version 4). The estimating equation is (10) in the main text. The left-hand-side variable is an indicator variable for civil war outbreak. The calculation of the shocks is explained in Sections 3.1.1-3.1.2. Time-invariant country-commodity weights are set equal to country-commodity export shares averaged over the sample period. The minerals, oil, and gas shock is defined as in (7) but with the summation only over commodities classified as minerals, oil, and gas. The agricultural commodity shock is defined as in (7) but with the summation only over agricultural commodities. (Hence, the two types of shocks sum to the fixedweight commodity shock involving all commodities.) The $10 \%$ (3\%) price maker cutoff basically implies that commodity exports of country-years are not used to obtain export weights if the country's share of world exports exceeds $10 \%(3 \%)$ and is explained in Section 3.1.3. * denotes significance at the $10 \%$ level; ${ }^{* *}$ significance at the $5 \%$ level; and $* * *$ significance at the $1 \%$ level. 


\section{APPENDIX TABLE 23. 3-year commodity price shocks and civil war outbreak beyond Sub-Saharan Africa 1957-2009: minerals, oil, and gas versus agricultural commodity prices}

\begin{tabular}{|c|c|c|}
\hline \multirow[t]{2}{*}{ Price maker cutoff } & $10 \%$ & $3 \%$ \\
\hline & (1) & (2) \\
\hline 3-year minerals, oil, gas & -0.002 & $-0.018 * *$ \\
\hline \multirow[t]{2}{*}{ price shock $t$} & $(-0.23)$ & $(-2.05)$ \\
\hline & {$[0.82]$} & [0.043] \\
\hline 3-year agricultural & $-0.024 *$ & $-0.028 * *$ \\
\hline \multirow[t]{2}{*}{ commodity price shock $\mathrm{t}$} & $(-1.88)$ & $(-2.07)$ \\
\hline & {$[0.062]$} & {$[0.041]$} \\
\hline Country fixed effects & $Y$ & $Y$ \\
\hline Year fixed effects & $\mathrm{Y}$ & Y \\
\hline $\begin{array}{l}\text { Country specific linear time } \\
\text { trends }\end{array}$ & $Y$ & $\mathrm{Y}$ \\
\hline Observations & 5019 & 5019 \\
\hline Countries & 118 & 118 \\
\hline R squared & 0.1 & 0.1 \\
\hline
\end{tabular}

Note: The analysis includes all larger countries in Africa, the Middle East, Latin America, and Asia. The commodity price and export data is from Bazzi and Blattman (2014). The civil war data is from the same source used by Bazzi and Blattman but updated using the latest version (UCPD 2016 version 4). The estimating equation is (10) in the main text. The left-hand-side variable is an indicator variable for civil war outbreak. The calculation of the shocks is explained in Sections 3.1.1-3.1.2. Time-invariant country-commodity weights are set equal to country-commodity export shares averaged over the sample period. The minerals, oil, and gas shock is defined as in (7) but with the summation only over commodities classified as minerals, oil, and gas. The agricultural commodity shock is defined as in (7) but with the summation only over agricultural commodities. (Hence, the two types of shocks sum to the fixed-weight commodity shock involving all commodities.) The $10 \%$ (3\%) price maker cutoff basically implies that commodity exports of country-years are not used to obtain export weights if the country's share of world exports exceeds $10 \%(3 \%)$ and is explained in Section 3.1.3. * denotes significance at the $10 \%$ level; ** significance at the $5 \%$ level; and ${ }^{* * *}$ significance at the $1 \%$ level. 